\title{
Emerging epistemologies : making sense of teaching practice
}

Citation for published version (APA):

Niessen, T. H. J. (2007). Emerging epistemologies : making sense of teaching practice. [Doctoral Thesis, Maastricht University]. Universiteit Maastricht. https://doi.org/10.26481/dis.20071130tn

Document status and date:

Published: 01/01/2007

DOI:

10.26481/dis.20071130tn

Document Version:

Publisher's PDF, also known as Version of record

\section{Please check the document version of this publication:}

- A submitted manuscript is the version of the article upon submission and before peer-review. There can be important differences between the submitted version and the official published version of record.

People interested in the research are advised to contact the author for the final version of the publication, or visit the DOI to the publisher's website.

- The final author version and the galley proof are versions of the publication after peer review.

- The final published version features the final layout of the paper including the volume, issue and page numbers.

Link to publication

\footnotetext{
General rights rights.

- You may freely distribute the URL identifying the publication in the public portal. please follow below link for the End User Agreement:

www.umlib.nl/taverne-license

Take down policy

If you believe that this document breaches copyright please contact us at:

repository@maastrichtuniversity.nl

providing details and we will investigate your claim.
}

Copyright and moral rights for the publications made accessible in the public portal are retained by the authors and/or other copyright owners and it is a condition of accessing publications that users recognise and abide by the legal requirements associated with these

- Users may download and print one copy of any publication from the public portal for the purpose of private study or research.

- You may not further distribute the material or use it for any profit-making activity or commercial gain

If the publication is distributed under the terms of Article $25 \mathrm{fa}$ of the Dutch Copyright Act, indicated by the "Taverne" license above, 


\section{Emerging}

epistemologies

Making sense of teaching practice 


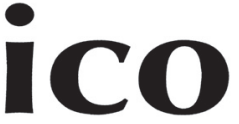

Dit onderzoek werd uitgevoerd in het kader van het Interuniversitair Centrum voor Onderwijsonderzoek.

\section{Fontys}

University of Applied Sciences

Design: Luc de Bruijn

Printing: Datawyse Maastricht

(C) Theo Niessen, Maastricht, 2007

ISBN: 978-90-9022II3-7 


\section{Proefschrift}

Ter verkrijging van de graad van doctor aan de Universiteit Maastricht op gezag van de Rector Magnificus, Prof. Mr. G.P.M.F. Mols, volgens het besluit van het College van Decanen, in het openbaar te verdedigen op vrijdag 30 november 2007 om I2.00 uur.

door

Theodorus Johannes Hubertus Niessen 



\section{Promotores}

Prof. Dr. G.A.M. Widdershoven

Prof. Dr. C.P.M. van der Vleuten

\section{Copromotor}

Dr. T.A. Abma

\section{Beoordelingscommissie}

Prof. Dr. R. Vos (voorzitter)

Prof. Dr. N. Lyons, National University of Ireland, Cork

Dr. H. Roebertsen

Prof. Dr. Th.A. Schwandt, University of Illinois

Dr. E. Wesseling 



\section{Table of contents}

Chapter 1 Introduction 9

Chapter 2 On the nature and form of epistemologies 19

Revealing hidden assumptions through an analysis of

instrument design

Published in European Journal of School Psychology

Chapter 3 Contemporary epistemological research in education 41

Reconciliation and reconceptualization of the field

In press: Theory and Psychology

Chapter 4 Understanding the lived curriculum

An epistemological analysis

Chapter 5 The performance of meaning

A focus on epistemological dynamics

Chapter 6 Teacher involvement in curriculum revisions

From a concern-based to a responsive approach

Chapter 7 General conclusion and discussion

Nederlandse samenvatting

Curriculum Vitae

Een woord van dank

ICO Dissertation Series 

1

Introduction 

The subject of this is thesis is the development and application of an epistemological perspective to understand teachers' experiences and their resistances against curriculum revisions. The data were gathered having evaluated a Problem Based Learning (PBL) course through means of Responsive Evaluation. We developed the epistemological perspective within a hermeneutic process. This first chapter deals with the background, the method and central questions within this study. We conclude this chapter by presenting an outline of the studies that together form this thesis. 


\section{Background to the study}

The domain of personal epistemology

Teaching and learning are about knowing and knowledge; about being able to estimate the veracity of knowledge. It is also about the questions how we acquire knowledge and how students should come to know. Traditionally, these questions are grounded within philosophy or more particularly within the branch called epistemology. From the sixties (of the previous century) on, with the seminal work of William Perry (Perry, 1968) these questions became an issue within educational psychology. From that moment on the empirical study of beliefs about knowledge and knowing has attracted researchers from many fields, with differing terminology, research paradigms and areas of interest. These examined individuals' beliefs about how knowledge is acquired, the theories and beliefs they hold about knowing (e.g., Hofer \& Pintrich, 1997), the structure of beliefs (e.g., Schommer, 1990), and how these beliefs are a part of and influence cognitive and motivational processes (Hofer \& Pintrich, 1997). Personal epistemology, as this domain is characterized today, has made important contributions to education by putting epistemology on the agenda as a category of informal knowledge that plays an important role in students' knowledge, reasoning, study strategies, and participation (Hammer \& Elby, 2002) and teachers' ways of teaching.

Despite the development and progression in the young field of personal epistemology there is still much to be explored and improved. The advancement of the epistemological perspective depends in part on the aspects that were not taken into account till now (Hammer \& Elby, 2002). Those aspects concern the form or nature of epistemological beliefs. By this is meant that there are different views about the question how to characterize, describe and model epistemological beliefs. Emulating mainly out of the field of "cognitive psychology" and "conceptual understanding", most researchers presume a form of epistemological beliefs: "as essentially unitary components of essentially stable epistemologies" (Hammer \& Elby, 2002, p. I70). This means that researchers characterize epistemological beliefs as stable declarative bits of knowledge or as constitutional characteristics i.e. as traits. We will claim that this view is problematic, because it presumes a consistency across contexts that is neither plausible nor evident: "It is a default presumption, not the result of a deliberate process of investigation, and we contend it is inadequate" (Hammer \& Elby, 2002, p. I7I). The underlying assumption about the nature of epistemological beliefs is recognizable within the many questionnaire studies or standardized interview studies conducted within the field of personal epistemology. Although the item formulation and questions are far removed from learning or teaching practices, researchers do nevertheless assume they pertain to these contexts. It is important to unravel this default position in detail, because different ideas about the form and 
nature illuminate different opinions about the influence of epistemological beliefs and how epistemological beliefs should be investigated. Within this thesis we will develop an understanding about the nature of epistemological beliefs that is not necessarily unitary. Drawing on enactivist theories (Davis \& Sumara, I997, 2000; Davis, 2004) we will propose epistemological beliefs as being malleable and dialogical. The context in which we have been developing and appropriating these notions is within the evaluation of "The introductory course on Problem Based Learning (PBL) for new staff members" at University of Maastricht (UM). We will be interpreting teachers experiences with PBL and their resistances to curriculum revisions from an epistemological perspective. In this study we use ideas and insights from various disciplinary fields, among them hermeneutic and dialogic ethics, psychology and enactivist theories.

\section{Problem Based Learning and the phenomenon of resistance}

Problem Based Learning is an instructional method that is soundly positioned within the UM (see also chapter 6). It is grounded within constructivist learning principles. This means that learning is meaningful when students engage in collaborative processes of knowledge construction. Real life problems are taken as its point of departure because these provide a powerful learning surrounding to students. This mode of learning has major consequences for teachers entering the PBL system as well. Contrary to frontal modes of teaching their role is not to instruct students but to facilitate the process in order to enable students to attain the necessary base of knowledge.

From its establishment within the faculty of Medicine almost thirty years ago, PBL spread out through the other faculties as well. Although PBL nowadays seems to be widely accepted at the UM, many students and new staff members still struggle to understand and appropriate PBL. Teachers are worried whether or not they may still display their expertise. Moreover, fostering a group process requires other skills than the traditional ones, and these skills may not be well developed. The result is that teachers feel resistant towards this mode of teaching. According to Don Margetson (I99I) these concerns and resistances are understandable since PBL is not just another instructional method of learning, but rather a radically different stance towards knowledge and knowing: “a conception of knowledge, understanding, and education profoundly different from the more usual conception underlying subjectbased learning" (ibid, p. 43).

\section{Generic problem definition}

The definition to the general problem that will be addressed within this thesis is: How can epistemological beliefs be described from an enactivist perspective and what 
merit does this new description add to the understanding of teachers' experiences and resistances within a PBL related teaching context? This problem definition is not only theoretically relevant, it also has practical relevance since an enactivist epistemological interpretation and understanding of the experiences and resistances of teachers has repercussions to those involved encountering it professionally or otherwise.

Since PBL is a different conception to the nature of knowledge and knowing the epistemological perspective might be helpful in enhancing the understanding of the struggles and resistances new staff members experience during the transition from a classical to a PBL related system of teaching. As explained in the former section, the evaluation study of PBL at the UM will be conducted parallel with the development of a more malleable and dialogical epistemological perspective. In order to develop an alternative approach to epistemological beliefs, we will draw on the meta-theory or worldview of enactivism (Varela, Thompson, \& Rosch, I997). Enactivism is a view on cognition in which it is assumed that beliefs are formed through the actions a person performs, both mentally as well as physically (Varela, Thompson, \& Rosch, I997). Reasoning from enactivism, epistemological beliefs are understood as enacted structures (both mentally and physically or spatially) which are experientially and biologically formed, and adapted through interactions with the environment. The term enactivism is intended to foreground the notion that knowledge is not pre-existent, but enacted (Davis \& Sumara, I997, 2000, 2002; Sumara \& Davis, I998) through interactions between differing elements. The grounding of the epistemological perspective within this meta-theory is able to acknowledge and preserve complexity and contextuality.

\section{Research method}

This study has two objectives. The first objective of this study is to enhance the understanding of the struggles and resistances of teachers engaging in PBL with help of an epistemological perspective. In order to realize this objective, the second objective is to develop an enactivist epistemological perspective. Working from the notion that researchers don't demonstrate but interpret objects of knowledge, in this case the development of epistemological perspective can be characterized as hermeneutical. It has been carried out through multiple hermeneutic cycles (see figure I). The output of each hermeneutic circle has been input for examination in the next circle. This led to adjustment of the theory being developed but also to a refined understanding of practice. It as such has been a dialogical and iterative endeavor between the data and the developing framework (our pre-understandings). The role of the researcher within this research has been that of an interpreter, who is sensitive to what is explicitly and subluminally communicated: “...the role of the evaluator as and interpreter who must have what he called "anthropological 
sensitivity" an ability to pay careful attention to the texture and concrete details of people's experiences, their activities over time, and their physical and social surroundings." (Stake, I99I - from Schwandt, 200I).

The evaluation project of the PBL course followed a responsive approach, having appropriated Responsive Evaluation (RE) as our research method within this investigation. The information gathered during this evaluation provided us with the data to develop and build our alternative epistemological form. With regards to this goal, RE was used instrumentally. However responsively evaluating the "Introductory course on PBL for new staff members", we also attended a moral obligation to include all stakeholders equally within this process.

$\mathrm{RE}$ has been developed by Robert Stake in reaction to "pre-ordinate" evaluation practices in which certain data was excluded. Departing from the assumption of value pluralism Stake claimed that different stakeholders have different expectations to the worth of a program or practice. The information of all these stakeholders is thus relevant estimating the worth of a program. At the same time responsiveness is also an epistemic and moral endeavor in itself. This means that it shows itself not so much in the use of a method, but in the researchers' interpretive stance towards the world and during the investigations: "As an epistemic and moral virtue, responsiveness is a distinctive capacity for, or way of, interpretively moving about the world that we aim to realize (albeit always imperfectly) in interacting with fellow human beings" (Schwandt, 200I, p. 75). Focusing on understanding during this responsive cycle, moving around cautiously and interpretively, talking about these understandings with our participants we think responsiveness as a moral virtue was and always has been part of our ground assumptions.

The thesis reports of investigations that were conducted within a PBL related environment. Within this context there is specific need for more contextualized and textured accounts to the teaching that is taking place (Savin-Baden, 2000). Within the: "Introductory course on PBL for new staff members" participants find the moratorium to talk about this transition and their relating struggles and resistances. This has been the reason to select and evaluate the introductory course on PBL for new staff members.

\section{Overview of the study}

A cyclical process of defining theoretical underpinnings and evaluation activities was the basis for the development of our enactivist epistemological account and to characterize and understand teacher's experiences and resistances epistemologically. We will provide an outline of this thesis along five chapters. It is important to note the process within each chapter must be characterized as hermeneutical (see figure I). 


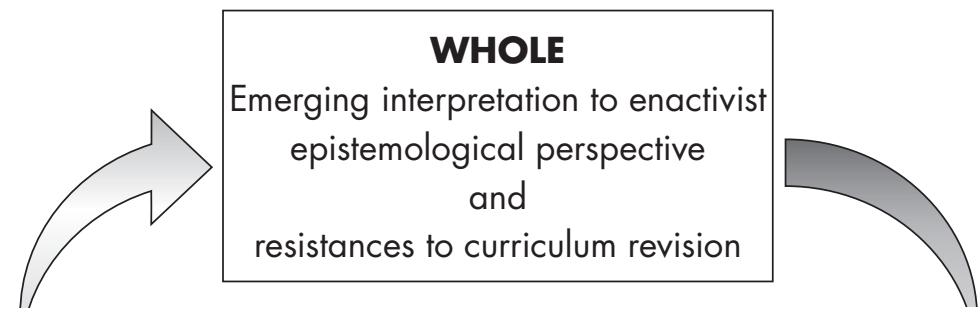

INTEGRATION

CONTEXTUALISATION

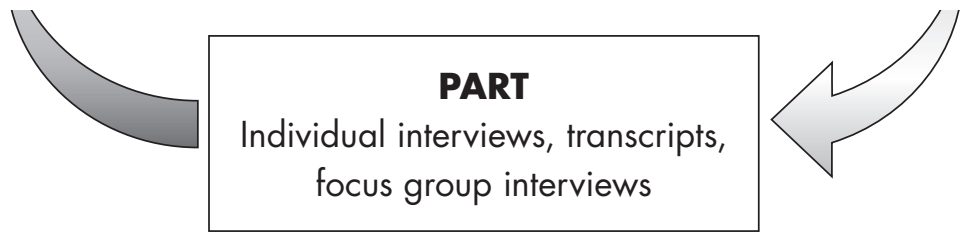

Figure 1: The use of the hermeneutic circle within the different chapters (adapted from Paterson \& Higgs (Paterson \& Higgs, 2005)

Within CHAPTER 2, we describe our efforts to characterize the construct of epistemological belief within a field that lacks explicit characterizations to this term. Oddly enough the field is dispersed with many different research designs and instruments to elicit epistemological beliefs. Departing from the assumption that worldview, method (research design) and concept definition should harmonize, our research question is whether and how the research design might reveals cues about the nature of the construct. By the nature of the construct is meant: the form, the organization of and access to epistemological beliefs. Along these questions a six dimensional framework is developed to which a research design may be evaluated. We gathered 30 instruments and scaled 4 along the proposed dimensions. We state that the proposed framework might facilitate the process to converse explicitly about the nature of the construct epistemological belief, but that the willingness for further investigation into ones own and others worldviews is of equal importance to succeed in this task.

CHAPTER 3 characterizes the field of contemporary epistemological research (linguistically, methodologically and ontologically) and sketches the contours of an enactivist interpretation to the epistemological domain. This characterization means to be truthful to the messiness and complexity of everyday teaching practice. This study focuses therefore on daily teaching moments as they are reported by the participants. Drawing on an interview fragment with one of the teacher trainers epistemological beliefs are characterized as temporarily crystallized enactments forming a configuration between teacher, students and other elements. 
Within CHAPTER 4 our epistemological perspective is expanded to take into account and interpret not only those experiences directly related to actual teaching encounters, but also those referring to experiences in early childhood as a student and their teachings with Maastricht University and/or elsewhere. Epistemological beliefs are still characterized as configurationally enacted phenomena. The difference with the portrayal in chapter 3 is that the dialogical enactment is also identifiable on an individual level as contrasting voices or I-positions. The analyses were returned to the participants and a subsequent (telephonic) talk with the participants about it revealed that in some occasions these were insightful or meaningful providing eyeopeners about their own practice.

Grounding the development of the epistemological perspective within reported experiences, the study in CHAPTER 5 adheres the feasibility of our perspective focusing on conversations during focus group interviews. These analyses let to a further fine-tuning of the epistemological perspective with regards to its malleability, the individual and contextual nature. It is claimed from this study that within the investigation of epistemological beliefs one should take into account the fact that people act into already meaningful surroundings in which personal relations to one another are equally important. Epistemological beliefs are grounded within personal and normative convictions. Close analysis of conversation shows that the participants do subtly alter there beliefs and opinions but that these alternations from a conceptual change view are not easy to discern.

In CHAPTER 6 we focus on an article written about PBL by Moust et al (Moust, Berkel, \& Schmidt, 2005). This article refers to the signs of erosion within the system that crept in over thirty years of PBL and their concern-based approach to mend these deficiencies. Within this article we characterize this approach and the implicit assumptions underlying it and provide a responsive approach that is situated within an enactivist framework. In the final chapter - CHAPTER 7 - we will summarize some of the finding and drawn conclusions to future research. 


\section{References}

Davis, A. B., \& Sumara, D., J. (I997). Cognition, complexity, and teacher education. Harvard Educational Review, 67(1), I05-I25.

Davis, A. B., \& Sumara, D., J. (2000). Curriculum forms: on the assumed shapes of knowing and knowledge. Journal of Curriculum Studies, 32(6), 82I-845.

Davis, A. B., \& Sumara, D., J. (2002). Constructivist discourses and the field of education: problems and possibilities. Educational Theory, 52(4), 409-428.

Davis, B. (2004). Inventions of teaching: a genealogy. Mahwah, New Jersey: Lawrence Erlbaum Associates, Publishers.

Hammer, D., \& Elby, A. (2002). On the form of a personal epistemology. In B. Hofer, K. \& P. R. Pintrich (Eds.), Personal epistemology (pp. I69-I90). Mahwah, New Jersey: Lawrence Erlbaum Associates.

Hofer, B. K., \& Pintrich, P. R. (I997). The development of epistemological theories: beliefs about knowledge and knowing and their relation to learning. Review of Educational Research, 67(I), 88-140.

Margetson, D. (I99I). Why is problem-based learning a challenge? In D. Boud \& G. Feletti (Eds.), The challenge of Problem Based Learning (pp. 42-50). London: Kogan Page.

Moust, J. H. C., Berkel, H. J. M. v., \& Schmidt, H. G. (2005). Signs of erosion: Reflections on three decades of problem-based learning at Maastricht University. Higher Education, 50, 665-683.
Paterson, M., \& Higgs, J. (2005). Using hermeneutics as a qualitative research approach in professional practice. The Qualitative Report, 10(2), 339-357. Retrieved from http://www.nova.edu/ssss/QR/ QR310-332/paterson.pdf.

Perry, W. G. (I968). Forms of intellectual and ethical development in the college years. New York: Holt, Rinehart and Winston, Inc.

Savin-Baden, M. (2000). Problem-based learning in Higher Education: Untold stories. Buckingham: SRHE and Open University Press.

Schommer, M. (I990). Effects of beliefs about the nature of knowledge on comprehension. Journal of Educational Psychology, 82(3), 498-504.

Schwandt, T. A. (200I). Responsiveness and everyday life. New Directions for Evaluation, 92, 73-88.

Sumara, D., J., \& Davis, A. B. (I998). Unskinning curriculum. In W. F. Pinar (Ed.), Curriculum: New identities for the field (pp. 75-9I). New York: Garland Publishing.

Varela, F., J., Thompson, E., \& Rosch, E. (1997). The embodied mind - Cognitive science and human experience (Sixth printing ed.). Cambridge, London: The MIT Press. 


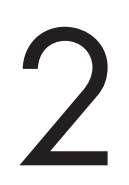

On the nature and form of epistemologies: revealing hidden assumptions through an analysis of instrument design 
This chapter has been published as: Niessen, T.J.H., Vermunt, J., Abma, T.A., Widdershoven, G.A.M. \& Vleuten, C.P.M. van der (2000). On the nature and form of epistemologies: revealing hidden assumptions through an analysis of instrument design. European Journal of School Psychology, 2(I-2), 39-64. 


\section{Abstract}

Many researchers from a variety of disciplines have shown an interest in the domain of personal epistemology. Although research on personal epistemology is flourishing, the field is fragmented by the use of a multitude of disparate labels. It is not clear from which basic assumptions they stem. This lack of clarity hampers a true dialogue about the differences and commonalities of the underlying foundations. This article is based on the proposition that the assumptions underlying the different labels can be inferred and compared by careful scrutiny of the design of the research instrument used. We developed a six-dimensional framework that may assist in clarifying those assumptions by determining the place of the instruments on each of the dimensions. In order to test the framework, we collected 30 instruments with different designs and determined their locations on the dimensions to reveal some of the implicit assumptions. It is concluded that focusing on instrument design may enhance the discussion about the underlying assumptions and raise it to a more explicit and fundamental level. 
"There are in fact a number of reasons for selecting a methodological approach, but one's decision often expresses values about what the world is like, how one ought to understand it, and what the most important threats to that understanding are." (Firestone, 1987)

\section{Introduction}

22 Research in the field of epistemology is flourishing. Many researchers from different disciplines have taken an interest in the domain of personal epistemology. The interest from the field of educational psychology dates from the sixties of the previous century with Perry's seminal work (Perry, I968, 1988). Epistemology in general is concerned with questions like: What is the nature of knowledge? and: How does a person come to know? Students' and teachers' ideas about these questions have been shown to follow developmental trajectories, which tend to influence their behaviour. Research on epistemology has made important contributions to education by putting epistemology on the map as a category of informal knowledge that may play an important role in students' knowledge, reasoning, study strategies, and participation (Hammer \& Elby, 2002).

However promising the contributions by epistemological research may seem, the successes partly masks the fragmentation of the field that is evidenced by the plethora of disparate labels used to indicate epistemological commitment: epistemological beliefs, epistemological thinking, epistemic cognition, epistemological theories, ways of knowing, epistemological posture, epistemological reflection, epistemological stance, epistemological resources and epistemological repertoires (Hofer \& Burr, 200I; Hofer \& Pintrich, 1997; Hofer \& Pintrich, 2002; Pintrich, 2002).

In order to foster a genuine dialogue about the meaning and value of these labels, we should explicate and examine the differences between them and how they draw on diverse default assumptions or world hypotheses (Pintrich, 2002), which have neither been well defined nor well described (Alexander, Murphy, \& Woods, I996; Guba \& Lincoln, I989). The main objective we pursue in this article is to facilitate and further this clarification process by presenting a dimensional framework that may be helpful in identifying and illuminating some of those paradigmatic differences. Discussion and awareness of those differences between underlying assumptions and constructs is the indispensable first step toward clarification and advancement of the contributions to education from the epistemological domain.

\section{Background and research question}

Reviewing contemporary epistemological research for the purpose of identifying differences and commonalities between different labels, we found that many researchers fall short in giving a clear definition of the labels they use, particularly 
with respect to the underlying, implicit world hypotheses. Quite possibly, researchers do have more in-depth ideas and views about this, but they are prevented by journal guidelines and constraints to explicitly formulate their assumptions. It is also thinkable that for pragmatic reasons researchers choose not to include this kind of information, because they want to publish in a certain journal. Another barrier to explicit delineation of assumptions might be that researchers have reservations about confrontation with insights they have not sufficiently thought out and which may destabilize the ideas they have always espoused.

In studying the literature, we encountered a wide variety of instrument designs (formats), such as open-ended interviews, vignettes, Likert-type questionnaires and observations. In the absence of explicit rationales for the choice of a certain label, we wondered whether the design of the research instrument might indirectly reveal something about the nature (i.e. the assumptions regarding world hypotheses) of the labels. This indirect linkage is visualised in Figure r. This approach to the search for the meaning of labels is based on the assumption that sound research is characterised by a certain degree of congruence in the different phases of a study. Every researcher is led by world hypotheses, whether consciously or not (Pintrich, 2002). We contend that these world hypotheses are reflected in the description of the key research concepts and also guide the selection of the research instrument(s) (design) the researcher deems the most appropriate to investigate the key concepts.

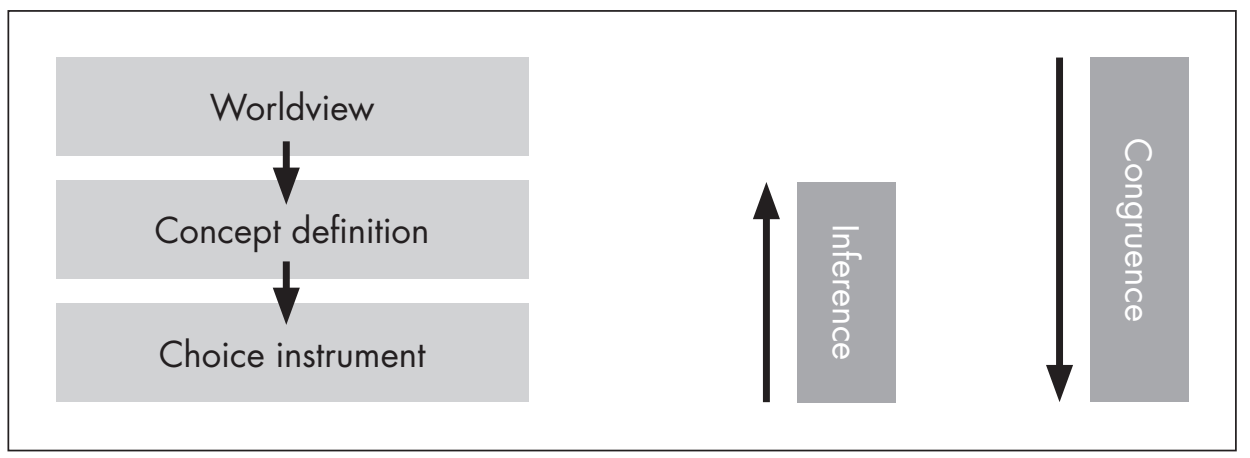

Figure 1: Linkages between world view and choice of research instruments

Reasoning on the basis of this congruence assumption, we claim (see Figure I inference) that we need not focus exclusively on the search for explicit explanations per se, but that a fruitful approach might be to direct our attention to the researchers' choice of instrument and its design. The main research question is:

How does a researcher's choice of instruments implicitly reveal cues about how the researcher perceives the nature of the epistemological construct? 
In accordance with Schoenfeld (Schoenfeld, I999b) statements about the nature of knowledge, we refer to 'the nature of epistemologies, by which we mean more specifically:

(a) What form do epistemologies take?

(b) How are epistemologies organized and

(c) How does one get access to epistemologies?

To be able to address the question about the nature of epistemologies, we need a structure that will enable us to uncover the - often hidden - default assumptions. In the next section such a framework will be developed. In the subsequent section we will examine its viability - methodologically and practically. Finally, we will make some comments which we believe are essential for the advancement of the domain and the use of this framework in particular.

\section{Method}

The first step in the development of the framework was a search of the Social Sciences Citation Index for relevant literature and instruments with respect to epistemology. Next, we collected as many instruments as possible. Some of these instruments had been fully described in the literature, others we retrieved by sending an email request for the complete version to the authors who reported its use, often the developers of the instrument. In this way, we collected 30 instruments for examining personal epistemologies.

Table I gives an overview of some of the instruments that have been developed over the years, labelled by author and categorised by subject domain. We do not claim that this overview is exhaustive. There are several reasons why it is virtually impossible to obtain a complete list of all available instruments. Firstly, many researchers do not explicitly label their research as "measuring epistemologies". Secondly, research of personal epistemologies covers a broad field covering several subject domains. One has to be an expert in all these domains to be able to gain a comprehensive overview. Thirdly, it may not only be hard to obtain all the instruments, it also seems unnecessary to do so, because many instruments are slightly revised versions of previously developed ones.

The inclusion criterion for instruments was the occurrence of the term epistemology and/or a derivative thereof. The information about the instruments was gathered by studying the instruments and, if no copy was available, by studying the relevant literature.

Next, by analysing the instrumentsin an iterative manner and studying the scientific literature on epistemologies (Chinn, I993; diSessa, I993; Duell \& Schommer-Aikins, 200I; Elby \& Hammer, 200I; Hofer \& Pintrich, I997; Hofer \& Pintrich, 2002) and (critiques to) cognitive psychology (Davis \& Sumara, I997, 2001, 2002a, 2002b; 
Table 1. Instruments on epistemologies and some descriptive characteristics1

\begin{tabular}{|c|c|c|c|c|c|}
\hline & Source & Definition & Outcomes & Format & Or/deri \\
\hline \multicolumn{6}{|l|}{ General } \\
\hline 1. Perry $(1968,1988)$ & bo & epbel & epista & inview & ori \\
\hline 2. King \& Kitchener $(1994,2002)$ & bo/art & epbel & epidi & inview & $\mathrm{pa}$ \\
\hline 3. Kitchener \& et al (1999) & art & epbel & epidi & cofor & $\mathrm{pa}$ \\
\hline 4. Boyes \& Chandler $(1990,1991)$ & art & epbel & epista & inview & insp \\
\hline 5. Baxter Magolda $(1992,1994,1996,2002)$ & art & epbel & epilev & oeq & simto \\
\hline 6. Belenky et al. (1986) \& Mc Vicker Clinchy (2002) & bo/art & epbel & epicat & inview & aot \\
\hline 7. Schommer $(1990,1994 a \& b, 2002)$ & art & epbel & epidi & liquest & insp \\
\hline 8. Jehng et al. (1993) & art & epbel & epidi & liquest & $\mathrm{pa}$ \\
\hline 9. Schraw et al. (2001) & art & epbel & epidi & liquest & $\mathrm{pa}$ \\
\hline 10. Kuhn et al. $(2000,2001,2002)$ & art & epbel & epipo & quest & \\
\hline 11. Hofer $(1997,2000,2001$ a \& b, 2002) & art & epbel & epidi & cofor & pa \\
\hline 12. Roozendaal et al. & art & epbel & epidi & quest & $\mathrm{pa}$ \\
\hline 13. Tirri et al (1999) & art & sedef/epicat & epistan & inview oe/c & inspi \\
\hline 14. Lonka et al (1999) & art & epist & epifac & liquest & \\
\hline 15. Lyons(1990) & art & epist & epist & castud & \\
\hline 16. Philips (1998, 2001) & art & epibel & epidi & liquest & simto \\
\hline \multicolumn{6}{|l|}{ Mathematics } \\
\hline 17. De Corte et al (2002) & art & epbel & epifac & liquest & $\mathrm{pa}$ \\
\hline 18. Roulet (1998) & the & epbel & epistanc & castud/cofor & $\mathrm{pa}$ \\
\hline 19. Schoenfelt $(1983,2000$ a \& b) & art & epbel & epibun & castud/cofor & ori \\
\hline 20. Hill $(1993,1997,2000)$ & art & epbel & epista & quest/inview & inspi \\
\hline 21. Speer \& Aguirre (2000) & art & epbel & epibun & cofor & $\mathrm{pa}$ \\
\hline \multicolumn{6}{|l|}{ Physics } \\
\hline 22. Hammer \& Elby $(2001,2002)$ & art & epireso & & cofor & insp \\
\hline 23. diSessa (1993) & art & epireso & p-prims & cofor & ori \\
\hline \multicolumn{6}{|l|}{ Science } \\
\hline 24. (Butler) Songer \& Linn $(1990,1991)$ & art & epbel & & cofor & ori \\
\hline 25. Yerrick et al (1998) & art & sedef & epistanc & cofor & \\
\hline 26. Benson (1989) & art & & epiview & castud/cofor & ori \\
\hline 27. Lederman (1987) & art & epicat & epifac & cofor & \\
\hline 28. Hashweh (1996) & art & epibel & & quest & \\
\hline 29. Maor et al (1995) & art & & & cofor & ori \\
\hline 30. Abd-el-khalick et al (1998) & art & & & cofor & \\
\hline
\end{tabular}

1 Explanations of abbreviations in Table 1:

Sources: article (=art); thesis (=the); book (=bo)

Definition: construct definition: epistemological belief (=epbel); epistemological development (=epidel); epistemological cognition (=epicog); reflective judgement (=rejud); epistemic doubt (=epidob); epistemological reflection (=epiref); epistemological categories (=epicat); epistemological perspectives (=epipers); epistemological style (=episty); epistemologies (=epist); several definitions (=sedef); epistemological resource (=epireso)

Outcomes: The terms in which the outcomes of the study are stated: epistemological categories (=epicat); epistemological levels of reflective judgment (=epilev); epistemological stages (=epista); epistemological stances (=epistanc) epistemological dimensions (=epidi); epistemological factors (=epifac) epistemological positions (=epipo); epistemological perspectives (=epipers); epistemological standards (=epistan)

Format: Likert-questionnaire (=liquest); questionnaire (=quest); case study (=castud); interviews (inview); combined formats (=cofor); open-ended questions (=oeq); open-ended (=oe); closed (=c); semi-structured (=ss)

Original/derivation (=ori / deri): original (=ori); inspired (=insp); partly adopted (=pa); wholly adopted (=wa); similar to (=simto); as opposed to (=aot) 
Davis, Sumara, \& Kieren, 1996; Kincheloe \& Steinberg, I993; Säljö, 2002; Shapiro \& Kirby, I998; Sumara \& Davis, I997; Varela, Thompson, \& Rosch, I997; Widdershoven, I999), we developed a six-dimensional framework, which would enable us to identify some of the assumptions about the nature (i.e. organization, form and access) of the construct underlying the design of a specific instrument. In order to enhance the trustworthiness and viability of the results, we discussed the six-dimensional framework with colleagues (member check: (Lincoln \& Guba, I985) and presented it to international educational research forums (peer debriefing: (Lincoln \& Guba, I985) : (I) the Junior Researchers (JURE) conference of EARLI in Amsterdam, The Netherlands, 200I; (2) the meeting of the Special Interest Group on Learning and Professional Development of the European Association of Research on Learning and Instruction (EARLI) in Turku, Finland, 2002; and (3) the ICO Summer School in Rethimno, Greece, in 2002. In the next section we present a more detailed description of the six-dimensional model to frame the assumptions that guided the instrument design. These will thereafter be 'tested' for their practical viability.

\section{Results}

The framework we developed consisted of six dimensions, which were expected to enable a researcher to verify whether his or her espoused assumptions about the organisation, form and access of epistemologies are congruent with the assumptions underlying his or her choice of instrument and thus its design. Dimension I relates to the question whether epistemologies consist of disparate epistemological factors or whether it is impossible to distinguish separate epistemological components. Dimension II represents the question whether epistemologies are static or more malleable in nature. Dimension III is related to the question whether epistemologies are cognitive phenomena, existing exclusively in people's heads or whether epistemologies are also observable as non-cognitive structures in our world. Dimension IV asks if epistemologies are pitched at a general level or whether they are (more) context specific. In the latter case, one should take into account that researchers may think about and define context in very different ways (Pintrich, 2002). Dimension V represents the question whether it is possible to speak explicitly about epistemologies. Finally, dimension VI addresses the question whether it is feasible to speak openly about one's epistemologies.

\section{The six dimensions}

Figure 2 graphically represents the six dimensions. However, in order to be able to assign instruments to their appropriate position on the different dimensions further clarification is required. In the subsequent paragraphs we will explain the dimensions 
in more detail. Dimensions I and 2, 3 and 4 and 5 and 6 relate to respectively the organization, form and accessibility, of the epistemological construct implied by the researchers' choice of instrument.

How are epistemologies organised?
(1) Isolated
Entwined
(2) Static

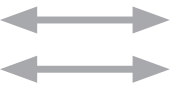
Dynamic

What form do epistemologies take?
(3) Cognitive
(4) General

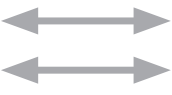
Physical
Context-specific

How are epistemologies accessed?

(5) Explicit

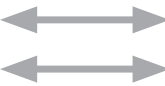

Implicit

(6) Self referential

Attributing

Figure 2: A framework of six dimensions for analysing the nature of epistemologies

\section{Dimension I - Organization: Isolated versus Entwined}

Many researchers use (Likert-type) questionnaires to elicit epistemologies (Duell \& Schommer-Aikins, 200I). This choice implies the assumption that it is possible to identify separate epistemological dimensions that can be identified by subsequent confirmatory and/or exploratory factor analysis. On the other end of the isolatedentwined continuum, we find the researchers who question whether epistemologies can be dissected into different belief components (Pintrich, 2002). These researchers would use more naturalistic or ethnographic research instruments, such as openended, non-directive interviews and/or participant observation, which make it difficult to discern separate factors. The assumption of these researchers seems to be that the whole is more than the individual parts. Pintrich (2002) stresses that, ultimately, these different researchers call upon different, incompatible theories.

"In this manner the difference between these cognitive developmental models and the more cognitive perspective,..., reflects the traditional organismic and mechanistic meta-theories that underlie the models. That is, the cognitive developmental models assume that epistemological thinking is more qualitative, organic, or holistic (the whole is greater than the parts) and cannot be broken down into independent components, at least not coherently. In contrast, the more mechanistic cognitive models do assume that there can be a quantitative analysis of the components and that these somewhat independent components 
can be described and summarized in some manner to represent the nature of epistemological thinking." (Pintrich, 2002, p. 395)

\section{Dimension II: Organization: Static versus Dynamic}

Many researchers refer to the label they use to identify their epistemological construct in terms of people having it as some sort of characteristic that is static and impervious to change (for example people having epistemological beliefs). This is reflected by the instruments chosen and the language used: questionnaires and vignettes emphasize the static and stable nature of epistemologies. Focusing on the interface between people, other researchers point to the fact that epistemologies are co-created in ongoing actual classroom action (interaction). Epistemologies are thus emergent and therefore more malleable and dynamic in nature (Freeman, I991, I996a, I996b). Epistemologies in the latter sense do not solely exist as unchanging, static cognitive components nor are they solely the result of dialectical processes, as exemplified by Soviet psychologists like Bakhtin. According to Freeman, both processes occur:

"However, a central question remains about the conceptions of practice which the teachers come to articulate and act upon through their experience in the in-service program. Do these conceptions exist a priori, but on a tacit level as Shulman implies, to be "made explicit" through the process of teacher education? Or are they formed through the participation in professional training? This study would suggest that both processes are taking place simultaneously and interactively... So the process of making the "the tacit explicit" is not a linear one of revealing what is known; it seems to be a dialectical one in which familiar and tacit knowledge interacts with - and is reshaped by - newly explicit understandings." (Freeman, 1991, p. 453)

According to Freeman (I99I), beliefs, including epistemological beliefs, have static components, but acquire their actual meaning and interpretation in ongoing practice. Epistemologies are so to say recreated and co-created in each new situation. That is why, according to Freeman, both processes are occurring simultaneously. Moreover, there is a process of representational recreation (Karmiloff - Smith, from (Wiliam, I998) whereby individuals through repeating dialogue become aware of and are better able to discuss their representations (epistemologies - our addition) on an increasingly explicit level.

\section{How are epistemologies formed?}

The next two dimensions focus on cues about the form epistemological beliefs take and the formation process in which epistemologies are structured. 


\section{Dimension III - Form: Cognitive versus Physical}

Researchers who focus on individuals through the use of self-reporting measurement techniques assume that epistemologies reside primarily within the individual, in people's heads as cognitive structures or components. Other researchers focus on the 'social historical context' on which epistemologies are inscribed:

"The values and beliefs of the dominant culture within society influence the ways that school systems are organized and how school buildings are built and serve to establish the rules and standards of behaviour within those settings. These values and beliefs are embodied in the artfactual world of the school setting. From the placement of the teacher's desk on a platform in front of a room to the honouring of a picture of Einstein in a special place on the wall, values and belief are material in the ways that we organize the spaces and features of the classroom." (Shapiro \& Kirby, 1998, p. 226)

Researchers at the physical end of the dimensional continuum point out that we live in an already interpreted reality. This means that - although people perceive and interpret the world in idiosyncratic ways - the physical structures (such as the way a class is organised) surrounding us are subsumed within epistemological inscriptions or beliefs, which set limits to the range of possible interpretations (Packer \& Winne, I995; Roth \& Lucas. Keith, I997; Roth \& McGinn, I998; Shapiro \& Kirby, I998) Semiotic analysis and research methods are suitable methods for eliciting these epistemologies (Hofer \& Pintrich, I997; Hofer \& Pintrich, 2002; Lakoff \& Johnson, I999; Shapiro \& Kirby, I998).

\section{Dimension IV - Form: General versus Context-specific}

Some researchers use more ethnographic methods, such as detailed observations of class discussions, to examine epistemologies. By doing so, they suggest that epistemologies should be seen as context-specific phenomena. Researchers who use questionnaires with general items (for example: "nothing is certain but death and taxes" from the Schommer questionnaire) apparently assume that epistemologies function on a more general and abstracted level. The issue of context-dependency of epistemologies is clouded by the discussion on the definition of context dependency. According to Pintrich (2002), the issue is ultimately pitched on differences about the underlying meta-theories:

"The more important issue concerns the refinement of our definitions of domains and contexts. For example, for many of the models in this volume, particularly the more developmental ones, domains refer to larger areas of our lives, from academic to work to the personal and social arenas of our lives. For other more cognitive models, domains have been 
synonymous with school subject areas or disciplines. Finally, for strong contextualist models, domains may be too broad a category and these models often propose a focus on epistemological thinking within a domain, but also how the classroom context represents and shapes the nature of knowledge and knowing within that domain. Accordingly, there is a need for clear statements about domain boundaries in our models." (Pintrich, 2002, p. 399)

Generally speaking, one may safely state that 'contextualists' tend toward the use of more ethnographic, naturalistic methods, and thereby clearly do not so much strive to get detached from context particularities and move to more abstract generalisable findings, as seek to obtain detailed insights into and be as sensitive as possible to the context from which epistemologies emerge. The research methods used by contextualist researchers are more narrative and focus more on understanding than on prediction.

\section{How does one get access to epistemologies?}

The final question about the nature of epistemologies is related to access to epistemologies. The first dimension under this heading refers to the question whether it is at all possible for persons to be explicit about their individual epistemologies. The second dimension refers to the question whether it is wise to ask straightforward questions about people's epistemologies.

\section{Dimension V - Access: Explicit versus Implicit}

The study of epistemologies generally focuses on an analysis of what people say they believe. Words are taken as vehicles for thought, and people are 'taken at their word'. This implies that the researcher believes in the ability and willingness of people to talk about themselves in epistemological terms. In the case of teachers' epistemologies, teachers' words are taken as revelations of what is in the teachers' minds and thus as expressions of their beliefs and thinking. In this light, the dimension Explicit versus Implicit refers to the question whether researchers believe that respondents' are capable of explicit reflection on their epistemological beliefs, and thus can be taken 'at their word' or whether it serves no purpose to ask respondents about their epistemological beliefs, because they have neither the language nor the willingness to discuss them openly and directly. Some researchers who hold the latter conviction do not ask teachers directly and explicitly about their epistemological beliefs but infer these, for example through detailed text analysis (Siskin, I994).

\section{Dimension VI - Access: Self - referential versus Attributing}

The dimension Self-referential versus Attributing focuses on the issue that some of the researchers who believe in respondents' ability to explicitly and directly discuss 
epistemological beliefs nevertheless think that one should take into account that what people say they believe and what they actually believe may be two different things. This becomes clear when one looks at actual school practice. What teachers profess to believe may not be evidenced by what happens in the classroom in straightforward ways. That is why some researchers think that it may be wiser not to take teachers at their word but to focus instead on beliefs they are able to attribute to them on the basis of detailed analyses of behaviour and natural conversations.

"A growing literature on teachers beliefs makes it clear that what teachers profess to believe and what they actually believe may be very different things; moreover, that what they 'believe' may not translate into classroom practice in straightforward ways. Just as in all other domains, beliefs shape the goals teachers have for classroom interactions. They shape the set of options teachers believe to be available to meet those goals, and they shape the ways in which those resources are employed. A comprehensive model of teaching must delineate the nature of teachers beliefs and elaborate the ways in which they work." (Schoenfeld, 1999b, p. 248)

\section{Placing the instruments on the dimensional scales}

In the previous section we have described the different dimensions in some detail. We will now evaluate some instrument designs using the proposed dimensions to ascertain the framework's practical feasibility (figures 3 to 8 ). Over the years numerous instruments have been developed to measure domain-specific and general (see Table I) epistemological beliefs. Given the limited space, we have selected four instruments that may be taken to be representative of the main formats.

First, the four instruments are described briefly to enable the reader to infer and verify how we have positioned the instruments on the six dimensions. Although this process was done with great care, the reader should keep in mind that this framework is first and foremost intended to achieve a more explicit level in the discussion about assumptions regarding organisation, form and accessibility of epistemological beliefs. It would be counterproductive for us to let the discussion get bogged down in a dispute about the accuracy of the positioning on the dimensions.

W.G. Perry (P) - (Perry, 1968, 1988)

In the fifties and sixties of the previous century, William Perry, Jr. conducted openended interviews with undergraduates at the end of each academic year, opening with the question: 'What stands out for you this year?' In this way he hoped to capture students' perceptions of their learning and development, not so much in terms of academic achievement as in overall changes they experienced within themselves. He found that students' ways of perceiving knowledge and values changed during the 
college years. Epistemological beliefs - as identified by Perry using non-directive, open interviews - may be likened to implicit - i.e. outside students' conscious awareness - filters through which students evaluate and encounter the challenges they meet.

M. Schommer-Aikens (SA) - (Duell \& Schommer-Aikins, 2001; Schommer, 1990; Schommer, 1994a; Schommer, 1998)

In the nineties, Marlene Schommer-Aikens was the first to report a major study to test the assumption of epistemological beliefs as a system of more of less independent beliefs. Independent beliefs are beliefs that do not necessarily have to mature congruently and simultaneously. By referring to a system of beliefs she indicated that in personal epistemology there is more than one belief dimension to consider. In order to assess these beliefs a Likert-type questionnaire was developed. Students had to respond to statements, such as 'Scientists can ultimately get to the truth.' or 'I don't like movies that have an open ending.'

\section{N. Lyons (L) - (Lyons, 1990, 1995)}

Lyon speaks of 'nested epistemologies' to highlight the fact that teachers and learners have interconnected and interacting epistemological perspectives. This means that values and ideas, teachers' subject knowledge, their relationships with students and conceptions about themselves and their students as epistemological subjects are part of and create a certain predisposition towards knowledge definitions. Lyons uses non-directive interviews as the major method for data collection. Excerpts from these interviews are used to exemplify the credibility of her use of the term epistemological beliefs.

J. Aguirre \& N. Speer (A\&S) - (Aguirre \& Speer, 1999; Schoenfeld, 1999b; Schoenfeld, Minstrell, \& Zee, 1999)

The method proposed by Aguirre and Speer (200I) uses detailed videotapes and audiotapes of actual classroom algebra lesson conversations. The parsing of this information is phenomenological. The analysis is often carried out line by line, in the search for an explanation of how and why teachers make decisions and the influence of certain bundles of beliefs on those decisions. Epistemological beliefs although not explicitly stated - are part of those belief bundles. 


\section{ISOLATED}

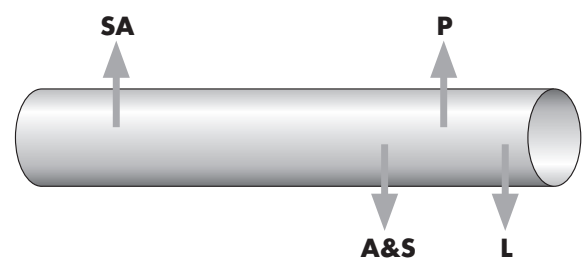

ENTWINED

Figure 3: Dimension I - Organization: ISOLATED VERSUS ENTWINED

Explanation: On the basis of the vignettes used by these four researchers and their instruments, we place SA on the left side of the continuum because her main research method - a Likert type questionnaire - implies the assumption that epistemologies are organized into different epistemological factors or dimensions which can be identified through factor analysis. $L$ on the other hand uses fragments from interviews with teachers and their students and thus organizes epistemological beliefs as holistic constructs that cannot be dissected into mutually exclusive factors. The ones in between from P and A\&S presume an organization - using open-ended questionnaires and observations, respectively - that is more holistic than fragmented or isolated.

STATIC

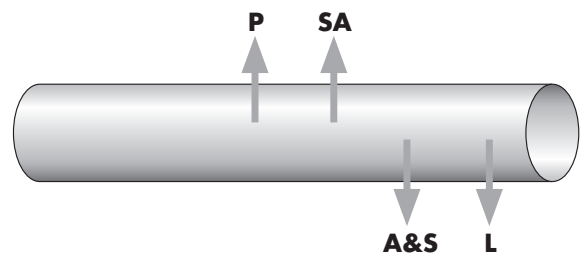

DYNAMIC

\section{Figure 4: Dimension II - Organization: STATIC VERSUS DYNAMIC}

Explanation: On the dimension static versus dynamic Lyons should be placed at the dynamic end of the continuum due to the malleable definition of the epistemological perspective. The use of interviews suggests the assumption that the triggering of epistemologies is context dependent. A situated perspective is also visible in the research by A\&S. In their case epistemological beliefs are elicited from observations. SA on the other hand used questionnaires, which suggests the assumption that epistemological beliefs are not so much malleable and situational as organized like theories or traits. Perry organizes epistemological beliefs by phases. Students change their epistemological outlooks in the course of the college continuum. However, the outlooks are seen as less malleable than in the perspectives of L and A\&S.

\section{COGNITIVE}

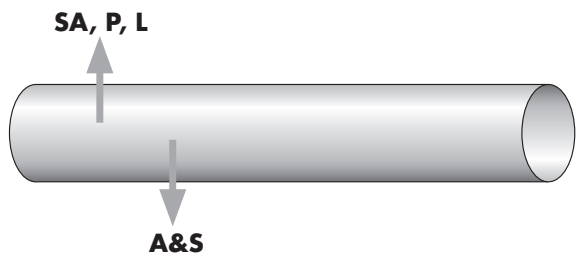

PHYSICAL

Figure 5: Dimension III - Form: COGNITIVE VERSUS PHYSICAL

Explanation : SA, P and S used instruments focusing on how individuals make sense of epistemological issues and thus implicitly adopt the cognitive psychological perspective of epistemologies residing solely inside people's heads, as cognitive constructs. By focusing on the interface between people, $L$ on the other hand leaves it open to question whether beliefs can exist outside the rigid boundaries of cognitive psychology. That is why we did not position her study on this dimension. 


\section{GENERAL}

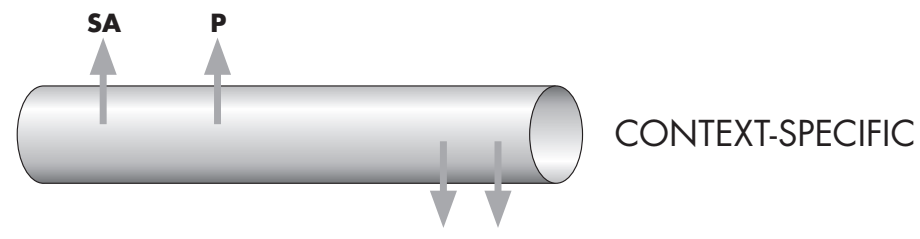

Figure 6: Dimension IV - Form: GENERAL VERSUS CONTEXT-SPECIFIC

Explanation: The dimension general versus context-specific refers to the extent to which the instrument is formed around the actual practice of students or teachers. In the questionnaire used by S, items are stated very generally "Nothing is certain but death and taxes." and "I don't like movies that have an open ending." P's model reflects a different general epistemological outlook, which is also not situation-specific. The instruments used by A\&S and L are formed around class encounters between student and teachers and are thus more attuned to the actual learning / teaching context.

\section{EXPLICIT}

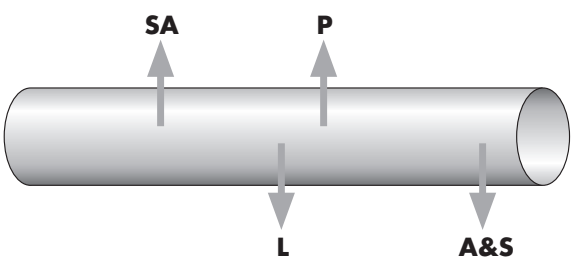

IMPLICIT

Figure 7: Dimension V - Access: EXPLICIT VERSUS IMPLICIT

Explanation: To what extent do the instruments facilitate an explicit discussion on epistemological beliefs. The questionnaire used by SA is based on the assumption that students have rather direct access to epistemological issues. L's approach assumes that students and teachers are not so epistemologically 'literate', because epistemologies are often unconscious and hold intricate relations with issues of self. P elicited students' epistemologies by talking about what stood out for them in a certain school year. A\&S do not think it wise or possible to have direct access to explicit epistemologies, because people do not have the language to talk about such issues.

\section{SELF REFERENTIAL}

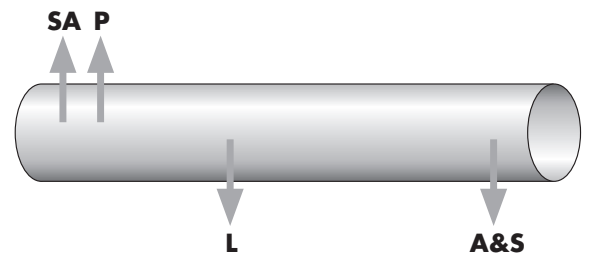

ATTRIBUTING

Figure 8: Dimension VI - Access: SELF REFERENTIAL VERSUS ATTRIBUTING

Explanation: This dimension is a normative refinement of dimension V. It questions respondents' ability to talk about their epistemological beliefs as well as the feasibility of such an approach. SA and P and L take the cognitive perspective that it is possible and prudent to let respondents explicitly report their epistemologies. A\&S are the exceptions to this dimension. They think that with self reporting instruments respondents may be influenced by social desirability. It is therefore - more reliable - to attribute epistemologies to people. 


\section{Discussion}

Reviewing the domain of personal epistemologies, we encountered a research area characterised by many disparate labels (Hofer, 2000; Hofer \& Pintrich, 2002). These labels are grounded in and supported by different paradigmatic communities from which they spring (Pintrich, 2002). To carry on a genuine dialogue about the differences and commonalities of these labels, it is imperative that these dialogues include an open discussion about the labels' paradigmatic roots or groundings. Since a direct comparison between these labels and their paradigmatic assumptions is not possible, because the labels have scarcely been clarified, we attempted to reveal some of these assumptions by analysing the implications of the researcher's choice of instrument. This approach was based on the point of view adopted in this article that research is congruent in all its phases (from the world view explanation to the choice of instrument). We thus explored whether the design of the instrument used could tell us something about the assumptions that characterise the nature of epistemologies, i.e. their form, organization and access (see figure 2).

We developed a multi-dimensional framework to help clarify which world views are likely to form the basis of a particular epistemological study by analysing instruments and the literature on epistemologies and cognitive psychology in an iterative manner. Our main objective was to offer researchers a framework that might enable them to develop an explicit definition of the assumptions underlying their labelling of epistemological beliefs or, in cases where a definition has been formulated, to consciously reflect on their assumptions and measure them against the dimensions of the framework. For example: Researcher A examines epistemological beliefs using a Likert-type questionnaire. The question is, does he agree with the assumptions implied by the use of this instrument? He may or he may not. The main issue is that the framework facilitates a fundamental discussion about the nature of these constructs and lifts it to a more explicit level. However, a framework based on the researcher's choice of instrument to identify and categorise the researcher's assumptions about the nature of epistemologies does not suffice to supply the researcher with an adequate operationalisation of the label he or she has applied. Referring to figure 2, we contend that any careful and thorough operationalisation should take into account and be grounded in a more or less explicit world view. We contend that research is always based on a world view - perhaps unconsciously but never coincidentally - which guides the researcher in his or her justification and explanation of the research construct (Jung, I98I). The framework developed in this article may assist researchers in taking a first step toward an explicit definition of those fundamental world view assumptions. Kagan (Kagan, I990) also addressed the issue that different techniques point to different world hypotheses, and at the same time stated that it is difficult to judge the validity of a technique unless one is familiar with the relevant foundations. 
"After reviewing various approaches to the assessment of teacher cognition, it becomes clear that one deeply problematic aspect of this literature is that techniques are derived from different epistemological traditions, Likert scales are derived from psychometric test theory, textual analyses of teachers' language from theory relating language to cognition, self-reflection hierarchies from studies of cognitive mediation, and concept mapping from schema theory and research on memory for verbal information. Each of these traditions provides a different definition of evidence and truth; some contradict each other. It is difficult for a reader to judge the validity of a technique unless he or she is familiar with the relevant foundation, and few consumers (non-specialists) could be expected to have such an eclectic background." (Kagan, 1990, p. 451)

Kagan is quite pessimistic about researchers' ability to transcend their own point of view, because it is impossible to be an expert in all the traditions in which instruments have their origin. Although we agree with Kagan's view, we would like to add that in our view it is not merely a question of the ability of a researcher to transcend his or her foundation but also the willingness of researchers to be open and susceptible to other world hypotheses:

"I have found over and over again that the acceptance of a new point of view...has much less to do with the validity of that point of view than with (one's) readiness to consider any alternatives whatsoever." (Schein, 1987, p. 107 -from Evans (1996))

To be genuinely interested and knowledgeable about the differences between underlying world views requires courage. Courage to put one's most innate and taken for granted assumptions to a critical test. We have noticed that in the recent literature on epistemologies new stances are receiving serious and considerable attention (Hammer \& Elby, 2002; Hofer \& Pintrich, 2002). We welcome this attention and openness and hope that as a combined result of this openness and a renewed discussion about the foundations of the domain the field will prosper and be ready for the next century. 


\section{References}

Abd-el-Khalick, F., Bell, R. L., \& Lederman, N. G. (I998). The nature of science and instructional practice: making the unnatural natural. Science Education, 82, 4I7-436.

Aguirre, J., \& Speer, N. M. (I999). Examining the relationships between beliefs and goals in teacher practice. Journal of Mathematical Behavior, 18(3), 327-356.

Alexander, P. A., Murphy, P. K., \& Woods, B. S. (1996). Of squalls and fathoms: Navigating the seas of educational innovation. Educational Researcher, 25, 3I-36.

Baxter Magolda, M. B. (I992). Student's epistemologies and academic experiences: implications for pedagogy. The Review of Higher Education, 15(3), 265-287.

Baxter Magolda, M. B. (I994). Post-college experiences and epistemology. The Review of Higher Education, $18(\mathrm{I}), 25-44$.

Baxter Magolda, M. B. (I996). Epistemological development in grade and professional education. The Review of Higher Education, 19(3), 283-304.

Baxter Magolda, M. B. (2002). Epistemological reflection: The evolution of epistemological assumptions from age I8 to 30 . In B. K. Hofer \& P. R. Pintrich (Eds.), Personal epistemology: The psychology of beliefs about knowledge and knowing (pp. 89-Io2). Mahwah: Lawrence Erlbaum Associates.

Belenky, M. F., Clinchy, B. M., Goldberger, N. R., \& Tarule, J. M. (I986). Women's ways of knowing: The development of self, voice and mind. New York: Basic Books.

Benson, G. D. (1989). Epistemology and science curriculum. Journal of Curriculum Studies, 21(4), 329-344.

Boyes, M., C., \& Chandler, M. (I99I). Cognitive development, epistemic doubt, and identity formation in adolescence. Journal of Youth and Adolescence, 21(3), 277-304.

Bruner, J. (2002). Making stories: Law, literature, life. New York: Farrar, Straus and Giroux.

Butler Songer, N., \& Linn, M. C. (I99I). How students' views of science influence knowledge integration? Journal of Research in Science Teaching, 28(9), 76I784 .

Chandler, M., \& Boyes, M., C. (I990). Relativism and stations of epistemic doubt. Journal of Experimental Child Psychology, 50, 370-395.

Chinn, C. A., Brewer, W. F. (I993). The role of anomalous data in knowledge acquisition: a theoretical framework and implication for science instruction. Review of Educational Research, 63(I), I-49.

Davis, A. B., \& Sumara, D., J. (I997). Cognition, complexity, and teacher education. Harvard Educational Review, 67(I), I05-I25.
Davis, A. B., \& Sumara, D., J. (200I). Learning communities: Understanding the workplace as a complex system. New Directions for Adult Continuing Education, 92(Winter), 85-95.

Davis, A. B., \& Sumara, D., J. (2002a). Constructivist discourses and the field of education: problems and possibilities. Educational Theory, 52(4), 409-428.

Davis, A. B., \& Sumara, D., J. (2002b). Constructivist discourses and the field of education: problems and possibilities. Educational Theory, 52(4), 409-428.

Davis, A. B., Sumara, D., J., \& Kieren, T. (I996). Cognition, co-emergence, curriculum. Journal of Curriculum Studies, 28(2), I5I-I69.

De Corte, E., Eynde, P. O. t., \& Verschaffel, L. (2002). "Knowing what to believe": The relevance of students' mathematical beliefs. In B. K. Hofer \& P. R. Pintrich (Eds.), Personal epistemology: The psychology of beliefs about knowledge and knowing (pp. 197-320). Mahwah: Lawrence Erlbaum Associates.

diSessa, A., A. (I993). Toward an epistemology of physics. Cognition and Instruction, $10(2 \& 3)$, 105225.

Duell, O., K., \& Schommer-Aikins, M. (200I). Measures of people's beliefs about knowledge and learning. Educational Psychology Review, 13(4), 4I9-449.

Elby, A., \& Hammer, D. (200I). On the substance of a sophisticated epistemology. Science Education, 85, 554-567.

Evans, R. (1996). The human side of school change: Reform, resistance, and the real-life problems of innovation. San Francisco: Jossey-Bass Publishers.

Firestone, W. A. (I987). Meaning in method: The rhetoric of quantitative and qualitative research. Educational Researcher, 16(7), I6-2I.

Freeman, D. (I99I). “To make the tacit explicit”: Teacher education, emerging discourse, and conceptions of teaching. Teaching \& Teacher Education, 7(5/6), 439454 .

Freeman, D. (1996a). "To take them at their word": Language data in the study of teachers' knowledge. Harvard Educational Review, 66(4), 732-76I.

Freeman, D. (1996b). The 'unstudied problem': Research on teacher learning in language teaching. In D. Freeman \& J. C. Richards (Eds.), Teacher learning in language teaching (pp. 351-378). Cambridge: Cambridge University Press.

Guba, E., G., \& Lincoln, Y., S. (I989). Fourth generation evaluation. Beverly Hills: Sage Publ.

Hammer, D., \& Elby, A. (2002). On the form of a personal epistemology. In B. Hofer, K. \& P. R. Pintrich (Eds.), Personal epistemology (pp. I69-I90). Mahwah, New Jersey: Lawrence Erlbaum Associates.

Hashweh, M. Z. (1996). Effects of science teachers' epistemological beliefs in teaching. Journal of Research in Science Teaching, 33(I), 47-63. 
Hofer, B., K. (200I). Personal epistemology research: Implications for learning and teaching. Journal of Educational Psychology Review, 13(4), 353-383.

Hofer, B., K., \& Burr, J. E. (200I). The development of personal epistemology: The evolving coordination of the subjective and objective. Paper presented the EARLI, Fribourg, Switzerland.

Hofer, B. K. (2000). Dimensionality and disciplinary differences in personal epistemology. Contemporary Educational Psychology, 25, 378-405.

Hofer, B. K., \& Pintrich, P. R. (I997). The development of epistemological theories: beliefs about knowledge and knowing and their relation to learning. Review of Educational Research, 67(I), 88-I40.

Hofer, B. K., \& Pintrich, P. R. (2002). Personal epistemology: The psychology of beliefs about knowledge and knowing. Mahwah, New Jersey: Lawrence Erlbaum.

Jehng, J. J., Johnson, S. D., \& Anderson, R. C. (I993). Schooling and students' epistemological beliefs about learning. Contemporary Educational Psychology, 18, 23-35.

Jung, C. G. (I98I). The structure and dynamics of the psyche. Princeton, NJ: Princeton University Press.

Kagan, D., M. (I990). Ways of evaluating teacher cognition: Inferences concerning the Goldilocks principle. Review of Educational Research, 60(3), 4I9-469.

Kincheloe, J., L., \& Steinberg, S., R. (I993). A tentative description of post-formal thinking: The critical confrontation with cognitive theory. Harvard Educational Review, 63(3), 296-320.

King, P. M., \& Kitchener, K. S. (1994). Developing reflective judgement: Understanding and promoting reflective growth and critical thinking in adolescents and adults. San Francisco: Jossey-Bass.

Kitchener, K. S., Wood, P. K., \& Jensen, L. (I999 August). Curricular, co-curricular, and institutional influence on real-world problem solving. Paper presented at the Annual meeting of the American Psychological Association, Boston, Massachussets.

Kuhn, D. (200I). How do people know? Psychological Science, 12(I), I-8.

Kuhn, D., Cheney, R., \& Weinstock, M. (2000). The development of epistemological understanding. Cognitive Development, 15, 309-328.

Kuhn, D., \& Weinstock, M. (2002). What is epistemological thinking and why does it matter. In B. K. Hofer \& P. R. Pintrich (Eds.), Personal epistemology: The psychology of beliefs about knowledge and knowing (pp. II9-I20). Mahwah: Lawrence Erlbaum Associates.

Lakoff, G., \& Johnson, M. (I999). Leven in metaforen. Nijmegen: Uitgeverij SUN.

Lederman, N. G. (I987). Science teachers' conceptions of the nature of science: Do they really influence teaching behavior? Science Education, 71(5), 72I-734.

Lincoln, Y., S., \& Guba, E., G. (1985). Naturalistic inquiry. Beverly Hills: CA: Sage.

Lonka, K., \& Lindblom-Ylänne, S. (I999). Epistemologies, Conceptions of Learning, and Study Success in Medicine and Psychology. Helsinki: Faculty of Medicine, University of Helsinki.
Lyons, N. (I990). Dilemmas of knowing: Ethical and epistemological dimensions of teachers' work and development. Harvard Educational Review, 6o(2), I59-I80.

Lyons, N. (I995). Re-imagining teacher education. Curriculum Inquiry, 25(I), 75-85.

Maor, D., \& Taylor, P., C. (I995). Teacher epistemology and scientific inquiry in computerized classroom environments. Journal of Research in Science Teaching, 32(8), 839-854.

Packer, M. J., \& Winne, P. H. (I995). The place of cognition in explanations of teaching: a dialog of interpretive and cognitive approaches. Teaching and Teacher Education, 11(I), I-2I.

Perry, W. G. (I968). Forms of intellectual and ethical development in the college years. New York: Holt, Rinehart and Winston, Inc.

Perry, W. G. (I988). Different worlds in the same classroom. In P. Ramsden (Ed.), Improving learning: New perspectives (pp. I45-I6I). London: Kogan Page Ltd.

Phillips, F. (I998). Accounting students' beliefs about knowledge: Associating performance with underlying belief dimensions. Issues in Accounting Education, 13(I), II3-I26.

Phillips, F. (200I). A research note on accounting students' epistemological beliefs, study strategies, and unstructured problem-solving performance. Issues in Accounting Education, 16(I), 2I-39.

Pintrich, P. R. (2002). Future challenges and directions for theory and research on personal epistemology. In B. K. Hofer \& P. R. Pintrich (Eds.), Personal epistemology: The psychology of beliefs about knowledge and knowing (pp. 389-4I4). Mahwah: Lawrence Erlbaum Associates Publishers.

Roth, W.-M., \& Lucas. Keith, B. (I997). From 'truth' to 'invented reality': A discourse analysis of high school physics students' talk about scientific knowledge. Journal of Research in Science Teaching, 34(2), I45-I79.

Roth, W.-M., \& McGinn, M. K. (I998). Inscriptions: Toward a Theory of Representing as a Social Practice. Review of Educational Research, 68(I), 35-59.

Roulet, G., R. (I998). Exemplary mathematics teachers: subject conceptions and instructional practices. University of Toronto, Toronto.

Rozendaal, J., S., de Brabander, C., \& Dahl, I. (2003). Epistemological understanding and interpretive theory of mind. Paper presented at the bi-annual conference of the European Association of Research on Learning and Instruction, Padova, Italy.

Rozendaal, J. S., de Brabander, C., \& Minnaert, A. (200I). Boundaries and dimensionality of epistemological beliefs. Paper presented at the bi-annual conference of the European Association of Research on Learning and Instruction, Fribourg, Switzerland.

Säljö, R. (2002). My brain's running slow today - the preference for "things ontologies" in research and everyday discourse on human thinking. Studies in Philosophy and Education, 21, 389-405.

Schoenfeld, A., H. (I999a). Looking Toward the 2Ist Century: Challenges of Educational Theory and Practice. Educational Researcher, 28(7), 4-I4. 
Schoenfeld, A., H. (I999b). Models of the teaching process. Journal of Mathematical Behavior, 18(3). 243-26r.

Schoenfeld, A., H., Minstrell, J., \& Zee, E. v. (I999). The detailed analyses of an established teacher's nontraditional lesson. Journal of Mathematical Behavior, 18(3), 28I-325.

Schommer, M. (I990). Effects of beliefs about the nature of knowledge on comprehension. Journal of Educational Psychology, 82, 498-504.

Schommer, M. (I994a). An emerging conceptualization of epistemological beliefs and their role in learning. In R. Garner \& P. A. Alexander (Eds.), Beliefs about text and instruction with text. Hillsdale, New Jersey: Lawrence Erlbaum.

Schommer, M. (I994b). Synthesizing epistemological belief research: tentative understandings and provocative confusions. Educational Psychology Review, 6(4), 293-319.

Schommer, M. (1998). The influence of age and education on epistemological beliefs. British Journal of educational Psychology, 68, 551-562.

Schommer-Aikins, M. (2002). An evolving theoretical framework for an epistemological belief system. In B. K. Hofer, Pintrich, P. R. (Ed.), Personal epistemology: The psychology of beliefs about knowledge and knowing (pp. I03-II8). Mahwah: Lawrence Erlbaum Associates.

Schraw, G. (200I). Current themes and future directions in epistemological research: a commentary. Educational Psychology Review, 13(4), 45I-464.
Shapiro, B., \& Kirby, D. (I998). An approach to consider messages of school science learning culture. Journal of Science Teacher Education, 9(3), 221-240.

Siskin, L. S. (1994). Realms of knowledge: Academic departments in secondary schools. New York: Falmer Press.

Sumara, D., J., \& Davis, A. B. (I997). Enactivist theory and community learning: toward a complexified understanding of action research. Educational Action Research, 5(3), 403-422.

Tirri, K., Husu, J., \& Kansanen, P. (1999). The epistomological stance between the knower and the known. Teaching \&Teacher Education, 15, 9II-922.

Varela, F., J., Thompson, E., \& Rosch, E. (I997). The embodied mind - Cognitive science and human experience (Sixth printing ed.). Cambridge, London: The MIT Press.

Widdershoven, G., A. M. (I999). Cognitive psychology and hermeneutics: Two approaches to meaning and mental disorder. Philosophy, Psychiatry and Psychology, 6(4), 245-253.

Wiliam, D. (1998). Being mathematical versus mathematical be-ing: situated activity, interactive emergence and mathematical education. Paper presented at the 24th annual conference of the British Educational Research Association, Queens' University of Belfast.

Yerrick, R. K., Pedersen, J. E., \& Arnason, J. (1998). "We're Just Spectators": A Case Study of Science Teaching, Epistemology, and Classroom Management. Science Education, 82(6), 619-648. 



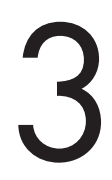

Contemporary

epistemological

research in education:

Reconciliation and reconceptualization of the field 
In press as: Niessen, T.J.H., Abma, T.A., Widdershoven, G.A.M., Akkerman, S. \& Vleuten, C.P.M. van der (in press). Contemporary epistemological research in education: Reconciliation and reconceptualization of the field, Theory \& Psychology. 


\section{Abstract}

In this article the authors challenge contemporary epistemological research within educational settings. After a reconciliation of the current models which treat epistemological beliefs as static and mechanical, the authors present a teaching experience to illustrate their enactivist view that epistemological beliefs should be conceptualized as fluid and dynamic constructs, emerging in web-like configurations. Answers to epistemological questions enfold within the interstices and mutual interactions between people and their environment. Boundaries between studentteacher, individual-community, cognition-bodily experience are becoming blurred. From this enactivist perspective the researcher's role changes considerably. Instead of determining teachers' personal traits and epistemological make-up, the researcher should sensitize teachers to the subtle ways epistemological beliefs are enmeshed within their day-to-day professional lives, focusing on the complex fabric of the teaching practice. 


\section{Movement}

We rehearse information, but perform meaning.

44 Information is like the web of links in a wire fence;

Meaning is like the cascade of waves on a mountain stream.

One you can stitch together endlessly, capturing what you're looking for, and keeping out what you don't want in. The other, just by drawing a border around it, vanishes before your eyes.

\section{Cliff Crego'}

\section{Introduction}

What is the true nature of knowledge and how does a person come to know? These questions first became subject of psychological investigation in the late sixties of the previous century by the seminal work of Perry (Perry, I968). Today, these questions are studied under the umbrella of research at personal epistemology (Hofer \& Pintrich, 2002). Personal epistemology has come to be seen as the common denominator for research done within this field and as the term signifying individual conceptions of knowledge and knowing. These conceptions are referred to by many disparate labels of which the most commonly used term is 'epistemological belief. Other labels are: epistemological posture, epistemological resource, ways of knowing (Niessen et al, 2004). Because the term (epistemological) belief is already more broadly used within (educational) psychology and thus easy to associate with, we will use this term throughout the article when referring to issues of knowledge and knowing. Within this article we provide a cognitive psychological and an enactivist account to epistemological beliefs and claim that the differences between both are ultimately reflected in Crego's distinction between the rehearsing of information and performing of meaning. We will apply the enactivist perspective to an interview segment to enable deeper understanding of teaching practice. The application of the enactivist account to this case has the character of a hermeneutic circle. This means that the enactivist account provides us with a background view that enables us to understand teachers' experiences more fully. At the same time, the process of application is also a practice of opening up and being caught by new insights while interpreting. These insights might alter our epistemological perspective. 
This study is part of a larger ongoing investigation to understand the phenomenon of resistance of teachers to a Problem Based Learning (PBL) learning environment using the epistemological perspective as our interpretive framework. PBL in short is an instructional method that, contrary to frontal teaching, chooses not to instruct students directly, but to facilitate the process in which students themselves and in collaboration with each other learn the necessary knowledge and skills by working on real life problems. The role of the teacher is paramount to the success of this method. This is why the example used throughout this article highlights a teacher that is situated within a PBL course. In the following we will first present the fragment taken from the interview with Josie. In this fragment she talks about her struggle to introduce a group of new staff members into Problem Based Learning. We will also provide a more in depth linguistic, methodological and ontological characterization to contemporary epistemological research. Finally the contours to the enactivist perspective will be drawn in more detail.

\section{Josie's case}

'Interviewer (I): How would you describe yourself as a trainer? Josie (J): I always try to get the group excited about PBL. I: How do you do that? J: By trying to get everybody involved. At the same time, this is a potential pitfall. For instance, in a training session last week there was a group of student tutors and this group was really very critical, because they had attended other PBL courses. That was when I found myself trying to create more structure - that's where I felt inadequate, because there were so many people with so much experience. In these instances it's important to offer students guidelines and structure. You should be able to deviate from this structure - but only in those cases - when it's possible. Some teachers see this very clearly. Personally, I tend to create structure together with the group - on the spot. With some groups this works out just fine and with other groups it would have been better if I had provided a clear structure from the start. We would have come further. I: Students get restless? J: No, yes, well, there's too much input and too few conclusions. I think that's a major thing in PBL - it's a major issue that too often, maybe, no actual conclusion is reached. That's really what I think is probably my own shortcoming, something that as a student I thought was missing in the system. That structure - the framework in which you work. I: What does this framework look like - what is it made of? Do you know what I mean? J: A connecting thread. I: You say that on the one hand you're trying to find this thread - and you want to connect it with the experiences of the participants - but that's difficult because their experiences are so diverse and a common theme is hard to discern. $J$ : Well, maybe that's because there just isn't one single thread and because PBL is based on the assumption that the available knowledge is relative. So you cannot say there's one single solution to a particular problem. The important thing is that you are working towards a solution.' 
Josie is a junior teacher trainer at the Faculty of Economics and Business Administration. She was one out of a group of ten teacher trainers and nine new staff members of Maastricht University who were interviewed about their experiences with PBL, their concerns and unresolved issues. The participants we interviewed came from different departments of Maastricht University and differed considerably in experience with PBL, general attitude towards teaching, general teaching experience and opinion about the value of PBL for student learning. Despite the marked differences in background and experience between the interviewees, Josie was not the only one who presented a complex and multilayered experience. Looking at other participants' day-to-day teaching experiences, we similarly encountered varied and multilayered stories. This phenomenon is neither strange nor new. Studies by Perry (Perry, I968) and Lyons (Lyons, I990), but also more recently from Phillion and Connelly (Phillion $\&$ Connelly, 2004) show us that when researchers turn their attention to actual teaching experiences, the presented picture of teaching and epistemological beliefs is more textured and complex. The selection to this particular segment has been guided by its potential to learn from it about the role of epistemological beliefs in teaching. According to Stake's (I994) “the potential for learning is a different and sometimes superior criterion to representativeness" (Stake, I994, p. 243).

The fragment shows how Josie is struggling with the question: "How do these students come to know?" In the interview, Josie as a teacher trainer talks about her ideas and ideals of student involvement within her courses. She says that in some situations she finds it difficult to realize these ideals. She refers to her attempts to structure group sessions. She thinks that in order to do so, she has to develop 'a connecting thread' that will enable the group to achieve a sense of closure. This metaphor nicely illustrates Josie's narrative approach to teaching. Her goal is to develop, together with the group, a storyline with a beginning, middle and an ending. She expects that this jointly developed plot will enable the group to close the session in a satisfactory way.

Josie's ideas and strategy implicitly characterize her epistemological approach to one of the key questions in epistemology: 'How does a person come to know?, or How should this group of students come to know?' We can see an answer emerging from the confrontation between her ideals, her self image and the group with its characteristics. When she says 'It's in these instances that it's important to offer students guidelines and structure', she refers to her failed attempt to provide guidance, which to her mind was necessary to give the group a satisfactory sense of closure. This experience appears to have triggered a slight change in her epistemological outlook. Instead of her a priori assumption that students should be regarded as knowledgeable others, who will work together with the teacher to create a common thread, she now thinks that the group process also depends on her ability 
to accurately estimate the amount of prior experience students bring to the course and her own experience and skills.

Josie's rapport with the group of students is coloured by her ideals about student involvement. It is also with this particular group of students, who have so 'much experience', that she discovers the failure of her usual strategy, i.e. developing a structure 'on the spot' together with the group. In her own words: 'Their experiences are so diverse and a common theme is hard to find'. As a result she is confused and forced to reassess her epistemological ideal of student involvement in light of the concrete situation. Looking back on this experience, she reflects on the epistemological perspective underlying PBL and in doing so realizes that there just isn't one single solution to a problem and that all knowledge can make a contribution.

The lived experiences of Josie as a teacher are interpreted as an indication that the epistemological questions can only be meaningfully understood when they are placed within the context of the story that defines the situation as a whole. To put it in more general terms, in order to assess a situation epistemologically or make sense of teachers' experiences epistemologically, we need to take account of the circumstances that constitute each new teaching situation. In Josie's case these circumstances included her conviction that a common thread had to be identified, her skills to get the group to do this, the group size and group members' varied experience. We would assert that her epistemological belief is essentially 'indexical' (Roth, Lawless, \& Tobin, 2000) meaning that it is significant only seen from within the concrete circumstances in which it arises. In the following section we will focus on the contrast between this view of epistemological beliefs and the prevailing views in contemporary epistemological research.

\section{Contemporary epistemological research}

Although the term 'contemporary epistemological research' suggests that there is a unified research domain, there are in fact different movements to which researchers within the domain of personal epistemology may turn. These movements may be referred to as 'trait oriented', 'theory minded' and 'resource oriented'. This means that researchers typify epistemological beliefs respectively as traits, theories or resources (Hammer \& Elby, 2002). Although we agree with Hammer and Elby that there are some important differences between these movements, we also discern an important mutual characteristic: all are rooted in cognitive psychology. This seems to offer an interesting perspective for an analysis and characterization to the field as a whole, because it would go to the very heart of research at epistemological beliefs regardless of the particular movement. In our view Crego's phrase 'rehearsal of information' very aptly captures the essence of contemporary epistemological research in relation to three interrelated angles: language, methodology and ontology. 


\section{Linguistic idiosyncrasies of contemporary epistemological research}

A striking linguistic characteristic of the cognitive psychological discourse about the foundations of thinking and believing is a marked preference for the use of nouns (Säljö, 2002). Since contemporary epistemological research is grounded in cognitive psychology, this characteristic is also discernable in epistemological research. The phenomenon addressed within epistemological research can be denoted by different labels: epistemological belief (Duell \& Schommer-Aikins, 200I; Hofer, 2000; Hofer \& Pintrich, I997; Hofer \& Pintrich, 2002; Schommer, I994, 1998), epistemological position (Perry, I968, I988); epistemological theory (Hofer, 2000; Hofer \& Pintrich, I997; Hofer \& Pintrich, 2002), epistemological standard (Ryan, I984 a, I984 b), epistemological resource (Hammer \& Elby, 2002), epistemological style (Martin, Silva, Newman, \& Thayer, 1994), epistemological reflection (Baxter Magolda, I992, I994, I996), epistemological posture (Désaultes \& Larochelle, I997), epistemological orientation (Belenky, Clinchy, Goldberger, \& Tarule, I986), epistemological antecedent (Powell, I996) and way of knowing (Belenky, Clinchy, Goldberger, \& Tarule, I986).

The worrying aspect of the predominance of nouns as the building blocks for thinking and believing is that it creates the impression that people's capacities and ideas should be conceived of as unchanging objects (Säljö, 2002). Nouns distract our attention from the processes in which epistemological constructs can be seen to emerge. Nouns denote a final state as opposed to a process in which actions and thoughts are continuously taking shape and modifying each other. The idea of stability is reinforced by the tendency to represent epistemological beliefs as stable cognitive traits or theories (Hammer \& Elby, 2002). Epistemological beliefs are seen as trait-like or theory-like features which are stored and acted upon inside the brain. From an epistemological trait perspective, individuals' beliefs and ideas about epistemology tend to cohere into stable 'positions' or 'levels', 'phases' or 'stages', which can be distinguished from other 'levels' and 'phases' with regards to organization and quality. They are seen as declarative knowledge to which a person has conscious and articulate access. In epistemological theories, beliefs are perceived as being structured in this way (Hofer \& Pintrich, 1997; Hofer \& Pintrich, 2002). Congruent with the tendency to see epistemological beliefs as stable and object-like traits or theories stored within the individual mind, most researchers tend to refer to epistemological beliefs in terms of 'individuals having them' (Pehkonen \& Törner, I999).

Another feature within Western society that reinforces thinking about epistemological beliefs as objects and unchanging is the linguistic tendency to typify mental phenomena dichotomously, i.e. as belonging to either-or categories (Amstutz, I999; 
Davis \& Sumara, I997). Examples of such dichotomies are: mental - physical, internal - external, individual - collective (Davis \& Sumara, 200I; Heft, 200I). Membership of one category precludes membership of the other one of the pair. This divisive either/ or mode of thinking reinforces the image of people as unchanging. Something or someone is or is not of some category. According to Langer (Langer, 1989, 1997) divisive thinking has this effect when people take categories or opposites literally or without mindful attention. She calls for heedful and critical thinking in which mindless acceptance of categories is regarded as the opposite of powerful learning. We think that a contemporary interpretation with a language that treats epistemological beliefs as stable and trait-like or object-like has troubles interpreting the epistemological picture that arises from teachers' concrete perspectives.

When we analyze Josie's account and realize that the way she tunes into the situation as a process that unfolds in interaction with the group, we realize that the boundaries between individual-collective, self-other, internal-external are not clear cut. They are fuzzy, blurred and overlapping and we see no clearly outlined either/or distinctions. We think epistemological beliefs should be better conceived of as emerging characterizations within a process of mutual adaptation i.e. Josie's attempts to tune in to the ideas of the group and to her own and reconcile them. Because this process unfolds concurrently with the teaching process, it cannot be fully anticipated a priori or even as it is being enacted. To us, this view is compatible with a concept of epistemological beliefs as continuously unfolding processes, i.e. like waves cascading down a mountain stream. Just as the water and the mountain are being shaped and reshaped in their continuous interaction, so is the answer to the epistemological question 'How do these students come to know?' being rephrased under the influence of interaction in a concrete teaching situation.

\section{Particularities regarding the methodology within a contemporary epistemological perspective}

Characterising the methodologies that are used in contemporary epistemological research, we see an equally differentiated array of instruments: production type tasks, open-ended interviews, vignettes, observations, ill- structured problems, and Likerttype questionnaires (Duell \& Schommer-Aikins, 200I). What is striking to us is that despite this diversity, epistemological belief research is exceptionally unitary in its preference for using the individual and his or her beliefs, knowledge, desires and attitudes, as the unit of analysis (Lyons, I990). We think this preference is congruent with the predilection for nouns emphasizing the object oriented way of thinking; It seems to us that an orientation towards epistemological beliefs as object-like has been (tacitly) operative in the development of instruments that are used to study them as personal and stable traits or theories. 
We notice that an orientation to the individual is especially recognizable in questionnaire (Likert-type) studies and standardized interview studies. Despite growing criticism of questionnaire studies, they have been and continue to be an important method in studies of epistemological beliefs (Duell \& Schommer-Aikins, 200I). Part of their popularity seems to be attributable to their easy and quick administration.

Nevertheless, Hammer \& Elby (2002) reveal a fundamental problem when they point out that item formulation is often far removed from day-to-day teaching practice while at the same time it is assumed to pertain to these contexts (see for example Schommer questionnaire: 'Nothing is certain but death and taxes'). According to Hammer \& Elby this is neither true nor viable when made explicit. Most epistemological studies ask subjects direct questions about their beliefs, often by presenting epistemological statements and asking them to rate their agreement/ disagreement on a Likert scale. For example, students may be asked whether they agree or disagree that 'the best thing about science courses is that most problems have one right answer' (Schommer, I990); 'the science principles in the textbooks will always be true' (Songer \& Linn, I99I); 'knowledge in physics consists of many pieces of information, each of which applies primarily to a specific situation' (Redish, Saul, \& Steinberg, I998). It is only by a presumption of unitarity that the results of these studies may be considered to apply to all contexts of learning (Hammer \& Elby, 2002).

However, the item formulation must be generic to preserve internal congruence throughout the whole study. It would be incongruent to perceive of epistemological beliefs as stable traits or theories but apply highly context-specific or dialogical research methods. A generic item formulation makes perfect sense given the a priori position that epistemological beliefs are stable phenomena. Epistemological beliefs are seen as tangible features and measured congruently. They can therefore be conceived of as entities that impact on teaching behaviour linearly i.e. cause exists as an inherent constituent of epistemological beliefs. Contemporary cognitive epistemological research is concerned with the search for explanations of the epistemological perspective in order to predict and control students' and teachers' behaviour. Using standardized (correlational) measuring techniques, researchers are able to identify these linear and law-governed patterns. The role of the researcher in this process is merely to uncover these relationships objectively, validly and reliably (Guba \& Lincoln, I989, I994; Lincoln \& Guba, I985, 2000).

Interpreting Josie's segment, it is true that Josie shows an epistemological preference to create a common thread together. At the same time we also see that this preference becomes 'active' and is questioned while interacting with this specific group. Her experience of the situation she describes has led her to acknowledge that in this 
instance - given her own and the group's experience - a different approach might have been more successful. Confronted with this new experience a breach is made within otherwise customized behaviour. These breaches provide opportunities for change and revision of ideas to local circumstances. We interpret Josie's ultimate handling of the situation as the result of reciprocal dynamics between different personal and situational elements, whose influence can be seen from a holistic point of view, but which cannot be reduced to any element or correlation in particular.

\section{The particularities regarding the ontology within a contemporary epistemological interpretation}

Ontology is the subdivision within metaphysics that deals with the nature of being. More concretely ontology is revealed in the question: What is real? We might thus ask whether epistemological beliefs are real. According to Baptiste (Baptiste, 200I), one of the most troublesome questions surrounding the issue of ontology is the distinction between the facticity and the quality of a thing.

Facticity refers to the question whether a thing exists. In our case we might ask if epistemological beliefs do exist. Departing from a realist perspective (Heron \& Reason, I997) the answer within contemporary epistemological research is that epistemological beliefs do indeed exist as theories, traits or resources. For realists, epistemological beliefs are just as real and tangible as observable objects.

The quality of a thing refers to the form of a phenomenon or the nature of an object. Within contemporary epistemological research epistemological beliefs are thought of as psychological and physical phenomena. They are psychological because they reside in a person's mind. They are also (presumably) physical on the basis of the default assumption that epistemological beliefs correspond to cognitive units in the brain (Hammer \& Elby, 2002).

Finally, there is the question if it would be possible for epistemological researchers to claim that epistemological beliefs exist without reference to cognitive psychology or cognitive science. Contemporary epistemological research although not explicitly referred to, heavily draws on cognitive science and cognitive psychology as its foundational precursors i.e. meaning that these strands are the background theories they implicitly build on. Varela et al (1997) have pointed at the reifying effect of cognitive science to cognitive psychology when describing the centrality of the computer metaphor and likewise language use. A language that is also apparent within educational research in general and epistemological research in particular (Davis \& Sumara, I997). It depicts humans as disenchanted, cerebral beings who receive and process information from events and objects to establish representations (beliefs, desires). These representations in turn govern and give meaning to their own behaviour and that of others. 
In Josie's interview, but also in the other interviews we conducted, we see from an enactive viewpoint first and foremost acting persons (Packer \& Winne, 1995) who stumble and haphazardly manage to guide their classes through the course. Josie's hesitation to infer definite conclusions about the preferred course of action in this particular situation is hard to interpret as an image of information rehearsal, the picture we see framed within contemporary epistemological research. As we see it, her answer to the question: How do these students come to know within this particular situation is embedded within a network of concrete relations and a process of mutual attunement.

In our view, Josie's hesitation to draw definite conclusions should not be deplored but welcomed, because it may open up opportunities that may lead to epistemological attunement, which may guide students and teachers to the most appropriate end. The interview excerpt with Josie illustrates the existential dialogical nature or ontology in which it is hard to dissect the knower from the known, mind from body, student from teacher, teacher from context (Hosking \& Bouwen, 2000). Josie's teaching might be viewed as a responsive choreography in which her behaviour and beliefs co-evolve within a relational web of individual inclinations or cognitions, her skills as a teacher trainer, the characteristics of the students she teaches and the dialogue between these elements altogether.

In the final section of this paper, we will explain and illustrate our enactive or dialogical world orientation. An enactivist world orientation is grounded in the assertion that people form complex fabrics of fundamentally and inextricably intertwined relationships with everything else - physically/ biologically and experientially / phenomenologically (Davis \& Sumara, I997). From this viewpoint, epistemological beliefs are not primarily or solely cognitive features, but they are temporarily crystallized enactments in ever changing webs of mutually defining elements.

\section{An enactive and dialogical perspective on epistemological beliefs}

So far, we have focused on a passage from Josie and characterized contemporary cognitive epistemological research from a linguistically, methodological and ontological point of view. The enactive epistemological perspective takes into account many elements such as the group experience, the group size, her own (in)abilities to provide a common thread (structure). In this final part of the discussion, we take up the challenge to sketch and explain more thoroughly the contours of an enactivist interpretation that enables us to take into account these elements Josie refers to. Although we typify our interpretation as enactivist we will also draws on theoretical notions derived from philosophical hermeneutics (Gadamer, I990; Widdershoven, 1999) and narrative psychology (Abma, 2000; Josselson \& Lieblich, I999; Lyons \& LaBoskey, 2002). 
Enactivism is an emerging world view that lingers in between and draws from different domains including philosophical phenomenology (Varela, I999), complexity theory (Waldrop, I992) and evolutionary biology (Bateson, I979, 1987). Although this world view is of reasonable recent date, it is receiving more and more attention within the domain of education (Davis \& Sumara, I997, 2001, 2002; Davis, Sumara, \& Kieren, 1996; Sumara \& Davis, 1997). Within the domain of contemporary epistemological research enactivism has been largely absent, although the work by Belenky et al. (Belenky, Clinchy, Goldberger, \& Tarule, 1986) and Lyons (Lyons, I990) shows strong similarities. In the following we will first explain enactivism as it is defined by Davis \& Sumara in the field of education (Davis \& Sumara, I997, 2000, 2002; Davis, Sumara, \& Kieren, 1996). Although not directly translated to the educational nor the epistemological field, we will also be using some of the terms (eclectically) used by Varela et al since they are eminent to the field of enactivism (Varela, Thompson, \& Rosch, I997).

To 'enact' means 'to work in or upon' or 'to act or perform'. 'Enactivism' refers to the idea of knowing in action. People come to know and believe about the world by interacting with it bodily, experientially and cognitively. This means that individuals are simultaneously biological and social beings that experientially embody both cognitive and physical dimensions within their actions. Because continuous interaction is such an important feature to enactivism one could claim that it holds a relational ontology meaning that all social realities and all knowledge of self, others and things are viewed as interdependent or co-dependent constructions existing and known only in relation to each other (Hosking \& Bouwen, 2000).

When we review Josie's her story again, we see a rather inexperienced teacher trainer who struggles with the epistemological question: "How should these students come to know?” Her commonly used approach to create a red thread together is rather problematic given her own (in)abilities, within a large group of experienced students. As a consequence of this inexperience she adjusts her epistemological outlook to include the notion that when faced with a rather experienced group she needs to hold more control. Interpreting her account enactively we would claim that her final outlook to this particular situation is the result from the interaction between her ideal to create a common thread together and her communication skills, her self image, the groups size and the amount of experience of the group. It is the confrontation of these elements within the concrete enactment that set the stage for this particular response to arise.

The enactive paradigm as exemplified by Varela et al (I997) emphasizes the relevance of action, embodiment and agent/environment mutuality. Therefore, in the enactivist perspective, cognition is not considered an abstract agent -internal process, but rather embodied action, being the outcome of the dynamical interaction between agent and 
environment and their mutual specification during the enfolding of the situation. Varela et al (Varela, Thompson, \& Rosch, 1997) have called this phenomenon as "coemergence" or "mutual specification" and earlier Maturana and Varela (Maturana \& Varela, I987) have called it "structural coupling". Sumara (Sumara, I996) signifies this mutuality as the us/not-us relationship meaning the inextricability between of what we call "subject" and what we call "context". The signifier "us/not-us" acknowledges that we can identify individual cognizing agents while simultaneously announcing that we can only perceive and interpret their action by attending to the conditions of their existence. Figure and ground - us and not/us - are simultaneously defined.

Hermeneutics is important helping us interpreting the us/not-us relationships between the "subject" and the "context". What is important to know are the relations among things. Gadamer (Gadamer, I990) calls this continual process of interpreting the relations among past, present and projected experience a "fusing of horizons". What hermeneutics points at is that Josie in our case is engaged in a continuous process of self-interpretation. Learning about things that are "not us" means being involved in a learning relation that informs one about herself. Her interpretation makes her learn that she is not knowledgeable to inform her students the way she normally does. She learns that her approach is not that fixed but contingent to the changing relations between her (us) and her students, the group size, the amount of experience, her skills (all not-us).

Narrative psychology helps to understand how people make sense of and give meaning to their own identity (us) and the context (not us). Stories help to endow meaning to situations, to weave events into a meaningful whole, and relate varied elements into a plotline (Josselson \& Lieblich, I999). A narrative is always contextbound; it positions a character in a specific time and place. A story does not only describe a specific situation, it also enables the narrator to find guidelines for action and to influence others to adjust their actions. Stories have a performative character. Josie finds out how to act in a similar situation by telling stories. Stories are appropriate to make sense of situations because they acknowledge particulars (Josselson \& Lieblich, I999; Lyons \& LaBoskey, 2002).

\section{Implications and conclusions}

Dynamic forms and dialogical structures are concepts that are not easy. Apart from the fact that the use of language in itself entails abstraction, it seems that our Western linguistic propensities lead us to freeze, fix, isolate and define epistemological beliefs as causal features that govern teacher and student behaviour, whether it be in 'phases' or 'stages' as is done by trait-like theories or as 'components' or 'correlations' within theory-like views of epistemological beliefs. One might say that Crego's metaphor of 
'rehearsing information' appears to play the leading role in today's epistemological research, whereas we think that the metaphor of the 'performance of meaning' resonates more immediately with the enacted experiences of teachers like Josie.

Departing from the enactive perspective, epistemological beliefs are evolving features. Varela et al. (I997) speak in this regard of 'co-emergence' and 'mutual specification'. Epistemological beliefs unfold in reciprocal, co-determined interactions between persons. The specific epistemological belief or perhaps better enactment we see exemplified in Josie's story is the result of reciprocal actions between her and the students she teaches. This means that her enactment ultimately cannot be reduced to anyone or anything in particular. It emerges in the dialogical process in which people mutually specify each other. In processes of typification or specification Josie, the group as well as the epistemological belief simultaneously emerge or said otherwise co-emerge.

Referring to Josie's fragment and the accompanying enactivist language of attunement and mutuality one might wonder if the enactivist perspective is not overly naïve or idealistic, assuming a too egalitarian and democratic portrayal of teaching. Within teaching power inevitably plays a role, potentially disturbing the processes of mutual tuning and balancing. Josie might have been a person holding on rigidly to her epistemological notions. This would have been an obstacle to reaching mutual understanding. We think learning can only take place when curiously and courageously opening to the other within dialogue. Would Josie have insisted and used her authority to hold on to her ideas, she would not have learned much about her self nor her students. From an enactivist perspective, one should strive to strike the balance between holding on to what is known and dear but at the same time keep an open mind to what is new. The lack of being mindful about this friction and holding mindlessly to ones own authority is a major obstacle potentially harming any learning taking place within student/teacher encounters (Langer, I989, I997).

From an enactivist perspective on epistemological beliefs, research should not focus on the components of experience (person, objects), but on the relations that bind them together within enacted webs of many interacting elements and persons. In this respect, Lyons (I990) refers to the need for a psychology of relations. Answers to epistemological questions emerge in the interstices between people. Lyons (I990) captures the complex and relational character of teaching practice by referring to it as 'nested' within relationships between people. From this perspective, epistemological beliefs characterize the relationships between people (student, teacher), subject content and the teaching/learning situation. To examine and characterize these webs of relationships as temporarily crystallized enactments, we need research that moves the unit of analysis from the individual person to the interface between people. Research should shift its focus from the individual as isolated cognitive being to 
cognition as formed within socially and situated mediated practices ${ }^{2}$. We have summarized some of the differences to the enactivist and cognitive perspective in table I.

\begin{tabular}{|l|l|}
\hline Cognitivist & Enactivist \\
\hline Cognitive pre-ordered world & Enacted enchanted world \\
\hline Individuality & Mutuality \\
\hline Beliefs necessarily stable / fixed & Beliefs not necessarily fluent \\
\hline Linear / direct influence from beliefs on behaviour & Enacted configuration \\
\hline
\end{tabular}

Table 1 Differences to the enactivist and cognitive perspective

Linear methodologies and causal models seem less appropriate to the perspective in which epistemological enactments are perceived as emerging in interrelated webs of personal and contextual features which constitute and mutually define each other. This issue is also addressed within complexity theories to which enactivism refers (Davis \& Sumara, I997; Phelps, 2002). Complexity theory emphasizes the importance of acknowledging the whole range of variables impacting on any context and the inability to control such variables while maintaining contextual integrity; in complexity terms, it is important to acknowledge the impossibility of reaching a full understanding of the whole through an understanding of its separate parts (Phelps, 2002).

Sceptics might wonder why we should even consider an epistemological perspective that is situational and seems to have less predictive power. However, it is our belief that the epistemological perspective that is opened up by an enactive perspective might well reveal stable tendencies within enactments that transcend time and place. However, it is not the researcher who has to determine whether this is 'really' so. Referring to Stake (Stake, 1994; Stake \& Trumbull, 1982), we contend that generalizations across time and situations are best made by the persons involved, since they are better able to appraise whether the epistemological beliefs that are revealed cover a broader (time \& place independent) terrain of action.

With this new epistemological perspective, the role of the researcher changes. We should not explain teaching behaviour through causal modelling, but rather sensitize teachers to the dialogical and situational nature of the epistemological perspective by providing and provoking them with thick descriptions (Geertz, I973). Thick descriptions attend epistemological beliefs in a manner that is sensitive to and acknowledges the complexities and contingencies of everyday teaching practice. With regard to those who, like Josie, already refer to epistemological beliefs and seem

2 There are already well articulated theories that provide clear explanations to this issue as for example the dialogical self-theory from Hermans and Hermans, Kempen \& Van Loon (H. J. Hermans, 2002; H. J. M. Hermans, Kempen, \& Van Loon, I992) 
to be aware that they take part in their functioning, the researcher's role might be to invite them to express their epistemological inclinations more explicitly and as concrete as possible focusing on concrete situations.

As regards our initial question whether contemporary epistemological research is equipped to understand teachers' lived experiences, we have strong reservations. While agreeing that the epistemological perspective is paramount within teachers' experiences, we are not equally convinced that the contingent and complex nature of teaching practice is appropriately represented by the language, research methodology and ontology that characterize contemporary epistemological research. Despite the obvious need for further fine-tuning, we think that our enactivist approach offers a promising perspective (Davis \& Sumara, 1997). Finally, and perhaps most importantly, we hope that teachers will be comfortable with this new perspective: an outlook that intends to take the complex nature of teaching practise seriously and tries to preserve it.

\section{Acknowledgements:}

We would like to thank Nona Lyons, Barbara Hofer and Mereke Gorsira for their helpful comments on previous drafts. 


\section{References}

Abma, T., A. (2000). Fostering learning-in-organization through narration: Questioning myths and stimulating multiplicity in two performing art schools. European Journal of Work and Organizational Psychology, 9(2), 2II-23I.

Amstutz, D. D. (I999). Adult learning: Moving toward more inclusive theories and practices. New Directions for Adult Continuing Education, 82(Summer), 19-32.

Baptiste, I. (200I). Qualitative data analysis: Common phases, strategic differences. Forum Qualitative Sozialforschung / Forum: Qualitative Social Research [On-line Journal], 2(3), Available at: http://www.qualitative-research.net/fqs/fqs-eng.htm.

Bateson, G. (I979). Mind and nature: A necessary unity. New York: E.P. Dutton.

Bateson, G. (I987). Men are grass: Metaphor and the world of mental process. In W. Thompson (Ed.), Gaia: A way of knowing. (pp. 37-47). Hudson, NY: Lindisfarne Press.

Baxter Magolda, M. B. (I992). Student's epistemologies and academic experiences: implications for pedagogy. The Review of Higher Education, 15(3), 265-287.

Baxter Magolda, M. B. (I994). Post-college experiences and epistemology. The Review of Higher Education, $18(\mathrm{I}), 25-44$.

Baxter Magolda, M. B. (I996). Epistemological development in grade and professional education. The Review of Higher Education, 19(3), 283-304.

Belenky, M. F., Clinchy, B. M., Goldberger, N. R., \& Tarule, J. M. (I986). Women's ways of knowing: The development of self, voice and mind. New York: Basic Books.

Davis, A. B., \& Sumara, D., J. (I997). Cognition, complexity, and teacher education. Harvard Educational Review, 67(I), I05-I25.

Davis, A. B., \& Sumara, D., J. (2000). Curriculum forms: on the assumed shapes of knowing and knowledge. Journal of Curriculum Studies, 32(6), 82I-845.

Davis, A. B., \& Sumara, D., J. (200I). Learning communities: Understanding the workplace as a complex system. New Directions for Adult Continuing Education, 92(Winter), 85-95.

Davis, A. B., \& Sumara, D., J. (2002). Constructivist discourses and the field of education: problems and possibilities. Educational Theory, 52(4), 409-428.

Davis, A. B., Sumara, D., J., \& Kieren, T. (I996). Cognition, co-emergence, curriculum. Journal of Curriculum Studies, 28(2), I5I-I69.

Désaultes, J., \& Larochelle, M. (I997). About the epistemological posture of science teachers. In T. Andrée, E. L. Jossem \& J. Barojas (Eds.), Connecting research in physics education with teacher education (pp. Section $\mathrm{D}_{3}$ ): International Commission on Physics Education.

Duell, O., K., \& Schommer-Aikins, M. (200I). Measures of people's beliefs about knowledge and learning. Educational Psychology Review, 13(4), 4I9-449.

Gadamer, H.-G. (I990). Truth and method (Vol. 2nd ed.). New York: Crossroad.
Geertz, C. (1973). Thick description: Toward an interpretive theory of culture. In C. Geertz (Ed.), The interpretation of cultures: Selected essays (pp. 330). New York: Basic Books.

Guba, E., G., \& Lincoln, Y., S. (1989). Fourth generation evaluation. Beverly Hills: Sage Publ.

Guba, E., G., \& Lincoln, Y., S. (I994). Chapter 6 - Competing paradigms in qualitative research. In N. K. Denzin \& Y. Lincoln, S. (Eds.), Handbook of qualitative research (pp. I05-II7). Thousand Oaks: Sage Publications.

Hammer, D., \& Elby, A. (2002). On the form of a personal epistemology. In B. Hofer, K. \& P. R. Pintrich (Eds.), Personal epistemology (pp. I69-I90). Mahwah, New Jersey: Lawrence Erlbaum Associates.

Heft, H. (200I). Ecological psychology in context: James Gibson, Roger Barker, and the legacy of William James's radical empiricism. Mahwah, New Jersey: Lawrence Erlbaum Associates.

Hermans, H. J. M. (2002). Special issue on dialogical self. Theory \& Psychology, 12(2), I47-280.

Hermans, H. J. M., Kempen, H., \& Van Loon, R. J. P. (I992). The dialogical self beyond individualism and rationalist. American Psychologist, 47(I), 23-33.

Heron, J., \& Reason, P. (I997). A participatory inquiry paradigm. Qualitative Inquiry, 3(3), 274-293.

Hofer, B. K. (2000). Dimensionality and disciplinary differences in personal epistemology. Contemporary Educational Psychology, 25, 378-405.

Hofer, B. K., \& Pintrich, P. R. (I997). The development of epistemological theories: beliefs about knowledge and knowing and their relation to learning. Review of Educational Research, 67(I), 88-140.

Hofer, B. K., \& Pintrich, P. R. (2002). Personal epistemology: The psychology of beliefs about knowledge and knowing. Mahwah, New Jersey: Lawrence Erlbaum Associates.

Hosking, D., M., \& Bouwen, R. (2000). Organizational learning: Relational-constructionist approaches: An overview. European Journal of Work and Organizational Psychology, 9(2), I29-I32.

Josselson, R., \& Lieblich, A. (I999). Making meaning of narratives: The narrative study of lives (Vol. 6). Thousand Oaks, CA: Sage.

Langer, E., J. (1989). Mindfulness. New York: Addison Wesley.

Langer, E., J. (I997). The power of mindful learning. Reading, Massachusetts: A Merloyd Lawrence Book - Perseus Books.

Lincoln, Y., S., \& Guba, E., G. (1985). Naturalistic inquiry. Beverly Hills: CA: Sage.

Lincoln, Y., S., \& Guba, E., G. (2000). Paradigmatic controversies, contradictions, and emerging influences. In N. K. Denzin \& Y. Lincoln, S. (Eds.), Handbook of qualitative research (Vol. Second Edition, pp. I63-188). Thousand Oaks: Sage Publishers, Inc.

Lyons, N. (I990). Dilemmas of knowing: Ethical and epistemological dimensions of teachers' work and development. Harvard Educational Review, 6o(2), I59-I8O. 
Lyons, N., \& LaBoskey, V. K. (2002). Narrative inquiry in practice: Advancing inquiry in practice. New York: Teachers College Press.

Martin, J., E., Silva, D., G., Newman, J., H., \& Thayer, J., F. (I994). An investigation into the structure of epistemological style. Personality and individual differences, 16(4), 6I7-629.

Maturana, H., R., \& Varela, F. J. (1987). Everything said is said by an observer. In W. Thompson (Ed.), Gaia: A way of knowing (pp. 65-82). Hudson, NY: Lindisfarne Press.

Niessen, T., J.H., Vermunt, J., D.H.M., Abma, T., A., Widdershoven, G., A. M., \& Vleuten, C., P.M. (2004). On the nature and form of epistemologies: revealing hidden assumptions through an analysis of instrument design. European Journal of School Psychology, 2(I).

Packer, M. J., \& Winne, P. H. (I995). The place of cognition in explanations of teaching: a dialogue of interpretive and cognitive approaches. Teaching and Teacher Education, 11(I), I-2I.

Pehkonen, E., \& Törner, G. (I999). Introduction to the abstract book for the Oberwolfach meeting on belief research. Paper presented at the Conference at Mathematisches Forschungsinstitut Oberwolfach (MFo), Oberwolfach.

Perry, W. G. (1968). Forms of intellectual and ethical development in the college years. New York: Holt, Rinehart and Winston, Inc.

Perry, W. G. (I988). Different worlds in the same classroom. In P. Ramsden (Ed.), Improving learning: New perspectives (pp. I45-I6I). London: Kogan Page Ltd.

Phelps, R. A. (2002). Mapping the complexity of computer learning: Journeying beyond teaching for computer competency to facilitating computer capability. Southern Cross University, Lismore.

Phillion, J., \& Connelly, F. M. (2004). Narrative, diversity, and teacher education. Teaching and Teacher Education, 20, 457-47I.

Powell, R. R. (1996). Epistemological antecedents to culturally relevant and constructivist classroom curricula: a longitudinal study of teachers' contrasting worldviews. Teaching and Teacher Education, 12(4), 365-384.

Redish, E. F., Saul, J. M., \& Steinberg, R. (I998). Students expectations in introductory physics. American Journal of Physics, 66(3), 212-224.

Roth, W.-M., Lawless, D., \& Tobin, K. (2000). Time to teach: Towards a praxeology of teaching. Canadian Journal of Education, 25, I-15.

Ryan, M. P. (I984 a). Conceptions of prose coherence: Individual differences in epistemological standards. Journal of Educational Psychology, 76(6), I226-1238.

Ryan, M. P. (I984 b). Monitoring text comprehension: Individual differences in epistemological standards. Journal of Educational Psychology, 76(2), 249-258.

Säljö, R. (2002). My brain's running slow today - the preference for "things ontologies" in research and everyday discourse on human thinking. Studies in Philosophy and Education, 21(4-5), 389-405.
Schommer, M. (I990). Effects of beliefs about the nature of knowledge on comprehension. Journal of Educational Psychology, 82, 498-504.

Schommer, M. (1994). An emerging conceptualization of epistemological beliefs and their role in learning. In R. Garner \& P. A. Alexander (Eds.), Beliefs about text and instruction with text. Hillsdale, New Jersey: Lawrence Erlbaum.

Schommer, M. (1998 a). The influence of age and schooling on epistemological beliefs. The British Journal of Educational Psychology, 68, 55I-562.

Schommer, M. (I998 b). The role of adults' beliefs about knowledge in school, work, and everyday life. In M. C. Smith \& T. Pourchot (Eds.), Adult learning and development: Perspectives from educational psychology. Mahwah, New Jersey: Lawrence Erlbaum Associates.

Songer, N. B., \& Linn, M. C. (I99I). How do students' views of science influence knowledge integration. Journal of Research in Science Teaching, 28(76I-784).

Stake, R.E. (I994). Case studies. In N.K. Denzin \& Y.S. Lincoln (eds), Handbook of Qualitative Research. Thousand Oaks, CA: Sage Publications, 236-47.

Stake, R., E., \& Trumbull, D. J. (1982). Naturalistic generalizations. Review Journal of Philosophy and Social Science, 7(I2), I-I2.

Sumara, D., J. (1996). Private readings in public: Schooling the literary imagination. New York: Peter Lang.

Sumara, D., J., \& Davis, A. B. (I997). Enactivist theory and community learning: toward a complexified understanding of action research. Educational Action Research, 5(3), 403-422.

Varela, F., J., Thompson, E., \& Rosch, E. (I997). The embodied mind - Cognitive science and human experience (Sixth printing ed.). Cambridge, London: The MIT Press.

Varela, F. J. (I999). The spacious present: A neurophenomenology of time consciousness. In J. Petitot, F. J. Varela, B. Pachoud \& J.-M. Roy (Eds.), Naturalizing phenomenology: Issues in contemporary phenomenology and cognitive science. Stanford: Stanford University Press.

Waldrop, M. M. (I992). Complexity: The emerging science at the edge of order and chaos. New York: Simon \& Schuster.

Widdershoven, G., A. M. (I999). Cognitive psychology and hermeneutics: Two approaches to meaning and mental disorder. Philosophy, Psychiatry and Psychology, 6(4), 245-253. 

Understanding the lived curriculum: an epistemological analysis 
This chapter has been submitted as: Niessen, T.J.H., Abma, T.A., Widdershoven, G.A.M. \& Vleuten, C.P.M. van der (submitted). Understanding the lived curriculum: an epistemological analysis. Journal of Curriculum Studies. 


\section{Abstract}

Experiences of participants in a curriculum give researchers important information about the lived curriculum. We investigated whether an epistemological interpretation helps to understand the responses of teachers to the introduction of a new curriculum. We did this by conducting a case study at a university where newly appointed teachers are required to attend an introductory course on Problem-Based Learning (PBL). A responsive approach was used, involving in-depth, conversational interviews about PBL with different stakeholders (teachers and teacher trainers). The results show that dialectical and contingent epistemological beliefs play a role in stakeholders' attitudes towards PBL. Resistance and overcoming resistance to PBL do not appear to be straightforward processes. 


\section{Introduction \& research question}

Problem-Based Learning (PBL) is a didactical approach in which students are expected to actively engage in their own learning processes. This is achieved by giving small groups of students realistic problems to solve. PBL has been quite successful in higher education. Over 60 medical schools have adopted this approach in whole or in part

64 (Norman \& Schmidt, I992). The teacher's role in PBL is radically different from that in traditional educational approaches. Instead of imparting knowledge to students, teachers are expected to act as facilitator of the process whereby students develop the necessary knowledge by trying to resolve authentic problems individually and collaboratively. Many teachers have reservations about the PBL approach: How will PBL affect my role as a teacher? Will I still be allowed to teach in the traditional sense to some extent? And if not, how do I transmit my knowledge and expertise to my students? The central perspective of this paper is that these questions can be answered by looking at the lived or enacted curriculum, i.e. the curriculum to which teachers refer when they talk about their day-to-day practice in dealing with it. This information is valuable because it provides cues to the grounding of theoretical knowledge (i.e. the theoretical curriculum) in practice. According to Roth and Tobin (Roth, Lawless, \& Tobin, 2000), "the theoretical or written curriculum cannot include the tacit understanding (background, practical sense) against which specific acts of teaching become meaningful and are inherently out of synchrony with unfolding practice." Depending on the method that is used, research of the lived curriculum can be rewarding not only to researchers but to study participants as well. The value of such research is that it can hold up a mirror to the participants which gives them a deeper and broader understanding of their own functioning. In the study reported in this paper we pursued such a deepening of understanding or, as Guba and Lincoln put it (Guba \& Lincoln, I989; Lincoln \& Guba, I985), we wanted to achieve educational and ontological authenticity.

Looking at the lived curriculum and examining teachers' experiences is an active interpretational and dialogical process. It is interpretational because an a priori lens is used to characterize apparently disconnected experiences to form narrative wholes that become meaningful (Blumenfeld-Jones, I995). It is dialogical because efforts are made to authenticate interpretations by asking the opinions of the participants whose descriptions of their experiences are being interpreted.

We have examined whether an epistemological angle enhances our understanding of the struggles and reservations of teachers and teacher trainers in relation to PBL. The study focused on responses of teachers and teacher trainers to the 'Introductory course on PBL for new staff members' at Maastricht University, where PBL has been the dominant didactical approach for the past 25 years. The general significance of the epistemological angle is supported by the growing body of research that claims 
that epistemological questions are crucial to an understanding of teaching and learning (Hofer \& Pintrich, I997; Hofer \& Pintrich, 2002). However, we question the prevailing assumption in contemporary epistemological research that beliefs are stable mental phenomena that have a direct or linear impact on behavior (Hofer \& Pintrich, 2002; Niessen, Vermunt, Abma, Widdershoven, \& Vleuten, 2004).

In an earlier study we developed an epistemological perspective that focuses on and is grounded in the daily experiences that are the subject of teachers' conversations about their encounters with students. Our findings in that study suggest that there is no nor can there be a direct linear causational relation between teaching behavior and epistemological beliefs, since epistemological beliefs are changing continuously. A teacher's answer to the epistemological question: "How should my students come to know?" is construed in a dialogue between the teacher's individual characteristics, such as skills, inclination to teach in a certain manner, and self-image and student and group characteristics, such as the experience present in the group and group size. The newly formed unity of teacher and student, the configuration of different elements within an instantaneous act is what we call a "belief". We should stress, however, that this configurational stance does not imply a denial of individual contributions. What we question is if individual contributions have a linear and direct effect on individual behavior. The absence of such a direct relation is supported by our earlier finding that teachers' answers to the question "How should these students come to know?" result from a co-determining effect of different elements in the dialogue between teacher and student (Niessen, Abma, Widdershoven, \& Vleuten, 2004).

\section{Research method}

We used responsive evaluation as the method to explore teachers' experiences to gain an understanding of the lived PBL curriculum. Responsive evaluation is a wellestablished vision and rationale for evaluation within education (Stake, I975; Stake \& Abma, 2005). In responsive evaluation, evaluation is redefined as a dialogue or conversation with all stakeholders about the value and meaning of a particular program or practice as a vehicle for learning, understanding, and improvement (Abma, 2005; Abma \& Widdershoven, 2005). In this study the subject of the evaluative dialogue is the introductory PBL course for new staff members at Maastricht University.

A full-fledged responsive evaluation involves a sequence of individual and group interviews with and among different stakeholders. Although we conducted the full sequence of data gathering, this paper reports on individual interviews only, because we wanted to focus on teachers' individual struggles from an epistemological perspective.

Responsive evaluation starts from the experiences of different stakeholders. The strength of this method is that it yields a highly variegated picture of the issue of interest. 
We used maximum variation sampling technique (Patton, I990) to ensure variety among our interviewees with regard to affiliation (Faculties of Medicine, Law, Economics, Health Sciences, and Arts \& Culture), general teaching experience, especially in relation to PBL, and gender. Snowball sampling (Patton, I990) was used to achieve maximum variation in our study population. This type of sampling pursues variety in responses by identifying and selecting participants who hold different opinions and are likely to bring up a wide range of issues in relation to the question of interest.

We conducted in-depth conversational interviews with nine teacher trainers and ten new staff members about their experiences with the introductory PBL course. The conversational interviews did not focus exclusively on teachers' struggles. The purpose was to explore teachers' experiences with the PBL course in the broadest sense. Starting questions were "Can you tell me what stands out for you in this course?" and "Can you tell me about your first experiences with PBL." We allowed the course of the interview to be determined by the interviewee as much as possible, although the interviewer had a list of topics in case the conversation lost momentum.

An authentic understanding of experiences can only result from in-depth examination of the pre-narrative structure that binds those experiences (Widdershoven, 200I). Because an in-depth examination is very elaborate we have limited our description to the stories of two respondents. It should be noted, however, that a learning history and an in-depth epistemological analysis were written for each of the interviews we conducted and discussed with the participants. The stories examined in this paper were selected because of their relevance to the practice of curriculum development. We singled out the stories of Robert, a new staff member at Maastricht University who had recently attended the PBL introductory course and Sarah, who has been a teacher trainer of the course for some time, because their stories present different angles on one of the common problems experienced by teachers in relation to PBL, i.e. whether PBL should be a goal in itself or a means to attain more satisfactory learning experiences for students.

We used the criterion of (ontological) authenticity (Lincoln \& Guba, I985) as the determinant of the quality of our descriptions. Authenticity denotes contextualness in terms of value pluralism. This is based on the concept that every context or situation contains multiple perspectives and that quality is achieved when research leads to "improvement of the individual's (and group's) conscious experiencing of the world." (Lincoln \& Guba, I985, p. 26). Thus quality in terms of (ontological) authenticity is attained when participants' conscious experiencing of the world is enhanced as a result of epistemological analysis.

We agree with Blumenfeld-Jones (I995) that to achieve ontological authenticity through our descriptions (and subsequent conversations about these descriptions), 
the descriptions should meet the fidelity criterion, from the Latin word fidelitas, meaning faithfulness. According to Blumenfeld-Jones, researcher and participant should reach consensus about a minimum of common ground regarding the learning history that is being written. Thus all the participants in our study were given the learning history (story) and asked to give their reaction. Additionally, BlumenfeldJones stipulates that the researcher should also: “...act with fidelity by being true to the situation of the teller by recognizing, constructing, and establishing linkages between events, small and large, immediate and distant, immediate and historical. An attempt at fidelity illuminates the way the world is a web within which actions are performed and motivated and understandings are directed" (Blumenfeld-Jones, I995, p 28).

Thus to act with fidelity means not only to act in accordance with the facts, but also to be perceptive and faithful to the teller's story as a whole by conveying subtleties that are spoken as well as those that remain unspoken or implied but are exemplified through epistemological analyses. Whether we have succeeded in this is first of all for the participants to determine (as we have asked them to do). However, we think that public scrutiny is important as well because this study is partly about developing and refining our epistemological perspective. By providing detailed portrayals, analyses and explanations we hope to enable others to evaluate our inferences. First, we present the stories of Robert and Sarah. Next, we present the epistemological analyses of these stories to answer the question whether the epistemological perspective is helpful to us, but more importantly whether it helps the participants to understand their struggles and resistance. Finally, we will show in what way we have tried to achieve quality, i.e. truthfulness to the criteria of authenticity and fidelity.

\section{Robert's story}

Robert (R) is new at Maastricht University. He teaches contemporary history at University College Maastricht (UCM). I interviewed him at our department. When I asked him to tell me about his experiences with PBL as a new teacher, he gave no direct answer but started to talk about his education in primary and secondary school and at university and how it was characterized by conventional, frontal, teacher centered teaching.

R: "I've come to realize that my primary and secondary school, to start with those briefly, were very traditional schools, which I think, even though this was before a number of educational innovations, would even in those days have been characterized as very traditional indeed. Then I went to Leiden, so that was in the early eighties, where I read history and there teaching was mostly what you would call extremely traditional." 
Traditional education with frontal classroom teaching in a transmissive didactic mode offers a stark contrast to small group, non directive, collaborative, studentcentered educational formats that are the hallmark of the Maastricht PBL approach. In PBL, the teacher's role resembles that of a midwife who assists in childbirth, whereas in traditional education, teachers are more like storks delivering ready-made babies. PBL is a Socratic approach, where the teacher encourages students to take part in collaborative knowledge construction.

Robert's traditional educational background was reinforced by his father being a history teacher of the old school and proud to be so. This background fed Robert's initial misgivings about PBL. These were not based on deliberate reflection, but stemmed from Robert's upbringing in a family of traditional school teachers where good teaching was considered synonymous with imparting to students what you knew, i.e. being a proper teacher.

R: "Well, the sad thing of course is that I really didn't have all that many ideas about it but just thought the term seemed outrageous, just one of those modernisms. Perhaps this had something to do with too, oh that may or may not be a relevant thing to mention that my father is also a teacher or was, until he took early retirement a year ago, so that he, anyway in, how shall I put it, in a small circle, it was sort of accepted that the best thing was to be a proper teacher.

A proper teacher indeed and in a favorable sense at that and I think he was definitely not bad at that at all, he taught history too. But he was a real story teller, who told stories and I think he would tell you that pupils enjoyed listening to his stories, but that rather reinforced, that undoubtedly played a role in the choice, in any case the choice of my primary school. For in those days when I started primary school he was also head of a primary school. But, well, and when you hear such a term, and always very .... how shall I put it, skeptical towards all sorts of educational innovations about which one might read, and which time and again proved to have been introduced prematurely or did not work out or caused frustration or whatever, then it's just another term you hear and you think, well, o.k. it's probably frightfully interesting and all that, but ......"

What changed his initial reservations about PBL into a more neutral/positive attitude were his educational experiences at the Central College Study Abroad Program in Leiden. As a teacher he learned firsthand that many hours of frontal classroom teaching can be exhausting. As a result, he gradually came to see teaching as a process in which students might take an increasingly active role in their own learning.

R: "Well, I don't remember when I first heard about the system, it must have been years ago. And in the meantime I had been teaching and I had also thought things like .... 
Well stimulated by those Americans, I noticed that I didn't like it myself, the more so because at the college in Leiden we had to teach in long blocks of many hours, say three hours on the same subject every week.

And then you discover that it is really boring to talk non-stop for three hours and from the start I had thought well: they should do something with that, so you start with a sort of paper which you want to be really about what has been dealt with in class and not just some sort of add-on and that gradually expands into projects which students report in class and discuss ..."

The first time he really learned about PBL was in the introductory course at Maastricht. After his early experiences at school and university and his gradual change of view induced by his teaching experiences, he immediately took to the interactive aspect of PBL. His problem was with the format of the introductory course.

R: "Well, the way it was presented ... And ... there was rather a sharp distinction between some form of practical training and theory teaching. Two talks were given about the underlying concept of PBL and about how it, how things were for economics, so mainly what would happen with the combination of the bachelor/master structure and $P B L$ sort of in the near future. Well those two stories were presented in a very traditional way and by contrast there was a lot of practice with some sort of role play .... Mock tutorial group sessions with different roles and I thought that was an unbalanced structure somehow, because I think .... that in a course like this the main thing is that people get the feeling that it is a good system. That is really far more important than that you teach them certain skills.

Because basically those skills are not very special... Therefore, as far as I'm concerned, the course should focus more on showing the power of PBL. And I think you should do that in an experiential way and so the part that was presented in the traditional talk with some interesting examples and a few questions to the group like what do you think.... That's more like in a traditional setting where there are some teachers who tell funny jokes and use creative ideas, but that's not retained for very long I think.

Unless it's repeated many times, but this is a two-day course so actually you want results fast so I think you can confront people much more with for instance the limitations of what they think is a good educational system. Not just by telling them that the statistics show it to be so, but by having them experience it for themselves and that may be childish tests but I think you could structure more along the lines of:

Some knowledge may be easy to assimilate when it's just explained to you, but a lot, you see, is much better retained when you do it like this or that and it's much easier to apply when you do it this way or that way. And then maybe you may see that in a two-day course the afternoon of the second day with that motivation or that insight or a combination, might be used very effectively." 


\section{Sarah's story}

Sarah is a woman in her forties. When I enter her room at the appointed time she gets up enthusiastically and shakes my hand. She tells me that she has worked at Maastricht University for twelve years. Before she came to Maastricht she read theory of literature and she briefly taught English in secondary school. Although she enjoyed this - coming from a family of teachers - she soon accepted a position as a PhD student at Utrecht University. Now, she is one of the teacher trainers of the introductory PBL course of the Faculty of Arts and Culture. She tells me that she was revising her resume before I arrived because she is planning her next career move.

When I ask her to tell me about her work as a teacher trainer of the introductory PBL course, she starts by explaining that she is not an educationalist, i.e. she does not have a degree in educational science. However, being a qualified and highly experienced teacher, she sees herself as quite proficient in this area. She then talks about her memories of a period not so long ago when the course was taught by trained educationalists. These teachers did not last very long as teacher trainers due to differences in 'intellectual style'.

S: "We used to have quite a few educationalists on the staff, but I was not very happy with that. There was some sort of cultural difference, a difference in intellectual style also."

These differences in "intellectual style" partly concerned the educationalists' reliance on quantitative research, which they used to support and legitimize their educational recommendations.

S: "At the time when we still had educationalists on the staff we were a small department. Well and so they mainly did research and issued recommendations based on it, which I'm afraid we thoroughly ignored and because most teachers don't like being told how to teach by people who have never taught themselves and also, there was something in that intellectual style, that faith in numbers so to speak where especially people here, who often study the scientific enterprise from a meta level, tend to think like, yes well, whatever.."

Staff members of the Faculty of Arts and Culture were getting increasingly annoyed with the educationalists. This led to a break when one of the educationalists refused to take over a PBL session from a sick colleague. After this incident it was decided that it would be better to have faculty from the department train new staff members. At this point Sarah volunteered for this job.

Talking about resistance to PBL among new staff members, Sarah mentions that in her role as a teacher trainer she does encounter it, although not as much as the 
educationalists used to. As a possible explanation for this she first mentions that she is an experienced teacher and as such tries to align her teaching as much as possible with educational practice. She is good at this because being a cultural scientist herself, she is familiar with the faculty culture:

S: "Because they know that I'm a highly experienced teacher and that I'm not waving 7I research reports at them, although occasionally I do so, I must admit, but much closer to the reality of teaching and the curriculum which I know like the back of my hand so to speak and also because of that, it's more what I do apart from the course naturally, it is also workshops for teachers and they deal for instance with task construction.

So then I am much closer to educational practice than my predecessors, you see? Because I know most of them, for instance because I was a member of the Education Committee for many years. I know those modules and so it's much easier for me to say things like: Look, in your module for instance there is this or that, isn't there ..."

Sarah attributes teachers' resistance primarily to lack of time. Sarah mentions in this regard that the faculty has undergone constant reorganizations. Although staff are enthusiastic and willing to participate in her courses, lack of time due to reorganizations leads to many last minute cancellations. Apart from the majority, there is a small group of people who can be characterized as die-hard opponents to any kind of teacher training:

S: "There are those who feel like throwing up at the mere mention of the word didactics or skill training or at the idea that it's not just you doing your thing and I doing mine.

But that we have to talk about things because we work for the same course that there (inaudible). Well that's all bullshit, let a thousand flowers bloom, you do your thing, which you do best and I do mine, which I do best. You're king in your kingdom and I'm queen in mine. We must not cross boundaries. That's how these teachers react, so if you nevertheless, then you may easily start a border war."

Sarah thinks that basically these teachers are worried about the lack of possibilities to display their expertise in a PBL system.

S: "Well, what has been worrying them for a very long time is that their intellectual potential as it were remains untapped, their content expertise, that it remains unused in the tutorial group, because, to put it briefly, they're not allowed to say anything."

Experienced (senior) staff, in particular, who are motivated by a love of teaching, seem reluctant to change their well tried successful approach. 
S: "Yes, we have had some cases of people in their fifties, who naturally already have, who are set in their ways as teachers and who use an approach which in all probability is very effective and successful, at least as they see it and who, well, they really don't see why they should do things differently."

Sarah thinks that a course designed and structured like a workshop or studio might be more effective to stimulate attendance. Such a course would enable teachers to do what they must do anyway and will enable guidance to be better attuned to individual teachers' wishes.

S: "So there must be much more development in the direction of a workshop, a studio, where teachers do the work they have to do anyway but with some icing on the cake and with a little bit of didactic reflection. Taking time to ask yourself things like: What do I really want, what do I want to achieve and is what I'm doing effective and also like, well, people, the box of tricks, adding to the toolbox so to speak, for as a teacher due to lack of time the needle tends to get stuck in a groove. You realize that you haven't really tasted it at all, that recipe for making (inaudible) and the seasoning and so in the end it gets really boring for everybody and that may not show unless someone else really shows you an example. So it's not enough to just say, well PBL does actually give more insight than this (inaudible). That won't lead anywhere. You have to be able to really show people look: You can also do it this way, now let's have a go at it."

In line with her approach Sarah defines her role and responsibility as that of offering teachers a realistic picture of educational practice, which mirrors the complexity of the task on which they are embarking.

S: "And I see it as my main task to give students a realistic picture of what they can expect, to give them an impression of the complexity of the task they are about to undertake. So to as effectively... There are things outside your control which you will have to deal with anyway and it's a far more complex role than the old-fashioned teaching role, for look, on the one hand you must not intervene directly, but on the other hand you are responsible for the content level and that is the sort of dynamics that creates complexity."

A sense of complexity she refers to as tragic.

S: "In some ways a teaching situation resembles a tragedy, meaning that, it does not mean that it's sad, but it does mean that by solving one problem you create another one or you get something right in one area and in another area things start to break down. For I try to prepare them as well as I possibly can for what they will have to deal with, so that they are not in for a shock and will not start to doubt themselves, for that's always a very bad thing for a teacher." 


\section{Analysis}

We have presented two different stories, or "learning histories" ${ }^{\text {", }}$, told by two persons in different positions, from different faculties and with different personal and educational backgrounds. In the following section we will present an epistemological analysis of these stories. What does the epidemiological perspective show us when we analyze Roberts' story?

As a child he saw the nature of knowledge as a fixed. People come to know by being taught. That is, knowledge is fixed and can be conveyed unchanged by teachers to students. Robert's early views are not surprising in view of his traditional upbringing with a father who was an old-school history teacher. His epistemological view results from what Lortie (Lortie, I975) described as the concept of "apprenticeship of observation": students implicitly develop and adopt views about knowledge and knowing, simply by observing the examples they as students are confronted with.

More interesting, however, is the way Robert characterizes those experiences today and why he should do so. In line with Giddens (Giddens, I99I) approach, we think that Robert's reaction to and reflections on his youth are instances of the epistemological struggle 'to keep a particular narrative going'. A narrative in which he seeks to develop a perspective on learning and teaching in line with his father's ideas and his traditional upbringing, while simultaneously distancing himself from it and trying to preserve and create continuity with it. Robert resolves his dilemma by positively interpreting his father's gift for story telling while at the same time distancing himself from traditional views on teaching (and thus on knowing) by saying that at the time he did not really think about issues like education and teaching ${ }^{2}$. Robert thus manages to preserve continuity with his fathers' story while at the same time legitimizing his disinvolvement with it. Robert's reaction to his childhood experience reveals that there is no straightforward answer to the epistemological question but that this answer emerges from subtly weighing and coming to terms with past experiences in current conditions.

When we look at this example from the perspective developed by Niessen et al. (Niessen, Abma, Widdershoven, \& Vleuten, 2004), it appears that this story illustrates very well how answers to epistemological questions are part of a process and transcend the boundaries of time, i.e. currently held views are affected by past views

I The term "learning history" is used here to refer to our reconstruction of someone's educational learning path during childhood and adult life. Term adopted and adapted from Van Basten (Basten, 2000).

2 They could be described as lay theories: "beliefs developed naturally over time without the influence of instruction. Pre-service teachers do not consciously learn them at announced, recognized moment from a formal teaching/learning episode. Rather, lay theories represent tacit knowledge lying dormant and unexamined by the student. Developed over long years of participation in and observation of classrooms and teaching/learning incidents occurring in schools, homes or the larger community, lay theories are based on untutored interpretations of personal, lived experiences." (Holt-Reynolds, I992) , p. 326) 
and experiences. Past stories are not replaced by new experiences but ways are sought to allow multiple incommensurable stories to co-exist. Gradually, not least because of his own experiences as a traditional teacher, Robert's attitude towards teaching has shifted from teacher centered to student centered. Robert recalls his first real confrontation with PBL in the teacher course. He mentions that he was familiar with the dialectical nature of the approach, but he criticizes the unbalanced structure of the introductory course. Probably, what he is getting at is that the course does not adhere to the principles of PBL. He wonders about the goal of the course and the best balance between frontal and experiential formats. His answer to the question of what constitutes a good PBL curriculum (i.e. good knowledge) is that frontal teaching has a role to play in education but that it is not suitable for the two-day introductory course. Attainment of lasting results in two days is better served by experiential learning. Again we see that Robert incorporates his father's 'traditional story' without giving up his adherence to experiential (more student-centered) learning. Epistemologically speaking, his answer to the question what is knowledge, or what is a 'real' PBL course, is the outcome of an interpretational process in which past experiences and current factors are weighed against and depend on each other. All elements - the ones Robert mentions as well as the ones he does not mention mutually need and define each other in the process of determining what constitutes a real PBL program. Together these elements form a configuration that sets the scene for Robert's idiosyncratic answer. Robert's story confirms the assumption that epistemologies arise from a dialogical process. His father's traditional voice emerges as an inner significant other in his story. This voice is heard in Robert's claim that 'frontal teaching' does have a role to play, but that within the setting of this particular course its role should be limited because of the need for quick results.

As a teacher trainer in the Faculty of Arts and Culture, Sarah tells a different story, due to her different position in a different faculty with a different culture. The main issue in her story is the resistance to PBL from the teachers she trains. This resistance is multi-faceted and complex. Her answer to the epistemological question of what constitutes true knowledge or in this case how to counter this resistance is equally complex and multi-faceted. It is multi-layered because resistance has several levels. The first level is that of the person with a certain educational background as a teacher trainer, i.e. with teaching experience, affinity with participants' educational practice, affinity with content and communication style. Then there is the faculty level, which refers to the working climate, reflected in a meta approach to research, but also to the high workload due to continuous reorganizations. Sarah acknowledges that part of the resistance from new staff members is legitimate or at least understandable, because they can be highly successful and effective using traditional or frontal modes of teaching. Reflecting in this manner on the different perspectives on resistance, 
she acknowledges the contingent and dialectical nature of the construct and of education in general.

At one time she refers to the situation as tragic. Although the model proposed by Niessen et al. (2004) does not include this term, we suggest that the tragic dimension within education and teaching (Burbules, I990, 1997) is consistent with the view implied in the model, since it resembles a particular stance towards knowledge and knowing, which acknowledges the quest for certainty but also accepts that education is contingent and local in character. To view education from the standpoint of tragedy is to abandon foundationalism and to believe that doubt and uncertainty make us better educators - in part because they reemphasize our dependence on each other, including our students and in part because they insulate us somewhat from false claims about the value of what we have to offer. It means that the focus in teaching should be less on specific outcome standards and more on creating opportunities for discovery, discussion and development. It implies recognition of our limited capacity to accomplish educational aims without fostering more cooperative relations with students, parents, and other partners in the educational process. Most of all, it means that we should be more modest in our claims of social transformation or reform through educational processes. As Burbules (I997) rightfully claims: "Tragedy tells us something about the value of teaching. There is hope but within an awareness, a constructive sense of thinking about teaching to what it can and cannot accomplish. The tragic sense is the point of tension between seeing the necessity of things as they are and the persistent imagining of them turning out otherwise."

A tragic viewpoint thus seizes opportunities for success while at the same time acknowledging the prospect of failure. It encompasses awareness of contrasts and moves beyond the dichotomy of optimism versus pessimism by incorporating both and thus focusing on the middle road. An affinity for tragedy sets the stage for a view that incorporates the shades of grey that characterize most educational situations (Burbules, 1990).

Sarah's but also Roberts' approach to dealing with resistance is a path that forms as it is being walked. Success or failure is never determined a priori but lies within the opportunities that arise during the walk, i.e. within the interstices that are formed through internal and external dialogues. Resuming the interpretation of Sarah's story, we see her more or less coming to the conclusion that there is no definitive solution to the question of what constitutes an appropriate approach to countering resistance against PBL. Referring to all the levels and factors that play a role, she seeks an answer in an ongoing dialogue between herself and course participants. She gives an example of what her dealing with resistance in face-to-face contact actually entails; establishing a relationship with teachers and providing concrete suggestions how interactive PBL elements may improve a course (versus waving figures and reports at 
teachers to promote PBL). What her story does offer is an account of or reflection on the multi faced and subtle nature of resistance and her approach to it.

In a sense Roberts' story is also about resistance, i.e. his resistance, as a participant, to the unbalanced structure of the course. Sarah's story incorporates the personal level as well as communal levels (department and faculty). Both stories address the epistemological nature of resistance from very different positions (teacher and teacher trainer) and suggest that dealing with resistance involves a process of seduction and efforts that meet with varying degrees of success. When we say seduction we refer to Sarah's attempt to entice teachers to give up their resistance by offering them interesting formats, like workshops and studios. Robert thinks that the prime goal of the introductory course should be to seduce students into being open to new experiences and to question the inclinations and ideas to which they are habituated.

\section{Conclusion \& Discussion}

We investigated whether an epistemological perspective is helpful for understanding the experiences and struggles of new staff members and teacher trainers that attend a course on PBL. Recounting and interpreting the stories told by Robert and Sarah, we constructed an intricate picture of a lived PBL curriculum. Our epistemological analyses reveal that struggles emerge out of clashes or confrontations between complex inner worlds and external influences (elements) that mutually define and constitute each other.

The resulting personal webs of heterogenic elements are made visible through our analyses. Recognizing this and talking about it with the teachers and teacher-trainers made us realize that curriculum theory should be more attentive to these bumps, turns and distractions. As Davis \& Sumara (2000) put it: “...while not discounting the importance of goals and focus, prompts a shift in attention onto the bumps and turns and distractions. It is these features, as much as anything else that gives the route - that is, the curriculum - its form."

We think it is important to find ways to sensitize teachers to their inner epistemological voices and to help them create or see the creative tension between present stories and past experiences; a tension that can help teachers to find the nuance that is inherent in complex teaching practice. Our view thus contradicts the claim of conceptual change theories that we should try and replace old experiences with new ones. Following Burbules, we would claim that it is important: "to keep the tension alive - a dialectic that does not move towards resolution, but that yields creativity out of the sustained movement back and forth between the two (or more) alternatives." (Burbules, I990)

With respect to the quality of our portrayals and our analyses, we think that the descriptions presented in this paper, combined with our conversations with the 
participants have induced some of our participants to review their previous experiences and to acknowledge that our perspective is fruitful in this respect, thus meeting Guba \& Lincoln's criterion of (ontological) authenticity. Sarah and Robert acknowledged that our portrayal was nuanced and truthful. However, they also said that the analyses did not teach them anything really new about themselves, because they were very reflective about their own lives anyway. Other participants found our learning histories illuminating, indicating that our re-enactments provided them with a sense of closure and a grasp of the past. Using our epistemological perspective, they were able to develop a possible re-interpretation through which they were able to attain a sense of self or identity (Giddens, I99I).

With respect to the criterion of fidelity, both we and the participants in this study think that the portrayals as illustrated in this article - recognizing and establishing linkages between many heterogenic elements, small and large, immediate and distant - have met what it means to act in fidelity: " ...illuminates the way the world is a web within which actions are performed and motivated and understandings are directed" (Blumenfeld-Jones, I995, p 28). This process of actively reconstructing or perhaps better re-enacting stories resembles the re-enactment of a musical piece by a musician (Bulhof, I995). Just as in the re-enactment of a piece of music, our interpretation resembles the original telling, but at the same time differs because we as researchers are actively partaking in the shaping of the re-enactment. And with each re-enactment we hope to enhance our abilities as well as those of the participant to be attentive to the different interpretations and thus heighten our awareness to novelty and nuance. 


\section{References}

Abma, T., A. (2005). Responsive evaluation: Its meaning and special contribution to health promotion. Evaluation and Program Planning, 28, 279-289.

Abma, T., A., \& Widdershoven, G., A. M. (2005). Sharing stories: Narrative and dialogue in responsive nursing evaluation. Evaluation and Program Planning, 28, 90-IO9.

Basten, F. M. R. C. (2000). Metaforen en verhalen over organisatiewetenschap en onderwijsinnovatie. Een leergeschiedenis. University of Nijmegen, Nijmegen.

Blumenfeld-Jones, D. (I995). Fidelity as a criterion for participating and evaluating in narrative inquiry. Qualitative Studies in Education, 8(I), 25-35.

Bulhof, I., N. (1995). Van inhoud naar houding: een nieuwe visie op filosoferen in een pluralistische cultuur. Kampen: Kok Agora.

Burbules, N., C. (I990). The tragic sense of education. Teachers College Record, 91(4), 469-479.

Burbules, N., C. (I997). Teaching and the tragic sense of education. In N. Burbules, C. \& D. Hansen (Eds.), Teaching and its predicaments. Urbana/Champaign: Westview Press.

Davis, A. B., \& Sumara, D., J. (2000). Curriculum forms: on the assumed shapes of knowing and knowledge. Journal of Curriculum Studies, 32(6), 821-845.

Giddens, A. (I99I). Modernity and self-identity: self and society in the late modern age. Stanford: Stanford University Press.

Guba, E., \& Lincoln, Y. (1989). Fourth Generation Evaluation. Beverly Hills, CA: Sage.

Hofer, B. K., \& Pintrich, P. R. (I997). The development of epistemological theories: beliefs about knowledge and knowing and their relation to learning. Review of Educational Research, 67(I), 88-I40.

Hofer, B. K., \& Pintrich, P. R. (2002). Personal epistemology: The psychology of beliefs about knowledge and knowing. Mahwah, New Jersey: Lawrence Erlbaum Associates.
Holt-Reynolds, D. (1992). Personal history-based beliefs as relevant prior knowledge in course work. American Educational Research Journal, 29(2), I23-I36.

Lincoln, Y., S., \& Guba, E., G. (1985). Naturalistic inquiry. Beverly Hills: CA: Sage.

Lortie, D. C. (I975). School teacher: A sociological study. Chicago: University of Chicago Press.

Niessen, T., J.H., Abma, T., A., Widdershoven, G., A. M., \& Vleuten, C., P.M. (2004). Contemporary epistemological research: The need for a reconceptualization. Paper presented at the Third International Conference on Dialogical Self, Warsaw.

Niessen, T., J.H., Vermunt, J., D.H.M., Abma, T., A., Widdershoven, G., A. M., \& Vleuten, C., P.M. (2004). On the nature and form of epistemologies: revealing hidden assumptions through an analysis of instrument design. European Journal of School Psychology, 2(I).

Norman, G.R. \& Schmidt, H.G. (I992). The psychological basis of problem-based learning: A review of the evidence. Academic Medicine, 67(9), 557-565.

Patton, M. (I990). Qualitative evaluation and research methods. Newbury Park, CA: Sage.

Roth, W.-M., Lawless, D., \& Tobin, K. (2000). Time to teach: Towards a praxeology of teaching. Canadian Journal of Education, 25, I-I5.

Stake, R., E. (I975). Evaluating the arts in education: A responsive approach. Merill: Columbus Ohio.

Stake, R., E., \& Abma, T., A. (2005). Responsive evaluation. In S. Mathison (Ed.), Enacyclopedia of evaluation (pp. 376-379). Thousand Oaks: Sage.

Widdershoven, G., A. M. ( 200I). Dialogue in evaluation: A hermeneutic perspective. Evaluation, 7(2), $253-263$. 
The performance of meaning: a focus on epistemological dynamics 
This chapter has been submitted as: Niessen, T.J.H., Abma, T.A., Widdershoven, G.A.M. \& Vleuten, C.P.M. van der (submitted). The performance of meaning: a focus on epistemological dynamics. Harvard Educational Review. 


\section{A bstract}

The epistemological perspective is pitched on an individual plane. Epistemological beliefs are seen as individual constructs residing in people's heads. We have stated elsewhere that epistemologies are instantiated within dialogues, and questioned the assumption that epistemologies are a priori held convictions within individual minds. Starting from an interactionist assumption, this study focuses on the process and tries to illuminate the dynamics that come into existence in a dialogue. These dynamics can be characterized as discursive and meaningful, thus changing the focus of epistemological research from a question of true knowledge to an issue of meaningful knowing. 


\section{Introduction and research question}

Starting in I968 with Perry's seminal work (Perry, 1968), research into epistemological beliefs has continued to gain stature within educational research as an approach to coming to grips with learning and teaching. Publication of the handbook on personal epistemology "Personal epistemology: The psychology of beliefs about knowledge and knowing" by Hofer and Pintrich (Hofer \& Pintrich, 2002) was a landmark in research into epistemological beliefs. Yet there is an issue with which the domain still has to come to terms. This is the issue of the "form" of epistemological beliefs, meaning that researchers are not sure whether to represent epistemological beliefs as theories or traits (Hofer \& Pintrich, 2002).

In general, epistemological belief defines a person's mental commitment to the question "What is true knowledge?" and "How does a person come to know?" (Hofer \& Pintrich, 2002). A teacher will form answers to these questions, which in turn will prompt him or her to act in a certain manner. Moreover, beliefs are assumed to be impervious to change. They are either characterized as stable traits or visualized as elements incorporated in broader cognitive theories (Hammer \& Elby, 2002). In both instances a belief is regarded as an inherent component of a person's cognitive make-up. Elsewhere we argued (Niessen et al., 2004) that this individual-and-stable-belief version is not consistent with general day-to-day experiences in education. For in practice teachers act instantaneously and they form responses to the epistemological question "How should students come to know?" while maneuvering between many students and other relevant elements within a particular teaching situation. None of the relevant elements by itself directly and fully determines the teacher's behavior. That is why we contended that an epistemological belief had best be regarded as a temporarily crystallized enactment between teacher and student, and that the dialogue between them was constitutive of the eventual teaching behavior. Teaching behavior is thus not necessarily linearly influenced or directed by a person's habitual inclinations or beliefs. The form we propose for describing an epistemological belief is neither a theory nor a trait but an enacted unity of teacher-and-student within a certain teaching situation.

Although in our previous study we defined epistemological beliefs as supple and dialogic, we did not really capture the dynamics in situ. The interviews we conducted with teachers yielded static, a posteriori snapshots, which did not convey the dynamics of the actual enactment or dialogue. Observing and following teachers during their conversations about teaching might better capture the real dynamics and enhance our understanding of the personal, contextual and malleable character of the epistemological perspective. 
We will start by giving some general background of the research method of the present study and the use of focus groups. Next we will present a passage from one of the focus group discussions and our analysis of it to illustrate our enactive understanding of the identified dynamics. Finally, we will present our conclusions about the individual, contextual and malleable character of the epistemological perspective and discuss practical implications.

\section{Responsive evaluation}

Our study was conducted among teacher trainers of a course on Problem Based Learning $^{\mathrm{I}}(\mathrm{PBL})$ that is obligatory for new teaching staff at Maastricht University, the Netherlands where PBL is the main instructional method. Most of the learning activities take place in small groups where students actively tackle realistic problems in a collaborative and self directed manner (Van der Vleuten et al., 2004). In this way students gain knowledge and interpersonal and teamwork skills at the same time. PBL is challenging to both students and teachers. In PBL the traditional role of the teacher as the transmitter of knowledge to students is fundamentally transformed into the role of the facilitator of students' active learning processes (Savin-Baden, 2000). We will use responsive evaluation to examine the dynamics that give rise to questions of knowledge and knowing. Responsive evaluation is a method that focuses on the interface between people $\epsilon^{2}$. A complete responsive cycle consists of a series of individual conversational interviews and, if necessary multiple, homogenous and heterogeneous 3 ) focus group interviews, which may be needed to establish the value of a program. Given that we are interested in investigating the subtleties of the dynamics within the epistemological perspective, we will confine our analysis to group interviews. The study is part of a larger investigation of the phenomenon of resistance to PBL and the assumed role of epistemological beliefs in relation to that.

\section{Data gathering and data analysis}

Responsive evaluation determines the value of a program in a dialogue among the various stakeholders. The first step is to identify the stakeholders of the course or practice under study. For the "Introductory PBL course for new staff members" the

I PBL is an instructional method in which students in a collaborative manner engage in real-life problem solving. In doing so, the students obtain the necessary communication skills and necessary knowledge base. The teacher or tutor as he is called within the PBL system facilitates this process so students themselves are able to acquire the necessary knowledge.

2 Responsive evaluation is a dynamic and egalitarian method for evaluating programs or practices dialogically (Abma \& Stake, 200I). The value of a program or practice is not established a priori, but accomplished in conversation by the various stakeholders who share their experiences with each other in a cycle of individual and focus groups interviews.

3 A homogenous group interview involves a conversation with one stakeholder category; in this study the stakeholders are the new staff members and the teacher trainers. In heterogenous group interviews, different groups of stakeholders are mixed in order to dialogically exchange experiences about the value of a program or practice. 
stakeholders are new staff members and teacher trainers who design and deliver the course. We organized two homogenous and two heterogeneous focus group interviews. The homogeneous focus groups consisted of 6 teacher trainers and 5 new members of staff, respectively. The two heterogeneous focus groups consisted of 7 and 6 participants.

84 The ro teacher trainers and 9 new staff members were selected by means of maximum variation sampling and snowball sampling (Patton, 2000). The participants varied in faculty of appointment, general teaching experience and PBL-related teaching experience. The difference between the focus groups in number of participants was due to last minute cancellations because of sickness and other engagements. Each focus group interview lasted two hours. The issues, claims and concerns that were discussed in the teacher trainer group and in the new staff members group were derived from individual interviews with the participants. The outcomes of the homogenous focus groups were used as input for the heterogeneous focus groups.

The method of analysis for any given study depends on the purpose of the study, the nature of the material and the ontological stance of the researcher. Departing from an enactivist ontological position, we analyzed the data from the perspective of the general enactivist stance that the cognizing organism cannot be separated from the surrounding world: "Knowledge is not in a book or in the library; knowledge is not in our heads. Knowledge is in the inter-action!" (Kieren, Gordon-Calvert, Reid, \& Simmt, I995, p. I). Enactivism is influenced by Marleau-Ponty's (Merleau-Ponty, I962) philosophy of phenomenology. It argues that phenomena are inseparable from the context in which they exist and from the person observing them.

Hermeneutically speaking, researchers need a focus, in the Gadamerian sense, to make sense of what they encounter (Gadamer, I990). In the course of the encounter the theoretical focus or perspective may change, which may give rise to renewed interpretations in the next hermeneutic (interpretive) cycle. The data analysis consisted of several cycles and critical examination of our first impressions. First, we read and re/read the interviews holistically. That is, we let our attention be guided or captured by what stood out ${ }^{4}$. These first readings yielded an initial understanding of what the dialogues revealed in terms of epistemological dynamics. We then partitioned each group interview into sections which represented a certain issue or concern. These were the units of our analysis, which we read and reread more closely to fine-tune our understanding as well as our models.

4 Holistic reading is here used as an antonym for selective reading in which one specifically searches for statements or phrases revealing the essence of the phenomenon under study

5 The analysis was done by the first author however peer reviewed by colleagues from Maastricht University \& Utrecht University. 


\section{Marc's contribution}

In the next section we closely analyze a dialogue on teaching, highlighting contingencies in the context. We present fairly long citations from the focus group interview to enable others to judge the process whereby we arrived at our insights.

The passages we cite from the discussion in the teacher trainer focus group illustrate the contingencies that inform epistemological issues and perspectives in interpersonal interactions. The citation starts when $\mathrm{Marc}^{6}$, a teacher trainer at one of the faculties of Maastricht University, enters the conversation at a point when the other teacher trainers are reaching consensus about a central issue in PBL, i.e. whether teachers should restrict their role to facilitating the group process or whether it is also acceptable for them to make content-related contributions. Amongst new staff members there is a widespread unwritten persistent belief that in PBL teachers must rigorously refrain from formally instructing students in any way. We discovered that this makes new staff members feel guilty when they talk too much during tutorials instead of rigidly adhering to their role of facilitator of the learning process, encouraging students to find the necessary information and insights for themselves. However, to Marc this is not the core issue.

Marc: "Can I make a suggestion about the group process. We should distinguish it from the learning process. Then there are no longer two but three components you can work with as a tutor. Self-directed learning, let's call that the learning process. I have great difficulty explaining to my tutors how they can intervene in students' learning processes to help them become self-directed learners. ... To pinpoint it exactly: look if you do this or that, then you really help students become better self-directed learners. This I find the hardest part of the role of the tutor. The content-related aspect is easy to deal with: take it with a bigger or smaller pinch of salt. It depends on the situation, what you feel comfortable with, et cetera. For the group process we have quite a few instruments as well. Usually you can explain all sorts of things to people - use texts, use videotapes. But as for the learning process, that's very hard to get across in groups. At least in our tutor training sessions, there you see very different ... at least in the Faculty of Health Sciences. ... In our faculty the tutors who attend the tutor training sessions are mostly graduate students or prospective graduate students. Well this is a very special population. All these people say, well I've done PBL. Nearly all of them have been a tutor at some time or other. And then you find yourself facing a group in which it is really hard to get to grips with self directed learning. That's my real problem."

Marc adds a third element to the conversation, the learning process, and hopes to

6 The names used in this article are not their real names. 
steer the conversation into the direction of his interest. He metaphorically plays down the previously discussed issue by saying: "take it with a pinch of salt", suggesting that the issue of a strictly facilitating tutor role versus one with some content-related tutor interventions constitutes no real problem for new staff members. Marc is more interested in how to help new staff members promote selfdirected learning in their students.

Lucy: "Personally I think that you go too far for a group in an introductory course. In my experience you should mention it but it goes a bit too far to discuss this in detail in the tutor training. In my experience this is a topic for advanced tutor training. Novice tutors are all very much focused on content. I see that when I observe tutors. They're all very much focused on content. Although during observations there are opportunities to talk about learning processes. How you could handle things differently by putting the ball back into the students' court. (...) And that's very hard to do in training novice tutors. ... And the process aspects as well, that's when I look at things from my own practice - those group dynamic processes, that's where their real problems are. Everybody is still so preoccupied with course content. The tutors are studying harder than the students. They're very pleased when they manage to master that. Let alone that they have time to pay attention to what the students are up to in the tutorial group. That's very difficult to deal with in an introductory course. ... What I do find very important indeed, and that's something I'm very clear about in training the tutors, is that I think tutors should think very carefully about what they think should be the rules for that group in that block. And that they should come to an understanding with the students about these rules in the first meeting. About what the tutor expects of the students, how they see the role of the discussion leader, about the quality of the credits, about the quality of the presentation and also that a tutor should think about these things. What is my position on being late, what is my position on this and mobile phones, for instance."

On the basis of her experience as a teacher trainer, Lucy claims that the goal Marc proposes is not so much irrelevant but too ambitious for the introductory PBL course. She thinks that new staff members' strongest concern is how to manage the content of the tutorial group discussion and not group dynamics or how to further selfdirected learning. She adds that this goal would be more suitable for an advanced course for staff members who are already familiar with PBL. New staff members should concentrate on practical "rules of thumb"; simple pointers on how to get a tutorial group off to a smooth start. She also suggests that the goals of an introductory course should be modest since there are no clear rules that apply to all situations and all persons. New teachers need practical know how; the kind of knowledge that novice teachers often lack. 
Dorothea: "It's funny to see that we have three aspects that are very important in teacher training: that is content, group process and learning process. And I agree with Marc and you that you cannot put the learning process at the very start of the course, but it does remain the hardest part I think. How to alert tutors and show them how learning processes work. For it's very difficult of course, as you're having to deal with content knowledge as well - of which as an observer I think it's also very hard to judge what exactly. So, how do you get an idea of what students are going through in a learning process? Apart from the fact that they're asking the right questions. So I find that it's very important and on the other hand also the hardest thing to ... direct."

Dorothea changes the direction of the discussion in a subtle but significant way. She agrees with Marc that it is really difficult to enhance teachers' ability to stimulate students' self-directed learning. Having said that, she also agrees with Lucy that this issue does not belong 'in the early stages' of an introductory course. It seems that Dorothea tries to put both perspectives into focus.

Yet, in a very important but subtle way her summary is more than a neutral summary of what has been said thus far. Dorothea expresses agreement with both Marc and Lucy that dealing with students' learning processes is too ambitious a topic for an introductory course. She implies that this is what Marc and Lucy both said. This remark is easily overlooked, but did Marc actually say this? When we look at the first part of the citation we can only conclude that he did not.

It would be easy to dismiss her comment as a slip of the tongue. However, Dorothea and Marc are colleagues who work closely together on a daily basis. Moreover, without Dorothea's intervention Marc's contribution might have been ignored or dismissed. The fact is that Dorothea's comment actively positions Marc as a knowledgeable other.

Elisabeth: "One of the things you can observe as a tutor at least in our sort of teaching is that certainties are being called into question. And when that happens, you see symptoms which at first may mistakenly be seen as negative. That students start to display a violent hatred towards you or are troubled or think they're headed for chaos. I myself find that - the other day I read an official term for it - and I thought that's a really good way of putting it - and that's disjunction. When you're learning something really new, at the time it's never enjoyable from a to $z$. No way. Then you're going through a crisis. But when students at some point with bags under their eyes... Often they say to you afterwards. Like then I thought oh awful and what is this about. I was really terribly angry with you. That also means that as a tutor you have to prepare the students and that's something you don't learn ... Students are so keen to enjoy themselves ... They want to have a good time all of the time and we give them that impression by talking about 
education in terms of consumers and products. Learning is not enjoyable all of the time (they fall silent).

Elisabeth: "We all agree."

Marc: "Still, you were thinking and I agree with the substance of what you said that it is very much domain specific. And of course your faculty of Arts a Culture is one where students from the very start or during the modules are trained to think critically about all sorts of things in society and culture. (...) And just like Dorothea I am also thinking how we can make the teachers we have to train more aware. So one of the big problems we have is of course that the teachers don't know the first thing about didactics. A teacher in primary education has had four or five years of teacher training and university teachers have had hardly any training in our situation. You are lucky when they show up on all four days. And, to think about those things, I find that very difficult to do.... I know that the timing is not right, for these teachers have only just started their professional development, but well - you have only four days, so you try to put some pressure on them. What I try to do is give them some didactic assignments. And not so much assignments from health care and still have them think about the question: what is teaching really all about. So that they can become somewhat more aware. You have only four days in which to do something - or actually only two days: so as a teacher trainer within this institution you should strongly appeal to intrinsic motivation or interest that these teachers develop while teaching. You have to deal with the conflict with research for which they are rewarded. So in a large faculty like ours I find it really difficult to get them to do that."

At this point, when the issue has almost reached closure we see Marc returning to the issue he raised when he entered the conversation.

\section{Data analysis}

Having stated elsewhere that epistemological beliefs are instantiated in interactions between people and other elements (Niessen, Abma, Widdershoven, \& Vleuten, 2004), we now focus on the interaction processes among conversing teachers instead of analyzing teachers' self-reported teaching experiences. We think this may enhance our understanding of the malleability, the individual and contextual nature of the epistemological perspective. Our first impression when we holistically analyzed the conversations was one of teachers' agreeing with each other at times but also qualifying or refuting each other's statements. The teachers interpreted each other's utterances, reformulating in their own words what the others had said, and rejecting, incorporating or taking further what was said by the others. This means that messages 
are not transmitted unchanged to the other participants but get transformed in the interaction process in the group.

For example, on closer reading we see that Dorothea attributes to Marc certain opinions he did not express explicitly. By doing so Dorothea places Marc's contribution again center stage in the conversation at a moment when Marc's opinion is in danger of being ignored or dismissed by the other participants. Contemporary epistemological research would probably claim that she does so because she strongly supports his view. It is her personal epistemological belief as well. Although we concede that this may have been the case, it is also true that Dorothea is a close colleague of Marc's. Thus she may not simply express her personal conviction, but be trying to affirm her relationship with Marc. This shows that it is impossible to answer the epistemological question "What is true knowledge? in a neutral vacuum but that the answer is created in an environment in which interpersonal relations play an important part, i.e. are part and parcel of the epistemological domain.

Yet, one might wonder if epistemological beliefs are as contextual or malleable as we claimed earlier. Marc initially takes a clear and straightforward position saying that emphasis should be less on content and process than on enhancing the capacity of new staff members to stimulate students to become self-directed learners. Additionally, he talks about the difficulty of achieving this goal since the majority of the teachers attending the introductory course at his faculty are graduate students or prospective graduate students.

At the end of the citation Marc returns to this issue and reiterates that attention should be paid to showing new staff members how to promote active learning. Solooking at it from a holistic perspective our first thought was that he had not changed his opinion. This interpretation argues against his epistemological beliefs being contextual and malleable. However, Marc does acknowledge Lucy's comment that the "timing might not be right for those teachers who have just started their professional development”. Moreover, he formulates his claim more modestly, saying that new staff members should "become somewhat more aware." This suggests that Lucy has made him aware of an important issue. Moreover, this more tentative formulation has opened the way to a reconciliation of ideas, with Lucy also seeing "opportunities for talking about learning processes" in the introductory course.

There is more to be said however. The conversations we witnessed are meaningful. The participants talk (implicitly) about issues that matter to them as teacher trainers. They implicitly speak about the values that they see as underpinnings of the introductory course. Take for example Lucy's opening statement. What is actually at stake is the value she places on "attunement". She purposefully seeks to identify and address the concerns of the participants. Although she leaves room for discussing the issue Marc raises, she feels his goal is not feasible for an the introductory PBL 
course. Nevertheless, she does concede that it might be a relevant topic for more experienced tutors.

The value that emerges from Lucy's contribution is "mindfulness" to increase new teachers' awareness of their own teaching styles. To Marc "loyalty" to the PBL system and not "attunement" or "mindfulness" is the overriding concern. In the unfolding conversation these values are being considered implicitly. Dorothea thinks they are both important and tries to reconcile them. Elizabeth finally describes students' learning processes with the term disjunction. This is greeted with unanimous approval.

\section{Conclusion and discussion}

What does this analysis contribute to our understanding of the epistemological perspective? When people present their own experiences and ideas to others in a conversation, these ideas become part of the discourse in which they are reinterpreted, rejected, modified, and incorporated. This process involves new experiences which are always slightly different. This causes friction. Within this friction, openings or possibilities for change emerge.

As our example shows, these changes may be subtle and small. Conventional epistemological research based on theories of conceptual change might even label them as insignificant. At the end of the conversation Marc persists in his belief that fostering self-directed learning is an important subject for the introductory PBL course. So, what are the small yet significant changes within this conversation? Although Marc does not change his mind, he agrees with Lucy and Elizabeth that the "timing might not be right for those teachers who have just started their professional development." He acknowledges the relevance of their comments. Their remarks may have induced him to tone down the way he expresses his belief that the main issue is for teachers to learn how to foster self-directed learning, because he now talks about the importance of teachers "becoming somewhat more aware."

From an enactivist viewpoint we think that most changes come about in gradual evolutionary processes in which small perturbations originating in interactions between participants may alter the overall balance minutely yet significantly. The remarks by Lucy and Elizabeth seem to have made the overall manner in which Marc addresses his issue somewhat less blunt. This change is highly significant because it opens up a possibility and space for a fusion of horizons. Such changes, although minor, enable adaptation to local and situational contingencies. Earlier Marc mentions that the participants in the PBL course in his faculty are already quite familiar with PBL. So perhaps this population is not the same category of teachers which Elizabeth referred to as teachers who "just started their professional development". 
The verb occasioning as used by Davis (Davis, 2004) aptly represents the way in which minor perturbations may influence dialogues in small but significant ways. In contrast to the linear belief approach, the term occasioning signifies unawareness of the direction in which perturbations (the contributions by different participants in a conversation) and their effects are heading. The term occasioning describes human action as situated within webs of relations (a bricolage). Everything connects with everything. There appear to be mutual influences, although not in the form of clear linear pathways, but rather meandering along as the conversation unfolds.

Conversations are also meaningful because they contain various implicit values. References are made to values grounded in personal experiences and relating to issues that are important to participants at a personal level. Perhaps the phrase "meaningful knowing" is a more appropriate description of the dialogic process. The aim is not necessarily to reach consensus about certain values, it may be to converse and learn about these values so as to achieve some clarification. As participants in a conversation reflect on and explicate their values to each other, a small distance or breach is created between the situation at hand and the values that are being enacted. This breach is a precondition for becoming attentive to one's own and other persons' values. Epstein (I999) referred to this way of mindful thinking within medical practice when he said: "Mindful practitioners attend in a nonjudgmental way to their own physical and mental processes during ordinary, everyday tasks. This critical self-reflection enables physicians to listen to patients' distress, recognize their own errors, refine their technical skills, make evidence-based decisions, and clarify their values so that they can act with compassion, technical competence, presence and insight." (Epstein, I999, p. 833)

The conversations seem to be meaningful at another level as well. For Dorothea the answer to the epistemological question "What is true knowledge?" is situated within a pre-existing set of relationships between participants. Ascribing to Marc certain opinions he did not express explicitly, she places Marc's contribution again at the center of the conversation at a moment when he is in danger of being ignored or dismissed by the other participants. Doing so she may not only be uttering her personal epistemological belief but also actively confirming her close working relationship with Marc.

This analysis of the teachers' conversation is intended to clarify the contextual and personal nature of the epistemological perspective. The passage from the focus group interview illustrates that a conversation is always set against a background that is meaningful already. This is exemplified by the apparent effect of the relationship between Dorothea and Marc, which shows when Marc's contribution to the conversation is in danger of being ignored. If it is true that Dorothea's epistemological answer is inspired by this relationship, this would provide support for the conclusion 
that epistemological beliefs are not purely individual. Epistemological questions are answered within discursive environments in which issues of true knowledge are intertwined with or mediated by the meaningfulness of the relations between the people conducting that conversation. 


\section{References}

Abma, T., \& Stake, R., E. (200I). Stake's responsive evaluation: Core ideas and evolution. In J. Greene, C. \& T. Abma (Eds.), New Directions for evaluation (pp. 7-2I). San Francisco: Jossey-Bass.

Davis, B. (2004). Inventions of teaching: a genealogy. Mahwah, New Jersey: Lawrence Erlbaum Associates, Publishers.

Epstein, R., M. (I999). Mindful practice. JAMA, 282(9), 833-839.

Gadamer, H.-G. (I990). Truth and method (Vol. 2nd ed.). New York: Crossroad.

Hammer, D., \& Elby, A. (2002). On the form of a personal epistemology. In B. Hofer, K. \& P. R. Pintrich (Eds.), Personal epistemology (pp. I69-I90). Mahwah, New Jersey: Lawrence Erlbaum Associates.

Hofer, B. K., \& Pintrich, P. R. (2002). Personal epistemology: The psychology of beliefs about knowledge and knowing. Mahwah, New Jersey: Lawrence Erlbaum Associates.

Kieren, T., Gordon-Calvert, L., Reid, D., \& Simmt, E. (I995). An enactivist research approach to mathematical activity: Understanding, reasoning, and beliefs. Paper presented at the Paper presented at the meeting of the American Educational Research Association, San Francisco.
Merleau-Ponty, M. (I962). Phenomenology of perception. London: Routledge.

Niessen, T., J.H., Abma, T., A., Widdershoven, G., A. M., \& Vleuten, C., P.M. (2004). Contemporary epistemological research: The need for a reconceptualization. Paper presented at the Third International Conference on Dialogical Self, Warsaw.

Patton, M. (2000). Qualitative research and evaluation methode (3rd ed.). Thousand Oaks, CA: Sage Publications.

Perry, W. G. (1968). Forms of Intellectual and Ethical Development In the College Years: A Scheme. New York: Holt, Rinehart and Winston.

Savin-Baden, M. (2000). Problem-based learning in Higher Education: Untold stories. Buckingham: SRHE and Open University Press.

Vleuten, C., P.M. van der, Dolmans, D. H. J. M., De Grave, W. S., Van Luijk, S. J., Muitjens, A. M. M., Scherpbier, A. J. J., et al. (2004). Educational research at the faculty of medicine, university of maastricht: Fostering the interrelationships between professional and education practice. Academic Medicine, 79(เо), 990-996. 



\section{6}

Teacher involvement in curriculum revisions:

from a concern-based to a responsive approach 
This chapter has been submitted as: Niessen, T.J.H., Abma, T.A., Widdershoven, G.A.M. \& Vleuten, C.P.M. van der (submitted). Teacher involvement in curriculum revisions: from a concern-based to a responsive approach. Higher Education. 


\section{Abstract:}

In a recent article in Higher Education, Moust et al. (2005) advocated the concernbased approach as an appropriate method for curriculum revision. The basic idea underpinning this approach is acknowledgment of teachers' concerns to prevent resistance to curriculum change. Resistance is countered by adequate information to reduce uncertainties and to persuade teachers to replace their ideas by new ones. The purpose of this article is to redefine the concern-based approach by taking teachers' concerns as the starting point for a genuine dialogue among all stakeholders in curriculum change, which then becomes the vehicle for practice improvement. Drawing on enactivist theories and a responsive methodology we argue that a focus on concerns is in itself valuable, but only effective - in terms of evolutionary adjustments taking into account the educational context - if these concerns are exchanged in dialogues between all stakeholders. We draw on our earlier evaluation of an introductory teacher trainer course on PBL as a case to illustrate a responsive approach to teacher involvement and to gain a better understanding of curriculum change and resistance to it. 


\section{Introduction}

Problem Based Learning (PBL) is an instructional method that differs significantly from traditional or frontal modes of teaching. By collaborating to resolve authentic problems, students acquire the knowledge and skills they will need for their future work environments. In PBL the teacher's role is that of a facilitator of students' learning processes rather than that of an instructor who imparts knowledge. As the change from traditional teaching to PBL is a rather stark one, teachers faced with this change often show signs of resistance. Over the years this resistance has led to modifications in PBL. Moust, Van Berkel and Schmidt (2005) recently published in Higher Education an article on resistance to and modifications of PBL entitled: "Signs of erosion: reflections on three decades of problem-based learning at Maastricht University."

The authors report on both the small and the more far-reaching changes that have crept into the practice of PBL over the years. They also suggest ways to remedy the observed problems by paying special attention to teachers' concerns. Professional development strategies should be congruent with those concerns: "the professional development of teachers should be in line with the different stages of concerns teachers have. Professional development activities which aim to modify instructional behaviour must start from the subjective realities of the individual teachers involved" (p.68o). We will discuss this concern-based approach and compare it to a responsive approach to the question of how to revitalise curricula and address teachers' resistance to change. Although both approaches are similarly favourable towards teacher involvement focusing on teachers' claims, concerns and issues, the responsive approach is likely to stretch the boundaries of teacher involvement in curriculum revision initiatives.

First we will address assumptions underlying teacher involvement in curriculum revision by focusing on the language used in the article by Moust et al. (2005). Language is not a neutral medium for passing on information, but a tool that can be used to manoeuvre towards certain solutions and responsibilities. After discussing the responsive approach we will highlight the differences between the two perspectives and examine the implications for curriculum revision initiatives.

\section{The power of language}

The PBL curriculum of Maastricht University has changed considerably over the thirty years since its introduction. In some instances students today study less. There has been an increasing drop in students' preparation time for PBL sessions. The Maastricht PBL approach is characterised by a seven-step format. Students have tended to skip certain steps, which has detracted from the value of PBL and lessened its worth as a didactic tool. Staff members have altered the PBL model too. Instead of 
acting as facilitators of the PBL process they have tended to revert to teacher-centred, frontal teaching modes. According to the authors these changes have crept in accidentally or were introduced deliberately by faculty officials. Either way they have compromised the ideas underlying PBL.

The authors refer to the changes within the PBL curriculum as "signs of erosion", "defects", "inhibitions", "problems" and "breakdowns" (p. 675). Through this choice of words responsibilities are assigned and certain solutions are implicitly given precedence. The term "change(s)" acquires specific meaning within the context of such a framework. It implies a dichotomy between educationalists, who support and develop PBL and teachers (or faculty staff), who cause problems while enacting it. A chasm is created between these two sides with legitimacy being claimed for one side only. Moust et al. (2005) give precedence to the developers of PBL over staff members and faculty officials who are causing the problems within the PBL curriculum. The article suggests that if only the latter would adjust their behaviour, PBL would once again function properly.

Beside the power of verbal expression, part of the normative inclination of the authors is communicated through the plot or sequence of the article. Moust et al. start by claiming that PBL and its principles have a sound basis in research. Then, referring to the changes that have haphazardly invaded the PBL approach through the actions of teachers and faculty officials as "problematic", "inhibiting" or "defecting", they turn their message into a one sided one. They negate that staff members may have sound and legitimate reasons for departing from PBL instructions, even though their views may not have a firm research foundation but may be rooted in personal and anecdotal evidence. Roth et al. (Roth, Lawless, \& Tobin, 2000) distinguish between the theoretical and the enacted curriculum. The theoretical curriculum is the one developed by educationalists and might be looked upon as the general framework within which teachers are required to operate. However, the theoretical curriculum differs from the lived experiences of teachers or the enacted curriculum. According to Roth et al. (2000) the latter has a legitimacy of its own for it deals with the indexical nature of practice, which cannot be accounted for within the theoretical curriculum. Treating lived experiences as equivalent to and not solely as supportive of the theoretical curriculum may prevent typical either/or thinking and ensuing legitimacy and resistance issues.

Finally, Moust et al. characterise PBL as a relatively static and circumscribed blueprint in which "changes in one element can seriously damage other elements in the 'house' of PBL” (p.669). This may cause staff members to feel estranged, rebellious or threatened by a blueprint that leaves little room for personal interpretation and ignores sound reasons teachers may have for departing from instructions they may see as rather stifling. This raises the question of how to characterise and address the 
phenomenon of resistance and how to take staff members seriously when aiming at repairing and strengthening PBL. First we will seek to answer these questions by focusing on Moust et al.'s (2005) concern-based approach. Next, we will attempt to formulate an answer using a responsive approach, i.e. an approach with a similar focus on teachers' concerns but with a more radical view of teacher involvement within curriculum revision initiatives. The two approaches and their differences will be used to elucidate the phenomenon of resistance and how it can be dealt with.

\section{Addressing signs of erosion within PBL: two approaches}

In addressing and remedying signs of erosion due to resistance from teachers, Moust et al. (2005) draw on Van den Berg and Ros's (Van den Berg \& Ros, I999) concernbased approach. According to this approach curriculum developers should create opportunities for teachers to discuss their concerns ${ }^{\mathrm{I}}$ about PBL. It is important to understand concerns with respect to their types (Van den Berg distinguish various types of concerns) in order to develop faculty development programmes that help faculty members change their ideas, skills and attitudes. For example a teacher with "self concerns" is helped by providing more information about the innovation in question. In addition Moust et al. (2005) say that overcoming resistance "happens not by fiat or command, but by taking a learning orientation to change processes in schools."

With respect to this latter issue: “...innovators and school leaders (should - author's addition) consider carefully how teachers perceive their role, the relations of teachers to others and the significance of the change itself for teachers" (p. 680). These concerns should be the point of departure when trying to bend teachers' ideas towards the core PBL principles. School leaders are important in this respect, i.e. they should change their approach to a transformative outlook. This means that they should make sure that teachers have a correct understanding of the meaning and usefulness of the expected changes, for otherwise there is a good chance that teachers will gradually relapse into their old and familiar ways of teaching. The ideas underpinning PBL should be explained and clarified but most of all transformative leadership involves creating a culture that is favourably inclined towards risk taking and openness to innovation.

As we said earlier increased attention for teachers' concerns is important to come to a real understanding of the issues with which teachers are struggling. Responsive Evaluation (RE) resembles the approach used by Moust et al. in that it also focuses

I "Berg \& Ros (I999) describe concerns as long-lasting questions, uncertainties, and resistances that teachers may have in response to new situations and changing demands." (From Moust et al, 2005, p. 675) 
on the concerns of teachers and teacher trainers. We have used it in evaluating the "Introductory course on PBL for new staff members at Maastricht University." RE can be traced back to Robert Stake who developed it in the mid seventies as an alternative to "pre-ordinate evaluation" (Stake, I975). He saw the latter as the dominant approach, which was strongly biased in favour of (preferably experimental and quantitative) measurement procedures and accepted only two kinds of data as legitimate: goals and outcomes. These goals and outcomes were centred around the scientist-researcher-evaluator. Stake wanted to make RE meaningful to different stakeholders' experiences (Abma, I996, 200I). Building on these assumptions, we can look upon RE as a method for evaluating programmes or practices in which the evaluation process is viewed as emerging from the interactions and relationships among the participating stakeholders.

Like the concern-based approach, RE has a formative goal, i.e. transforming the curriculum. However, in contrast to the concern-based approach RE does not start from outcomes that are stipulated in advance by one stakeholder group but it moves towards outcomes that are dependent on the deliberative dialogues ${ }^{2}$ between all stakeholders. It is important to note that the emergent and dialogical nature of the RE approach is supported by enactivism, a recent theory on cognition (Varela, Thompson, \& Rosch, I997) that has functioned as the default view from which we departed. This dialogical worldview differs fundamentally from the mechanical outlook that is the point of departure used by Moust et al. Although a discussion of these basic groundings seems fundamental, it would also be quite elaborate and we will confine ourselves here to sketching the contours of the enactivist view.

Enactivism postulates that people and phenomena arise and become operative within their moment to moment copings and interactions with each other. This means that nothing or nobody can ever be postulated as fully pre-existent. Every person, concept and object becomes real through enactment and recognition by others only and so is continuously emerging in interactions within the environment. This also holds for the curriculum in education contexts. A curriculum is as much "made" through the enfolding interactions around and within it as by the developers' initial groundings (Davis \& Sumara, 2000). We would even go so far as to say that without interaction and dialogue there would not be much of a curriculum. RE provides us with a means of curriculum revision that is congruent with this worldview, with revision depending on literally and figuratively constructive dialogues between the various stakeholders and their different perspectives.

2 "Deliberation refers to the interaction and dialogue between participants. They do not just accept each other's beliefs and persuasions, but will explore these. Listening, probing and dialogue characterise this process, rather than confronting, attacking and defending. Central feature of dialogue are openness, respect, inclusion and engagement." (Abma, 2005) p. 280. 


\section{An example: evaluation of an introductory PBL course for teachers}

In the following we will discuss and illustrate a responsive approach to curriculum revision using the evaluation of the "Introductory course on PBL for new staff members". This description is the backdrop against which we will highlight some of the differences between RE and the concern-based approach (table I).

\begin{tabular}{|l|l|l|}
\hline & Concern-based approach & Responsive Evaluation \\
\hline $\begin{array}{l}\text { Characterisation } \\
\text { outcome change }\end{array}$ & $\begin{array}{l}\text { Direction of the outcome is defined } \\
\text { a priori by one stakeholder group. }\end{array}$ & $\begin{array}{l}\text { Direction outcome is emergent in the } \\
\text { deliberative dialogue between stakeholders. }\end{array}$ \\
\hline How does change occur? & Radical conceptual change & Change is evolutionary process \\
\hline What is resistance? & Individual / cognitive phenomenon & Situational, configurational phenomenon \\
\hline
\end{tabular}

Table 1. Differences between a concern-based and responsive approach

Using the concern-based approach Moust et al. (2005) show themselves to be appreciative of teachers' concerns. However, this appreciation is conditional and limited by the authors' perspective, i.e. that of the educationalist intent on restoring PBL in such a way that its holistic nature and cognitive psychological underpinnings remain intact. These issues are fundamental and non-negotiable. Within RE on the other hand no issues or concerns are a priori excluded from change. After identifying the different stakeholders of the Introductory PBL course, i.e. new staff members and teacher trainers, we established which claims, concerns and issues relating to the course were relevant to each group. By focusing on homogeneous groups first we were able to keep an open mind with respect to which issues each stakeholder group considered pertinent and important. Only after this procedure was completed were the groups mixed to engage in a deliberative dialogue about the issues identified. This procedure prevented a priori exclusion of any issue and ensured that the direction taken towards any outcome was emergent from the deliberative dialogues among the participants.

The view from the perspective of the concern-based approach with respect to the question of how change can be effected in teachers is that change can and should be effected radically. Although according to Moust et al., such a process requires ample time and effort from both the participants and the leaders monitoring and supporting this transformation, the basic view is that a radical change in teachers' ideas is to be brought about by revolution and not by evolution. Within this approach the metaphor of conceptual change is important, with teachers being assumed to change their views radically as a result of exposure to new ideas. Since this is a rational activity that can be defined as coming to comprehend and embrace new ideas because they are perceived as being more intelligent and rational, this framework 
requires provision of sufficiently clear and detailed information about the new ideas. Having talked with individual teachers and with groups of teachers about PBL teaching practices, we have come to realise that change comes about by evolution, not by revolution. This is also argued by Stake (1986), who states that change is instantiated when habitual behavioural tendencies are challenged by new, strange stories that do not fit the old experiences. For example, in one of the interviews a teacher trainer talking about his concerns relating to the training of new staff members, specifically referred to the circumstances within his Faculty, i.e. its culture and the specific population of the participants in the PBL course. Highlighting these circumstances and talking about them in conversations with others resulted in even more details being added. This process of adding context and texture to general PBLrelated issues and concerns within an open atmosphere resulted not only in more openness and susceptibility to detail, it also allowed participants to take small steps in modifying their views. For many do not change their views radically all at once. In our interviews change often involved acknowledging another person's position as a legitimate outlook, taking into account new details and redefining one's situation. Roth et al. have called this the ability for situational or indexical thinking (Roth, Lawless, \& Tobin, 2000).

Finally the two approaches differ in the way they characterise resistance. The vocabulary used in RE to characterise resistance and change has a reciprocal orientation. That is, resistance is regarded not as being located primarily and exclusively within a certain individual but in the mutually construed reality in which individuals are operating in conjunction. From an enactivist worldview and using RE as a methodology that is congruent with this view, we see resistance not as a "thing" or a characteristic that is to be found objectively "out there" "in the individual" but as a construction emerging in the interaction between individuals (and other elements) and/or internally between different I-positions within an individual person (Niessen et al, 2004).

For example, Josie, one of the teacher trainers we interviewed at Maastricht University, talked about an occasion on which she experienced resistance when she found that her usual teaching approach of creating a common thread together with course participants did not work. Reflecting on the occasion afterwards she realised this approach could not have worked in this particular instance because the group was too large, the participants too experienced, and her trainings skills at that point were those of an advanced beginner. Resistance as a phenomenon thus surfaces in the confrontation between her ideals and the specific circumstances of a particular teaching situation. This is why resistance should not be located exclusively within the individual but within the interstices that constitute a teaching situation as a whole. The latter level of resistance has been characterised as a collision between different 
I-positions (H. J. Hermans, 2002; H. J. M. Hermans, Kempen, \& Van Loon, I992). For example, Robert, one of teacher trainers we interviewed talked enthusiastically about his childhood and his father who was a traditional teacher. From his childhood frame of reference it appeared to make sense to talk about teaching as telling students what they need to know. When he talked about his other experiences and subsequent training, he expressed the view that a teacher should be more facilitating and not just tell students what to do. This was a different, more contemporary voice which he had acquired during later training. The struggle and resistance experienced by Robert related to the question as to which of these voices or I-positions should take precedence within a particular teaching situation. Josie's story on resistance was set at the interface level of a dialogue involving students and other elements. Simultaneously, at an inner level this dialogue took place between different I-positions. Within Moust et al.'s (2005) article participants' responses to PBL reflect concerns that hamper optimal implementation of PBL within Maastricht University. Resistance is positioned unilaterally within the individual as a psychological phenomenon. No reference is made to its nature or emergence as a shared accomplishment generated during an internal or external dialogue.

\section{How to deal with resistance?}

The answer to the question of how to deal with resistance differs depending on the approach adopted. From the perspective of the concern-based approach a successful anti-resistance strategy depends on the ability to accurately represent and describe the sources of resistance "within the individual" and to choose and implement strategies appropriate for countering and/or overcoming that source. Specific attention is paid to developing a framework in which different categories of concerns are identifiable so training can be tailored to redress the type of concern that causes resistance. In table 2 we refer to this approach as monological. This means that the direction of the counter measures to remove resistance is basically unilateral: from the educationalist to the participant.

Within RE there is no singular dominant reality. Meaning is a social and dialogical accomplishment. Resistance occurs when people do not understand one another or deliberately stop trying to do so. People may be unaware that they view things from different I-positions. When this happens people simply do not understand each other because they speak different languages. Within a dialogue these differences are often not fully addressed and as a result lead to communication spirals in which participants repeat what others have said without really understanding what the other is really saying (Akkerman, Admiraal, Simons, \& Niessen, 2006). People may also stick firmly to their own views offering minimal dialogical space to others.

From an enactivist or RE perspective, participants should engage in deliberative 
dialogue with each other about their interpretations. The responsive researcher or change manager should facilitate this process entering the dialogue space and identifying the I-positions from which different stakeholders depart. Facilitating processes to combat resistance also means identifying differences with regard to worldview assumptions, norms and values. It means pointing out inconsistencies within and between people's reasoning. To do so facilitators should ask for context, thickening the stories that are being told. It is important to add detail to experiences. This enhances participants' indexical sensitivity (Roth, Lawless, \& Tobin, 2000), that is the capacity to feel and accurately denote small but significant differences between contexts. Langer (Langer, 1997) has called this the capacity of mindfulness, i.e. the ability to think beyond habitually formed demarcations, boundaries and dichotomies. When all participants are being stimulated to think this way - helped by a facilitator - resistance is not an issue that gives legitimacy to one participant rather than another one but it is an issue on which all parties are invited to think beyond the given situation and move in new creative directions.

Put differently, resistance is the phenomenon that is encountered when dialogue stops because people reify their views, ideas or positions. Reification means that constructions of meaning are no longer negotiable but treated as facts and taken for granted. Within those moments people tend to ignore the other (or otherness) (Abma, 2000) and the situation is characterised by irreflexivity or mindlessness (Langer, 1989), repetition of standpoints, and the exclusion of other persons from the creation of meaning. This process may take the shape of a collision between different I-positions or a confrontation between different individuals. It is the task of the facilitator to show people their blind spots, to stir loose what has become stuck, to shake up what has become solid or stable. This may be done by various methods. It is important to use the method that is most likely to prevent repetition of standpoints. To do so it is important to step out of one's habitual framework. When participants are oriented orally one might turn to writing or metaphors to breach the impasse (Abma, 2000). Within Practice Development (Titchen \& Manley, 2006) which employs different creative methods participants are invited and enticed to think beyond what they know, thus creating a moratorium in which practices to minimise resistance can be developed.

\begin{tabular}{|l|l|l|}
\hline & Concern-based approach & Responsive Evaluation \\
\hline $\begin{array}{l}\text { Characterisation of the } \\
\text { phenomenon of resistance }\end{array}$ & Monologue, one-way approach & Dialogue, involvement \\
\hline $\begin{array}{l}\text { Actions for meeting } \\
\text { resistance }\end{array}$ & $\begin{array}{l}\text { To convince people to provide information } \\
\text { that is focused on experiences }\end{array}$ & $\begin{array}{l}\text { Create tension/ dynamic internally } \\
\text { and externally }\end{array}$ \\
\hline
\end{tabular}

Table 2. Characterising and meeting the phenomenon of resistance 


\section{Discussion}

The article by Moust et al. (2005) in Higher Education in which the process of the concern-based approach is characterised and discussed is important because it puts teacher involvement in curriculum revision initiatives on the agenda. The concernbased approach is helpful in eliciting teachers' ideas about teaching, education, and PBL. The impact of the article can be even more powerful when it is used to scrutinise the authors' assumptions, for instance by examining their use of language. Language is not a neutral medium for transmitting information. When we look for example at the divisive, dichotomous and monological language in the article by Moust et al. (2005) we can see that language can be a powerful tool capable of inducing resistance within itself. Grounding our research in enactivist theory, we propose a way of thinking that is dialogical in nature. A dialogicality that is apparent in language with the focus on mutuality and in the research method used, i.e. Responsive Evaluation (RE).

RE states that the need for curriculum revision and the content of the alterations needed to revise a programme, are not, not even primarily, determined by the scientist-researcher-evaluator. RE claims that there are more realities and that these realities are constructed within social-relational processes. This means that which curricular changes one envisions will depend on one's position in relation to the curriculum that is being evaluated. The performing teachers may want to change other features of the course or the curriculum than the teacher trainers or course developers. Within RE these different stakeholders engage in deliberative dialogue about the modifications that are needed. Within such conversations one stakeholder group should not claim precedence over another. As pointed out by Roth et al. (Roth, Lawless, \& Tobin, 2000) educationalists and those who want to change a curriculum should differentiate between the theoretical and enacted curriculum. Both are necessary to make the programme or curriculum work. Although RE is more in line with this assumption, we think RE could also be applied more systematically throughout the whole process of curriculum design or revision as is done in Participatory Design (Button \& Dourich, I996). Within this approach the end users of the programme or curriculum are legitimate partners throughout the design or revision process. The common or general goal within Participatory Design is to democratise technologies and invite end users of a technology as legitimate partners in the design process because it is impossible for designers to account accurately for the daily praxis (Button \& Dourich, I996). The role of the end user and end product should and can no longer be determined exclusively by the goal the designer has in mind. It is the dialogue amongst participants in a gradually developing design process that is constituting working programmes (Anderson \& Crocca, I993).

Stressing egalitarian dialogue and thus blurring the distinction between educational developer and teacher in no way implies that the educationalist's contribution is 
marginalised or dismissed. What it does mean is that the value placed upon a programme is to be determined dialogically and anchored within the positions of the relevant stakeholders. In conclusion we would like to return to the article by Moust et al. (2005) and their closing assertion: "It is our belief that pursuing the path of continued renewal is a good antidote to waning of interest and adherence to tradition". Expanding on this we would like to add that we hope that curriculum developers themselves will also engage in continuous renewal, taking teachers' experiences not solely at face value but also as meaningful experiences from which they can learn. 


\section{References}

Abma, T., A. (1996). Responsive evaluation. Delft: Eburon. Abma, T., A. (2000). Dynamic inquiry relationships: ways of creating, sustaining, and improving the inquiry process through the recognition and management of conflicts. Qualitative Inquiry, 6(I), I33-I5I.

Abma, T., A. (200I). Opening thoughts, in a special issue on dialogue and evaluation. Evaluation, 7, 238-252.

Abma, T., A. (2005). Responsive evaluation: Its meaning and special contribution to health promotion. Evaluation and Program Planning, 28, 279-289.

Akkerman, S. F., Admiraal, W. F., Simons, P. R. J., \& Niessen, T. J. H. (2006). An international academic project: the challenge of multivoiced discussions in a boundary crossing group. Culture a Psychology, 12(4), 46I-485.

Anderson, W., \& Crocca, W. (I993). Engineering practice and co-development of product and prototypes. Communication of the ACM, $36(4), 49-56$.

Button, G., \& Dourich, P. (I996). Technomethodology: paradoxes and possibilities. Cambridge.

Davis, A. B., \& Sumara, D., J. (2000). Curriculum forms: on the assumed shapes of knowing and knowledge. Journal of Curriculum Studies, 32(6), 821-845.

Hermans, H. J. (2002). Special issue on dialogical self. Theory \& Psychology, 12(2), I47-280.

Hermans, H. J. M., Kempen, H., \& Van Loon, R. J. P. (I992). The dialogical self beyond individualism and rationalist. American Psychologist, 47(I), 23-33.

Langer, E., J. (1989). Mindfulness. New York: Addison Wesley.

Langer, E., J. (I997). The power of mindful learning. Reading, Massachusetts: A Merloyd Lawrence Book - Perseus Books.
Moust, J. H. C., Berkel, H. J. M. v., \& Schmidt, H. G. (2005). Signs of erosion: Reflections on three decades of problem-based learning at Maastricht University. Higher Education, 50, 665-683.

Niessen, T., J.H., Abma, T., A., Widdershoven, G., A. M., \& Vleuten, C., P.M. (2004). Contemporary epistemological research: The need for a reconceptualization. Paper presented at the Third International Conference on Dialogical Self, Warsaw.

Roth, G.-W., Lawless, D., \& Tobin, K. (2000). Time to teach: Towards a praxeology of teaching. Canadian Journal of Education, 25, I-I5.

Stake, R., E. (1975). Evaluating the arts in education: A responsive approach. Merill: Columbus Ohio.

Stake, R., E. (I986). An evolutionary view of program improvement. In E. House, R. (Ed.), New directions in educational evaluation (pp. 89-IO2). Philadelphia: The Falmer Press.

Titchen, A., \& Manley, K. (2006). Spiralling towards transformational actions research: philosophical and practical journeys. Educational Action Research: An International Journal, 14(3), 333-356.

Van den Berg, R., \& Ros, A. (I999). 'The permanent importance of the subjective reality of teachers during educational innovation: A concern-bases approach. American Educational Research Journal, 36, 879-906.

Varela, F., J., Thompson, E., \& Rosch, E. (1997). The embodied mind - Cognitive science and human experience (Sixth printing ed.). Cambridge, London: The MIT Press. 


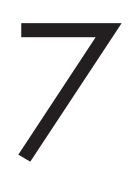

General conclusion

and discussion 

The aim within this study was to develop an enactivist epistemological perspective using the method of responsive evaluation and to investigate its merit for understanding teachers' experiences and resistances. Important to this thesis was the acknowledgement to preserve teaching as a complex and multi-faced endeavour. Within a complex teaching practice, in contrast to a complicated practice, we don't exactly know how teaching works. In a complicated world, like a system that works mechanically, the elements are known and cause and effect relationships can be adequately described. It is thus possible to understand human behaviour fully by reducing it to its parts. Within a complex worldview this is not possible since the elements - such as for example the epistemological beliefs - are in part dynamic and adaptive to the circumstances instead of inert. By providing thick descriptions or detailed accounts we have tried to highlight the intricate and adaptive nature of teaching practice in general and the epistemological perspective in particular. Analyzing these descriptions and transferring them to our own situation might help us to deepen our understanding about teaching and the resistances within it. In this final chapter we present the main conclusions to the three areas of interest within this thesis: a) the field of personal epistemology, b) the topic of resistance, and c) the field of Problem Based Learning and/or educational innovations. We will pay attention to the limitations within this study and to quality and generizability issues. Finally, we will dwell on suggestions for future research. 


\section{Conclusions with respect to the field of personal epistemology}

Research at personal epistemology, although of reasonable recent date, is getting more attention within the educational research community (Hofer \& Pintrich, 2002). Different streams of thought have used the epistemological lens to explain or understand learning and teaching. One of the troubling issues within this field concerns the form of personal epistemology (Hammer \& Elby, 2002). The research community is not explicit about and unsure whether to depict epistemological beliefs as traits, theories or resources. We have argued that underlying various streams of thought the same cognitive perspective is functional. This perspective ontologically builds on cognitive psychology and cognitive science as it precursors and is congruent with its linguistic and methodological propensities (Chapter 3).

We claimed that for the domain to become ready for the next century, researchers within different perspectives should carefully consider and investigate the default assumptions they depart from themselves, and also those of other researchers. This might be difficult as Donna Kagan (I990) mentions, because of our unfamiliarity with other relevant foundations. Although we agree with this, we would like to add that the difficulty is also related to the lack of openness of researchers to take on the perspective of the other as a legitimate position to think from (Niessen, Vermunt, Abma, Widdershoven, \& Vleuten, 2004).

Within this thesis we have developed an epistemological perspective that tries to acknowledge and preserve the complexity of teaching practice. We have tried not to reduce teaching behaviour to linear relations because this is not in line with an enactive perspective in which people and elements are configurationally related. By providing thick descriptions and detailed analyses we have tried to exemplify this complex nature. One of the conclusions within this thesis is that epistemological beliefs are dynamic and dialogical phenomena i.e. they are at work both within and between people (Chapter 3, 4 and 5). The dynamicity or dialogicality of the epistemological perspective within people takes the form of a dialogue between different voices or I-positions. Between people epistemological beliefs are characterised as temporarily crystallized configurations adapting themselves to the shifting circumstances (Chapter 3 ). Epistemological beliefs are therefore best acknowledged a posteriori through analyses of concrete experiences or stories.

The use of one case example (evaluation of the PBL course at the University of Maastricht) and context-bound analysis of epistemological beliefs raises the question whether, and to what extend the findings (i.e. the epistemological beliefs) are generalizable to other contexts and by whom these generalizations are best made. Drawing on the term "natural generalizations" from Robert Stake (Stake \& Trumbull, I982) we would like to argue that epistemological beliefs are transferable to other 
than the studied context. Since an epistemological belief is a narrative, personal and enacted experience, this transferability is best done by readers of the manuscript. They are best equipped to recognize similarities or dissimilarities between the studied and their own context. Robert Stake (I982) states that thick descriptions allow readers to decide what elements in the specific context might be transferable to other settings and situations that are encountered by the reader.

\section{Conclusions with respect to the phenomenon of resistance}

Contemporary literature on resistance is based on the assumption that everyone shares the same objective and homogeneous reality. Differences in people's responses to innovations must either reflect misunderstandings or individual characteristics that are "in the way" of change. Within this characterization resistance is objectified as a psychological phenomenon that exists "over there" "in the individual" (Dent, 2003; Dent \& Goldberg, 1999). To overcome resistance, one should be able to accurately represent and describe the sources of resistance "in the individual" and to choose and implement strategies appropriate for addressing and overcoming these sources.

A view that puts resistance "over there" "in the individual" creates a chasm between the innovator and the person that reacts to the innovation. The goal of this thesis was to criticize this dichotomous thinking. Formulating epistemological beliefs as enacted configurations is a way to transcend traditional boundaries between individual/collective, mind/body and develop a view that incorporates both at the same time.

According to enactivist and hermeneutic theories, reality as we know it is interpreted, constructed or enacted through social interaction. Within this view, it is not possible for participants to know any "true" independent reality. Resistance is not to be found "in the individual" but in the "configuration" which people collaboratively enact. This enacted configuration or unity both entails individual elements but at the same time transcends them because they only exist in dialogue with others. The whole package of individual-in-dialogue-with-someone-else-within-a-certain-situation sets the scene in which resistance emerges. We have shown this configurational level both in the interface between people (Chapter 3) and within persons as contrasting I-positions struggling for precedence within a certain teaching situation (Chapter 4). Traditional approaches treat resistance as a response to the current change situation. When managers can handle the current change situation properly, resistance will be minimized and ultimately overcome. Accordingly, managers use reduction strategies to address those issues that appear to arise in response to the current situation. From an enactive perspective, the reason that traditional resistance reduction strategies 
are unlikely to work is because they tend to rely on the situation at hand solely, dealing with resistance on an individual cognitive level. Underlying this traditional view is an image of the individual as "a bounded, unique more or less integrated motivational and cognitive universe, a dynamic centre of awareness, emotion, judgment and action, organized into a distinctive whole and set contrastively against other such wholes and against a social and nature background..." (Dent \& Goldberg, I999). This focus on the individual as a unique non-dividable unity neglects our finding that people act on a topic or issue depending a preceding voice or I-position (Chapter 4).

From an enactivist perspective, resistance is interpreted as an indication a creative tension between various inner voices or I-positions is lacking. A person is no longer able to view the situation from more than one position, with the result that dialogue stops altogether both within and between individuals. The word enactivism (to enact means to act out or to perform) signals continuing motion i.e. one comes to know through interaction. Resistance is a phenomenon in which our "natural" state, in which who we are arises in our moment-to-moment interactions between the different I-positions, is being hampered by the dominance of one I-position and/or when one person is trying to dominate the conversation over others. In order to prevent resistance and stimulate movement and dialogue where there is immobility, Nicholas Burbules (1997) states it is important: "to keep the tension alive - a dialectic that does not move towards resolution, but that yields creativity out of the sustained movement back and forth between the two (or more) alternatives (and voices - our adding)" (Burbules, 1997). One of the ways to do so is to foster and cultivate mindfulness (Langer, I989, I997; Langer \& Moldoveanu, 2000). Mindfulness is the ability to think through or past given demarcations into new categories. Within medicine (Epstein, I999) and teacher training (Napoli, 2004) mindfulness is seen as an important element for continuing professional development and quality improvement. Consistent with a narrative and constructivist view the selfconfrontation method (Lyddon, Yowell, \& Hermans, 2006) might be a valuable tool to facilitate and stimulate internal dialogue between different I-positions. The researcher-facilitator within RE can achieve this by using a differentiated set of instruments such as metaphors or creative writing (Chapter 6).

\section{Conclusions with respect to problem based learning}

Maggie Savin-Baden (Savin-Baden, 2000) concludes that there is a lack of studies into what actually occurs inside problem based learning curricula, especially with respect to the key elements context, identity and learning in relation. This is problematic since key elements within learning and teaching processes in PBL are 
missed: "The consequence of this is that because students', and to some degree staff's voices are largely missing from the literature on problem-based learning, key elements such as learning context, learner identity and 'learning in relation' are rarely acknowledged or discussed when implementing or enacting problem based learning" (Savin-Baden, 2000, p. 26).

The portrayals provided within Chapter 3 and 4 examine context, identity and learning in relation. In Chapter 3, we saw a junior teacher trainer within a PBL setting, Josie, who is troubled by the fact her usual teaching approach does not fit the context of an experienced group of students. "In relation" to this group she learns a lot about her own skills, views and abilities which are taken to the test. When meeting these instances openly and mindfully - as Josie did - they provide learning opportunities for the people involved. In Chapter 4, in the stories of Robert and Sarah, we saw that the notion of unified identity can be questioned by pointing at "inner" configurations and dialogues between different I-positions (Hermans, 2002; Hermans, Kempen, \& Van Loon, I992) or voices (Akkerman, Admiraal, Simons, \& Niessen, 2006). In the case of Robert, his approach to PBL was dependent to the I-position that took precedence when referring to certain PBL instances. The tension this created should be welcomed, as it served within Roberts' case as a plea for nuanced and contextual thinking and acknowledging that the I-position that takes precedence at one moment is never completely right or wrong. It is therefore necessary to think with nuances and mindfully about each new teaching situation. We agree with Maggie Savin-Baden that Problem Based Learning for some teachers can put their teacher identity or one of the I-positions in jeopardy because of the ways in which it can disturb teachers' understandings of what counts as knowledge or how a person comes to know and also what it means to be a teacher. One of our participants experienced the phenomenon of disjunction (Chapter 4). According to Savin-Baden (2000) disjunction is: “... a sense of fragmentation of part of, or all of, the self, characterized by frustration and confusion and a loss of sense of self, which often results in anger and the need for right answers" (Savin-Baden, 2000, p. I49). According to Don Margetson (I99I) this is not that strange since PBL is not just another instructional method but a different approach looking at issues of knowledge en knowing altogether. Some teachers have very strong habitual inclinations about how they themselves but also students should come to know. This is the reason why for some new staff members it can be hard to make a transition to this new and completely different approach. This is also difficult because epistemological beliefs are web-like, dialogical and contextual features. The answers to questions of knowing and knowledge emerge out of the interactions within these webs of personal and non-personal elements. Providing our participants with a posteriori descriptions of their day-to-day PBL teaching encounters - in which this web-like nature of 
epistemological beliefs is exemplified - might be a first step towards heightening their awareness and sensitivity towards the complex nature of PBL practice.

\section{Limitations of the study}

Compared to Dutch educational research, this thesis abides an unusually strong philosophical inclination. It is a general contention that such approaches lack practical implications. Alexander (Alexander, 2004), envisioning the possibilities for educational psychology in the year 2020, wrote that "we must come home to philosophy if we are to make advances in the next generation". "To come home with philosophy" in this study meant to translate and apply enactivism as a general (philosophical) worldview to the domain of personal epistemology with the intention to provide a different reading to teacher's experiences and resistances i.e. a reading that has real practical consequences.

Often, talking about practical consequences within education sciences means grosso modo talking about it in linear or causal terms. Within an enactivist framework in which everything is connected with everything, this assumption cannot be upheld. Our research shows that educationalist researchers should be moderate about what can be accomplished. Due to unforeseen linkages between elements in complex environments influence and change may be unexpected or wander in directions we did not foresee. As researchers, we should be attentive to this and try to create the same mindfulness about the persons we work with. Researchers and teachers should not solely focus on the outcomes but keep a keen and mindful eye to the subtle changes and movements along the educational and the research trajectory (Chapter 5).

Referring to the relation between educational philosophy and educational psychology Nicholas Burbules (Burbules, 2003) says: "The challenge to philosophy (or philosophy of education) of varying stripes is to reconceive the experimental ethos in a manner that makes theories answerable and revisable in the face of real-world consequences. The challenge to educational psychology is to reconceive the experimental ethos in a manner that is not narrowly empiricist or merely instrumental." Nicholas Burbules emphasizes that philosophy - if it wants to contribute to education - should be attuned to practical needs and issues raised by the educational field (Burbules, 2003). On the other hand, educational psychological research should not be scientifically narrow. It should allow for "experientialism", that is exploration and innovation. The aim of this thesis was to provide an example of the middle road between both extremes, avoiding being either overly empiricist or overly meta.

Responsive evaluation is normally not used for developmental purposes as we have done in this thesis. Apart from the evaluation of the introductory course on PBL for new staff members at Maastricht University, we have made use of the individual interview phase and focus group interviews for the development of our epistemological 
perspective. In our experience, the combination of these two goals worked out quite well. The teacher trainers and the new staff members provided us with useful suggestions (nuggets of knowledge (Scribner, I999)) during the dialogues they could use to adjust their PBL teaching practice or course content. After the evaluation, the enactivist epistemological perspective was developed and in turn applied to teachers' experiences. The feedback loops in which we provided our participants with the analyses and talked about them appeared to be rewarding to some participants (Chapter 4). Our approach lingered somewhere between purposefully fostering critical intelligence and providing narrative accounts that serves as portrayals that teach indirectly.

\section{Quality and generalizability issues}

Within hermeneutical research, reality, knowledge and social process cannot be separated. "Truth" is a social construction, an explicit or implicit convention of a social interchange which is subject to a constant dynamic multisided multigroup set of negotiations. From this assumption Egon Guba and Yvonna Lincoln (Guba \& Lincoln, 1989) developed a set of "quality" criteria (credibility, transferability, dependability and confirmability) to "parallel" the common denominators for the quality of a research (corresponding respectively to: internal validity, external validity, reliability and objectivity). The authors (Guba \& Lincoln, 1989) created this set of criteria in accordance with their basic assumptions. According to them, quality of research should be based on these "authenticity" criteria.

Authenticity "stresses fidelity to actuality and fact, compatibility with a certain source or origin, accordance with usage or tradition or complete sincerity without feigning or hypocrisy." (Webster's Third New International Dictionary). Authentic research means in other words being truthful. But being truthful to what or whom? Within this thesis we have developed the contours of an enactivist epistemological perspective with the help of responsive evaluation. What does authenticity in this context mean, specifically to the criteria that make up this construct: ontological authenticity, educational authenticity, catalytic authenticity and tactical authenticity? Ontological authenticity is attained when the participating members better understand their own experiences. In Chapter 4, various participants were provided with epistemological analyses by which their understanding about themselves or their practice was enhanced and alternatively structured. For others this was not the case since they were already reflexive and did not read or hear anything new. Educational authenticity is reached when the participants understand each other more clearly. Within the heterogenic focusgroups in which different stakeholders were mixed to talk about PBL it appeared that these dialogues were enriching. Both stakeholder groups were willing to deliberate about and rethink their contributions without falling into fight 
or flight reactions. Catalytic authenticity was not directly observable since it refers to the likelihood that participants will take actions or move as a result of the conversations. Although in general the conversations were found stimulating (some of new staff members claimed to have learned new things about PBL and teacher trainers also gained new insights about how to revise their introductory course) we did not systematically gather these insights and deepen them within follow-up sessions. Finally, tactical authenticity means that all stakeholders - not just the teacher trainers -should feel free and empowered to act during the evaluation. We ssumed that new participants would perhaps be hesitant to take position in the heterogeneous focus groups because of their lack of knowledge about PBL compared to the teacher trainers. We encountered tactical authenticity when new staff members felt free to discuss the content and format of the introductory course. In relation to the process of analysis, especially to the narratives and learning histories within Chapter 4, the criterion of fidelity (Blumenfeld-Jones, I995) was used as a marker for assessing quality.

The research reported in this thesis was restricted to a PBL context, more specifically the "Introductory course on PBL for new staff members." This evokes the question whether and to what extent our research is generalizable. Adri Smaling (Smaling, 2003) distinguishes different forms of generalizability. He refers to analogical generalisation within research that is based on a single case. The generalisation can be based on analogical reasoning by the author (receptive generalisation) or by the stakeholders in interaction with the researcher (responsive generalisation). Both can be applied to our research. In the case of receptive generalisation there is hardly any interaction between the researcher and the reader. The thing to do is to provide sufficient information so that the reader can decide for himself whether the study is relevant for him and to what degree ("naturalistic generalisation" by providing a "vicarious experience" (Stake \& Trumbull, I982).

According to Adri Smaling (Smaling, 2003) the researcher should facilitate this analogical reasoning process providing the following information: a) the status, position and roles of the researchers in the research situation, b) the selected fellowworkers, researched subjects and informants, c) the situations, conditions and social contexts of the research project, d) the selected methods, techniques and concepts, e) the (meta-)theoretical orientation, f) the reasons used to make the diverse choices mentioned above; and g) 'thick description'. We have provided information to these questions throughout the subsequent articles, typifying and explaining our enactivist and hermeneutical ontological posture, drawing detailed information about our participants, the PBL context and the introductory course on PBL. We further explained our method, its restrictions and frictions to its use, and the thick descriptions throughout the subsequent chapters. 
With respect to responsive generalisation Adri Smaling mentions the following: "The idea of responsive generalization can also be recognized in participative research, in which the researched subjects participate in the research as a kind of co-researcher and in which the researchers take the position as co-subjects" (Smaling, 2003, p.23). One can envision a continuum in which different degrees of participation are possible. Although having provided our participants with information about our analyses on several occasions, a major part of our research was devoted to develop the epistemological model. In this process, full teacher participation as co-researchers was lacking.

\section{Suggestions for further research}

This thesis is located on the interface between different fields of research. Within this section we will formulate suggestions for future research with respect to these fields. First we will pay attention to the field of personal epistemology. Secondly will address the phenomena of resistance and educational innovation since both are closely linked. Finally we will sketch some implications for the context in which this research was carried out - that of Problem Based Learning.

\section{Field of personal epistemology}

The field of personal epistemology within education is blooming since the seminal work of William Perry in the late sixties of the previous century. Although this attention is welcome, certain ontological, linguistic and methodological issues can be questioned from an enactivist perspective (see for an elaborate discussion of these issues chapters 2 and 3). We have tried to develop an epistemological perspective that treats epistemological beliefs as temporarily crystallized enactments on the interface between people (configurations) or within people. This view has repercussions for the assessment of epistemological beliefs. Since the activation or enactment of epistemological beliefs is instantaneous and emergent within the dialogues taking place within a certain teaching situation, we plea for an assessment of epistemological beliefs a posteriori, developing thick descriptions of teaching situations in which epistemological beliefs become apparent. Based on these thick descriptions the participants themselves are best equipped to judge or estimate to what extent the portrayed descriptions are transferable to other situations.

The role of the researcher changes significantly within this context. He or she should be a conversationalist: assisting participants in naming what is unfolding around them and inside them, continually renaming these changing nuances and unlocking the persistent grasp of old categories and dichotomies. Secondly, the researcher becomes a story-developer helping to trace and meaningfully record the interactions of the actors and objects in the expanding spaces. Thirdly, the researcher is in 
our eyes always a midwife helping teachers to interpret and make sense of (epistemological) configurations emerging within complex teaching practice and to understand their own involvements in these configurations. Of course researchers must be clear about their own entanglement and interest in these emerging systems of enacted realities. We recommend further experience with and reflection upon this new role of researchers.

More research is needed to explore different formats that enable visualisation of epistemologies as enacted configurations. We have used thick description since these stimulate attention for detail and complexity. Thick descriptions moreover demystify ready-made distinctions between individual and communal, teacher and student, cognition and body, nature and nurture etc., and show thus the grey shades that make up teaching lives. The use of metaphors (Bruner \& Feldman, I990; Roth, I993), considering the semiotic messages of school practice (Shapiro \& Kirby, I998) or considering practices in term of voices (Akkerman, Admiraal, Simons, \& Niessen, 2006) might equally be valuable. These methods could further enhance the capacity of mindfulness (Langer, I989, I997) i.e. the ability to think beyond habitually formed inclinations and demarcations. Research should closely monitor whether this ability is enhanced by the proposed alternatives. Finally, there is an increasing field of research within education research called Self-Study that is interested in increasing teachers (self)reflection skills (Loughran, Hamilton, LaBoskey, \& Russell, 2004). The self-confrontation method (Lyddon, Yowell, \& Hermans, 2006) might provide useful tools to do so. This method building on a narrative worldview intends to facilitate and stimulate the internal dialogue amongst different I-positions, thus increasing thinking about oneself and one's functioning. This method has already been applied to the field of mental health, education, and personnel management. It would be worthwhile to see whether this method could also be used for the professional development of teachers.

\section{Study of resistance}

The phenomenon of resistance has been subject of investigation from many angles within many disciplines. Yet, these studies are mostly grounded in modernist assumptions - typifying resistance as an individual psychological construct that must be overcome. From an enactivist point of view, resistance is configurational and dialogical in nature, and is related to the interface between individuals. It is important to transcend the dichotomy between placing the legitimacy either with the innovator or the person having to adopt the innovation. We claim therefore that the legitimacy of the innovation must be placed within the mutual dialogue itself i.e. within the conversation between different stakeholders in which none takes precedence over the other. 
In dealing with resistance, it is important to treat the contributions of different stakeholders equally and as equally legitimate, for antagonistic positioning allows only one side, either the educationalist or the teacher, to emerge as victor. This line of reasoning presumes that only one side in the relationship has legitimacy. Either the teachers have legitimacy to resist seemingly questionable innovations or the educationalists have legitimacy to impose new innovations upon recalcitrant teachers. Instances of dichotomous or divisive thinking like these, are not only counterproductive, they are the cause of inducing resistance itself.

It is more productive for all partners involved parties to work closely together - on an egalitarian footing - within curriculum development projects as is suggested Participatory Design or Empathic Design (Asaro, 2000; Schuler \& Namioka, I993). Support for this statement within education is also found with researchers like WolffMichael Roth et al (Roth, Lawless, \& Tobin, 2000) and Max van Manen (Manen \& Li, 2002). Both recommend to treat experiential knowledge of teachers as the users of a curriculum as equally vital to the well functioning of a curriculum as the knowledge provided by the educational developers. Responsive evaluation (Abma, 2005) creates a possible setting or moratorium for participants to engage in equal deliberation and transformative dialogue within the revision of educational curricula.

A potentially relevant approach for future research is Practice Development (McCormack, Manley, \& Garbett, 2005). This is a growing movement within nursing to continually improve patient-centred care. Based upon the theory of Jurgen Habermas it tries to assemble and use different forms of knowledge which it acquires engaging the different stakeholders within a shared change process. It might be worthwhile to look into this participatory research method more thoroughly for several reasons. First, within PD there is ample research on the issue of transforming cultures. This information might be informative to the topic of (meeting) resistance. Practice Development tries - head on - to engage the different partners within its quest to attain better care. Similar to the Participatory Design it might be insightful to follow this process from the beginning with the intention to learn more about the initiation and continuation of resistance over extended periods of time.

\section{Field of PBLdevelopment}

The evaluation in this study provided the participants with a platform to share experiences not only about the PBL introduction course but also about PBL in general. The value of this kind of evaluation was found first and foremost in the conversation itself which covered many topics the participants themselves were concerned or enthusiastic about. Afterwards, various teacher trainers announced they would alter their course as a result of what they heard within the evaluation. 
The course thus provided what Scribner called concrete "nuggets of knowledge" (Scribner, I999): small concrete suggestions concerning for example the use of different didactical formats within the introductory course.

With respect to the introductory course the participants agreed they needed to sustain and perhaps even stimulate diversity, acknowledging differences not only with respect to individual inclinations but also to culture and population. The epistemological characterisation developed in this thesis might add to this in a significant way. In order to remain progressive and open to revision, Problem Based Learning should develop itself along the lines of (emancipatory) Practice Development (McCormack, Manley, \& Garbett, 2005). This means that PBL should reinvent itself in interaction with stakeholders not only with respect to peripheral issues but also with respect to the core issues that make PBL for what it has been. Generally stated, engagement from stakeholders within development and revision processes of teacher development programs should be realized as a constant factor as is done within Participatory Design: "Participatory design is an approach to design that attempts to actively involve the end users in the design process to help ensure that the product designed meets their needs and is usable. In participatory design end-users (putative, potential or future) are invited to cooperate with researchers and developers during the innovation process. Potentially, they participate during several stages of an innovation process: they participate during the initial exploration and problem definition both to help define the problem and to focus ideas for solution, and during development, they also help evaluate proposed solutions." (Wikedipia).

Focusing on lived experiences this thesis revealed some of the intricacies and complexities new staff members and teacher trainers face meeting each other in the process of actualizing PBL within the introductory course. According to Maggie Savin-Baden (2000), this information is needed in order to open the black box of shared engagement in PBL, defined by Don Margetson (I99I) as a different view on knowledge and knowing altogether. This research helped addressing these issues and putting them on the agenda. More ethnographic research into the learning processes taking place within tutorial groups along extended periods of time in combination with open interview techniques would add to the information gathered within this thesis. In this thesis, the focus was on teachers and new staff members entering the PBL system at Maastricht University. A similar approach could be used addressing students' learning histories to their assimilation processes within PBL, again focusing on individual and joined dialogues taking place enhancing our picture of what is means to learn. 


\section{In closing}

This thesis is situated at the interface of different fields of research i.e. research at personal epistemology, research at PBL and the field of curriculum development. It does so by taking enactivism as its default view and Responsive Evaluation as its research method. Appropriating enactivism to the epistemological domain we were able to show and preserve teaching as complex endeavour. This complexity shows itself within the configurational nature of epistemological beliefs. This view has important consequences for the role researchers can play within teacher learning using the epistemological perspective as their analytic tool. They should not present themselves as detached observers searching for linear relationships, but as critical companions intending to stimulate self-reflection. If researchers take this role, they are able to regard teachers as partners with an expertise that is equal to that of other important stakeholders within curriculum revision initiatives. 


\section{References}

Abma, T., A. (2005). Responsive evaluation: Its meaning and special contribution to health promotion. Evaluation and Program Planning, 28, 279-289.

Akkerman, S. F., Admiraal, W. F., Simons, P. R. J., \& Niessen, T. J. H. (2006). An international academic project: the challenge of multivoiced discussions in a boundary crossing group. Culture \& Psychology, 12(4), 46I-485.

Alexander, P. A. (2004). In the year 2020: Envisioning the possibilities for educational psychology. Educational Psychologist, 39(3), I49-I56.

Asaro, P. M. (2000). Transforming society by transforming technology: The science and politics of participatory design. Accounting, Management and Information Technologies, 10(4), 257-290.

Blumenfeld-Jones, D. (1995). Fidelity as a criterion for participating and evaluating in narrative inquiry. Qualitative Studies in Education, 8(I), 25-35.

Bruner, J., \& Feldman, C. F. (I990). Metaphors of consciousness and cognition in the history of psychology. In D. E. Leary (Ed.), Metaphors in the history of psychology. (pp. 230-238). Cambridge, England: Cambridge University Press.

Burbules, N., C. (1997). Teaching and the tragic sense of education. In N. Burbules, C. \& D. Hansen (Eds.), Teaching and its predicaments. Urbana/Champaign: Westview Press.

Burbules, N., C. (2003). What educational psychology can contribute to educational philosophy. Educational Psychologist, 38(3), I83-I85.

Dent, E., B. (2003). The interactional model: An alternative to the direct cause and effect construct for mutually causal organizational phenomena. Foundations of Science, 8, 295-3I4.

Dent, E., \& Goldberg, S. (I999). "Challenging 'resistance to change'”. The Journal of Applied Behavioral Science, 35(I), 25-4I.

Epstein, R., M. (I999). Mindful practice. JAMA, 282(9), 833-839.

Guba, E., G., \& Lincoln, Y., S. (1989). Fourth generation evaluation. Beverly Hills: Sage Publ.

Hammer, D., \& Elby, A. (2002). On the form of a personal epistemology. In B. Hofer, K. \& P. R. Pintrich (Eds.), Personal epistemology (pp. I69-I9o). Mahwah, New Jersey: Lawrence Erlbaum Associates.

Hermans, H. J. (2002). Special issue on dialogical self. Theory \& Psychology, 12(2), I47-280.

Hermans, H. J. M., Kempen, H., \& Van Loon, R. J. P. (I992). The dialogical self beyond individualism and rationalist. American Psychologist, 47(I), 23-33.

Hofer, B. K., \& Pintrich, P. R. (2002). Personal epistemology: The psychology of beliefs about knowledge and knowing. Mahwah, New Jersey: Lawrence Erlbaum Associates.
Kagan, D., M. (I990). Ways of evaluating teacher cognition: Inferences concerning the Goldilocks principle. Review of Educational Research, 60(3), 4I9469.

Langer, E., J. (1989). Mindfulness. New York: Addison Wesley.

Langer, E., J. (I997). The power of mindful learning. Reading, Massachusetts: A Merloyd Lawrence Book - Perseus Books.

Langer, E. J., \& Moldoveanu. (2000). Mindfulness research and the future. Journal of Social Issues, 56(I), I29-I39.

Loughran, J., J., Hamilton, M. L., LaBoskey, V. K., \& Russell, T., L. (Eds.). (2004). The international handbook of self-study of teaching and teacher education practices. Dordrecht: Kluwer Academic Publishers.

Lyddon, W. J., Yowell, D. R., \& Hermans, H. J. M. (2006). The self-confrontation method: Theory, research, and practical utility. Counselling Psychology Quarterly, 19(0I/ March), 27-43.

Manen, M. v., \& Li, S. (2002). The pathic principe of pedagogical language. Teaching \& Teacher Education, 18, 2I5-224.

Margetson, D. (I99I). Why is problem-based learning a challenge? In D. Boud \& G. Feletti (Eds.), The challenge of Problem Based Learning (pp. 42-50). London: Kogan Page.

McCormack, B., Manley, K., \& Garbett, R. (2005). Practice development in nursing. Oxford: Blackwell Publishing.

Napoli, M. (2004). Mindfulness training for teachers: A pilot programme. Complementary Health Practice Review, 9(I), 3I-42.

Niessen, T., J.H., Vermunt, J., D.H.M., Abma, T., A., Widdershoven, G., A. M., \& Vleuten, C., P.M. (2004). On the nature and form of epistemologies: revealing hidden assumptions through an analysis of instrument design. European Journal of School Psychology, 2(I).

Roth, G.-W., Lawless, D., \& Tobin, K. (2000). Time to teach: Towards a praxeology of teaching. Canadian Journal of Education, 25, I-I5.

Roth, W.-M. (I993). Metaphors and conversational analysis as tools in reflection on teaching practice: Two perspectives on teacher-student interactions in open-inquiry science. Science Education, 77(4), 35I373.

Savin-Baden, M. (2000). Problem-based learning in Higher Education: Untold stories. Buckingham: SRHE and Open University Press.

Schuler, D., \& Namioka, A. (I993). Participatory design: Principles and practices. Hillsdale, NJ: Larence Erlbaum Associates.

Scribner, J., Parades. (I999). Professional development: Untangling the influence of work context on teacher learning. Educational Administration Quarterly, 35(2 (april)), 238-266. 
Shapiro, B., \& Kirby, D. (1998). An approach to consider messages of school science learning culture. Journal of Science Teacher Education, 9(3), 22I-24O.

Smaling, A. (2003). Inductive, analogical, and communicative generalization. International Journal of Qualitative Methods, 2(I), Article 5. Retrieved from http://www.ualberta.ca/ iiqm/backissues/2_I/ html/smaling.html.
Stake, R., E., \& Trumbull, D. J. (1982). Naturalistic generalizations. Review Journal of Philosophy and Social Science, 7(I2), I-I2. 



\section{Nederlandse samenvatting}

\section{Inleiding en probleemstelling}

Probleem Gestuurd Onderwijs (PGO) kent een lange geschiedenis aan de Universiteit Maastricht. 30 jaar geleden werd het concept geïntroduceerd bij de faculteit Geneeskunde. In de jaren daarna verspreidde het zich over de andere faculteiten. Als voorloper van het nieuwe leren heeft het concept van het PGO nu binnen vele Hogescholen en Universiteiten zijn intrede heeft gedaan. Toch worstelen vele nieuwe medewerkers die in aanraking komen met PGO met vragen als:

"Kan en mag ik mijn expertise laten zien of ben ik louter procesbegeleider?"

"Mag ik studenten sturen, en zo ja hoe?"

"Hoe stimuleer ik studenten om zelf het initiatief te nemen?"

Veel van deze ervaringen gaan over kennis: wat is ware kennis en hoe komt deze tot stand bij henzelf en hun studenten? Van oudsher horen deze vragen thuis binnen de filosofie, in het bijzonder de kennisleer of epistemologie. Vanaf de jaren zestig is ook de onderwijskunde zich steeds meer gaan interesseren voor dit onderwerp. De opvattingen van docenten en studenten beïnvloeden namelijk het studeer- en doceergedrag, zo is de aanname. In dit proefschrift zullen we de kennisopvattingen van docenten gebruiken om hun worstelingen met en weerstanden tegen dit onderwijsmodel beter te begrijpen.

Echter, tegelijk is het noodzakelijk een nieuw epistemologisch perspectief te ontwikkelen. Een perspectief dat beter aansluit bij de onderwijscomplexiteit van alledag. Het nieuwe te ontwikkelen raamwerk vindt zijn oorsprong in het mens- en wereldbeeld enactivisme. De probleemstelling die hieruit voortvloeit is: Hoe kunnen kennisopvattingen vanuit een enactivist raamwerk beschreven worden en welke meerwaarde heeft het voor het begrijpen van de weerstand van docenten tegen Probleemgestuurd Onderwijs?

Het onderzoek kan worden gekenmerkt als hermeneutisch waarbij de Responsieve Evaluatie (RE) als onderzoeksmethode is gehanteerd. Hierbij nemen onderzoekers de eigen interpretaties die tijdens het analyseren van data ontstaan kritisch onder de loep. Interpretaties worden voordurend uitgedaagd door daarover te discusiëren en na te gaan of ze te baseren zijn op de databronnen. RE evalueert programma's en praktijken dialogisch. Dit wil zeggen dat de waarde van een programma het resultaat moet zijn van het gesprek tussen de diverse belanghebbenden. Binnen dit proefschrift hebben we de "Introductiecursus PGO voor nieuwe medewerkers" op deze wijze gevalueerd.

De hoofdstukken van dit proefschrift zijn de hermeneutische cycli waarlangs de probleemstelling is uitgewerkt. Deze hoofdstukken en hun individuele bijdrage tot het geheel zullen we in de volgende paragrafen bespreken. 
Hoofdstuk 2

\section{Drie vragen, zes dimensies}

De literatuur geeft niet duidelijk weer wat onderzoekers precies onder kennisopvattingen verstaan. Definities blijven veelal impliciet in hun onderzoeksinstrumenten. Deze studie heeft een systeem ontwikkeld om tot een meer expliciete definitie te komen. Deze vragen zijn geformuleerd door nauwkeurig de verschillende instrumenten te analyseren die op het moment worden gebruikt. Ze worden geillustreerd door vier designs om zo een definitie van kennisopvattingen te herleiden en herkenbaarder te maken. Het model bestaat uit zes dimensies die zijn onder te verdelen in drie vragen: (A) Hoe zijn kennisopvattingen gestructureerd? (I) geïsoleerd versus verweven, (2) statisch versus dynamisch, (B) Welke vorm hebben kennisopvattingen? (3) cognitief versus fysiek, (4) generiek versus context-specifiek, (C) Hoe krijg je toegang tot kennisopvattingen? (5) expliciet versus impliciet, (6) zelf-reflexief versus toegeschreven.

Als voorbeeld zijn vervolgens vier bestaande onderzoeksdesigns met behulp van deze dimensies getypeerd. Geconcludeerd wordt dat deze aanpak tot reflectie op en verduidelijking van impliciete vooronderstellingen over 'kennisopvattingen' leidt. Maar voor een beter begrip van de verschillen blijft een explicieter verwijzing naar en verankering in het wereldbeeldbeeld noodzakelijk.

\section{Hoofdstuk 3}

\section{Wat is kennis en hoe komt het tot stand?}

Om een meer expliciete verantwoording van kennisopvatting naar een algemeen zingevend kader (wereldbeeld) te krijgen, legt dit hoofdstuk de basis voor onze eigen definitie hiervan, vertrekkend vanuit een enactivistisch wereldbeeld. Dit om aansluiting te zoeken bij de complexiteit van het onderwijskundig beroep. Zoals al gezegd: Een kennisopvatting is het antwoord op de vraag: "Wat is kennis?" en "Hoe komt kennis tot stand?” Kijkend naar concrete lessituaties uit de individuele interviews, zien we dat de antwoorden van docenten op deze vragen (=de kennisopvatting) niet in isolatie tot stand komen maar in gesprek met studenten en andere betrokkenen. Dus de docent met zijn ideeën en vaardigheden, de student of groep studenten met zijn of haar ervaringen, de zwaarte van het blok etc, tesamen bepalen ze hoe een docent zal handelen.

Zoals we in dit hoofdstuk aangeven, is de definitie dat de kennisopvatting van een docent gegrond is in de concrete lessituatie, strijdig met de gangbare definitie hierover. Veel onderzoek naar kennisopvattingen van docenten vertrekt namelijk vanuit de invalshoek, dat opvattingen zich bevinden in de hoofden van mensen. De enactivitische definitie van kennisopvatting heeft ook consequenties voor hoe we dit willen onderzoeken en de rol van de onderzoeker daarin. Vanuit dit oogpunt is 
het doel van onderzoek naar kennisopvattingen van docenten niet meer zuiver een kwestie van het 'meten van kennisopvattingen', maar het in dialoog met de docent blootleggen hiervan. Daarbij staan de praktijkverhalen van de docenten centraal. Dergelijk onderzoek levert niet alleen meer inzicht in de kennisopvattingen van de docent, maar zorgt ook voor reflectie van de docent zelf op de onderwijspraktijk.

\section{Hoofdstuk 4}

\section{Een leergeschiedenis}

In hoofdstuk 3 werden kennisopvattingen getypeerd als configuraties die ontstaan in docent-student interacties. De vraag rijst of hiermee het contextuele en gedeelde (i.p.v. het stabiele en individuele) karakter van opvattingen niet teveel nadruk krijgt. De deelstudie genoemd in hoofdstuk 3 gebruikt informatie uit de individuele interviews die zich beperkt tot klasseninteracties. Om aan deze punten tegemoet te komen wordt voor bijna iedere docent en trainer van de introductiecursus PGO een leergeschiedenis geschreven. Hierbinnen worden de ervaringen en fricties met PGO beschreven. Weerstanden uit het verleden en heden die vanuit hun rol als docent of student geïnitieerd worden. De leergeschiedenis heeft een "persoonlijker" (lees individueel) karakter en verenigt meer dan alleen klassensituaties. Ook de leergeschiedenissen worden met het epistemologisch perspectief nader geanalyseerd. Ook op dit niveau karakteriseren kennisopvattingen zich als configuraties. Nu alleen niet als configuraties waarin verschillende mensen binnen een situatie met elkaar in gesprek zijn, maar als een interne conversatie tussen contrasterende ik- posities (Nir \& Kluger, 2006). Een ik-positie is het oogpunt van waaruit men een bepaalde situatie beziet en becommentarieert. Zo is menig docent niet alleen docent maar wellicht ook vader, opa, broer, oud student. Dit zijn rollen van waaruit men een situatie vaak onderhuids belicht. Het is van belang docenten op deze contrasten te wijzen en het gesprek hierover aan te gaan om een gevoeligheid voor intern en extern detail te ontwikkelen. Dit kan ervoor zorgen dat docenten in de praktijk beter uit de voeten kunnen.

\section{Hoofdstuk 5}

\section{De dynamiek van kennis}

In bovengenoemde studies worden individuele interviews gebruikt voor het enactivistisch perspectief. Binnen dit hoofdstuk worden groepsinterviews geanalyseerd. Kennisopvattingen ontwikkelen zich niet individueel, maar in relatie tot de opvattingen en ervaringen van collega's. Aangenomen wordt dat gegevens die op groepsinteracties focussen een gedetailleerder beeld kunnen verschaffen van de dynamiek en het contextuele karakter van kennisopvattingen.

Uit een interviewfragment komt naar voren dat bijdragen van individuele participanten aan de gezamenlijk dialoog niet onversneden door anderen worden 
overgenomen. Er vindt een vertaling plaats waardoor de initiële bijdrage verandert en de ander als kennende of niet kennende persoon wordt getypeert. De beantwoording van de vraag: "Hoe komt kennis tot stand?" is dus een discursief proces waarbij naast het inhoudsniveau het betrekkingsniveau een belangrijke rol speelt. Dit is nieuw binnen het huidige onderzoek naar kennisopvattingen waarbij wordt aangenomen dat mensen zich niet beroepen op de betrekking met iemand anders.

\section{Hoofdstuk 6}

\section{Afbraak, erosie en defecten?}

Dit proefschrift heeft als context het Probleem Gestuurd Onderwijs. Het PGO onderwijs binnen de Universiteit Maastricht kent een geschiedenis van meer dan 30 jaar. In die tijd heeft PGO een aantal graduele veranderingen ondergaan, onder andere door weerstanden bij docenten. Moust e.a. (Moust, Berkel, \& Schmidt, 2005) beschrijven deze veranderingen én hun methode om deze veranderingen om te buigen in het artikel "Signs of erosion: Reflections on three decades of problembased learning at Maastricht University." Dit hoofdstuk analyseert de aanpak van de auteurs. Hieruit blijkt dat termen als "afbraak", "erosie" en "defecten" een onnodige en moreel onhoudbare dichotomie creëren tussen de ontwikkelaars van PGO en de medewerkers die deze werkwijze moeten toepassen. Gesuggereerd wordt dat de genoemde aanpak van Moust e.a. moet worden uitgewerkt naar een meer participatieve vorm van onderzoek. Hierbij blijven alle stakeholders of belanghebbenden rondom een programma gedurende het ontwikkelingsproces meer betrokken. De responsieve evaluatie in dit onderzoek lijkt hiertoe handvatten te geven al ligt onderzoek in de lijn van Participatory Design meer voor de hand. Dit omdat hier meer nadrukkelijker dan bij responsieve evaluatie, de potentiele gebruiker meer nauwgezet deelgenoot en gelijkwaardige gesprekspartner is.

\section{Hoofdstuk 7}

\section{Conclusies, bevindingen, gezichtspunten}

In dit hoofdstuk kijken we terug op het onderzoek. Eerst presenteren we de voornaamste conclusies over de drie aandachtspunten in deze studie,

a) het onderzoeksdomein naar kennisopvattingen,

b) het begrijpen van weerstand en

c) het aandachtsgebied Probleem Gestuurd Onderwijs.

Daarnaast staan we stil bij de generalisatie van de resultaten, de limitaties van deze promotiestudie en kijken we naar toekomstig onderzoek op onderhavige terreinen. De voornaamste conclusie over het onderzoeksdomein naar kennisopvattingen is dat dit niet noodzakelijkerwijs vaststaande fenomenen zijn "in de hoofden van" maar eerder antwoorden die in dialoog tot stand komen. 
Verder zien we dat opvattingen het beste a posteriori te onderzoeken zijn door het analyseren van praktijkverhalen van docenten. Tot slot constateren we dat niet de onderzoeker maar de onderzochte de meeste geschikte persoon is om uit te maken of de gevonden opvattingen generaliseerbaar zijn voor andere contexten.

Om het fenomeen 'weerstand' beter te begrijpen typeren we het concept eerst zoals het uit de huidige literatuur naar voren komt. Naast deze statische optiek waarin weerstand binnen het individu wordt gesitueerd, plaatsen we weerstand als dynamisch fenomeen dat ontstaat door contrasterende ik-posities. Daarbij geldt dat deze niet los kunnen worden gezien van de elementen uit de onderwijssituatie waardoor weerstand cq contrasterende ik-posities ontstaan. Dit werd zichtbaar in de casussen in de verschillende hoofdstukken. Wat betreft de omgang met weerstand zou men deze niet doelbewust proberen om te buigen maar veeleer te verduidelijken voor de perso(o)n(en) in kwestie. Men dient een sensitiviteit te ontwikkelen voor de interne en externe dynamiek die aanleiding geeft tot de ervaren weestand. Het concept mindfulness zoals gehanteerd door Langer biedt hiertoe aanknopingspunten (Langer, I989, I997).

Over het Probleem Gestuurd Onderwijs concluderen we dat er een behoefte is aan emic beschrijvingen die inzicht geven in de praktijken zoals van docenten en studenten binnen dit systeem. De beschrijvingen in deze studies voorzien in deze behoefte. Ze belichten de interactie en verwevenheid tussen de identiteit van de docent en de deelnemer binnen het PGO systeem en de context waarin het leren zich afspeelt.

Wat betreft de beperkingen in dit onderzoek wijzen we op het sterk filosofisch of beschouwende karakter van dit proefschrift en de hiermee vaak samenhangende idee dat het daarom praktisch gezien weinig te bieden heeft. Met de ontwikkeling van een enactivistisch epistemologisch perspectief heeft het beschouwend interpretatief (hermeneutisch) onderzoek wel praktische consequenties, maar laat het zich niet vertalen in direct lineaire doel-middel relaties. De bruikbaarheid van dit soort onderzoek ligt veeleer in het toegenomen inzicht en begrip in eigen en andermans situatie, bekeken vanuit de vragen: "Wat is kennis?" en "Hoe komt kennis tot stand?"

Voor de generaliseerbaarheid en de kwaliteit van ons proefschrift hanteren we de authenticiteitcriteria van Guba \& Lincoln (Guba \& Lincoln, I989, I994). Ook hebben we het criterium 'waarachtigheid' (Blumenfeld-Jones, I995) gehanteerd om de kwaliteit van onze interpretaties van de verhalen van docenten te bepalen. Hieruit volgt dat de kwaliteit van dit proefschrift vooral ligt in de diverse opvattingen van belanghebbenden die over het voetlicht zijn gekomen. Voorts heeft men meer begrip voor en kennis van diverse gezichtpunten gekregen . Tevens uit kwaliteit zich in de mate waarin deelnemers aangezet zijn tot actie n.a.v. het onderzoek. Ten slotte komt kwaliteit tot uiting in de herkenbaarheid en geloofwaardigheid van gegeven praktijkbeschrijvingen voor de diverse belanghebbenden. 
Verwijzend naar toekomstig onderzoek op onderhavige terreinen kunnen we stellen dat de rol van de onderzoeker binnen het epistemologische onderzoeksdomein verandert. Hij is niet langer de persoon die objectief relaties blootlegt tussen kennisopvattingen en onderwijsgedrag. De onderzoeker is interpretator van verhalen, een gesprekspartner die de onderzochte inzicht geeft in zijn of haar onderwijsgedrag. Daarom dient men op zoek te gaan naar onderzoeksmethoden die kennisopvattingen als doorleefde configuraties inzichtelijk weten te maken. Deze methoden zouden tegelijkertijd iemands "mindfulness" moeten ontwikkelen. Betreffende het onderzoek naar weerstand verdient het de voorkeur weerstand vanuit een participatoir en democratische perspectief verder te ontwikkelen. Voor wat het Probleem Gestuurd Onderwijs aangaat is de verdere ontwikkeling van PGO gebaat bij een democratisch gebruikersperspectief. De revisie van PGO zou in nauw overleg met de uiteindelijke gebruikers c.q. studenten, nieuwe medewerkers tot stand moeten komen. Deze bijdragen zijn relevant voor de verdere revisie van het onderwijskundige modellen die anders verworden tot theoretische verhandelingen en niet doorleefde onderwijspraktijken.

\section{Referenties}

Blumenfeld-Jones, D. (I995). Fidelity as a criterion for participating and evaluating in narrative inquiry. Qualitative Studies in Education, 8(I), 25-35.

Guba, E., G., \& Lincoln, Y., S. (1989). Fourth generation evaluation. Beverly Hills: Sage Publ.

Guba, E., G., \& Lincoln, Y., S. (I994). Chapter 6 Competing paradigms in qualitative research. In N. K. Denzin \& Y. Lincoln, S. (Eds.), Handbook of qualitative research (pp. I05-II7). Thousand Oaks: Sage Publications.

Langer, E., J. (I989). Mindfulness. New York: Addison Wesley.
Langer, E., J. (I997). The power of mindful learning. Reading, Massachusetts: A Merloyd Lawrence Book - Perseus Books.

Moust, J. H. C., Berkel, H. J. M. v., \& Schmidt, H. G. (2005). Signs of erosion: Reflections on three decades of problem-based learning at Maastricht University. Higher Education, 50, 665-683.

Nir, D., \& Kluger, A., N. (2006). The negotiating self: Identifying and transforming negotiation outcomes within the self. Paper presented at the $4^{\text {th }}$ International Conference on the Dialogical Self, Braga, Portugal. 


\section{Curriculum vitae}

Theo Niessen was born the 8th of August 1972 in Helden. He graduated in 1990 from Bouwens van der Boijecollege in Panningen. After finishing his Bachelor's degree in Nursing at Fontys University of Applied Sciences in 1994 in Eindhoven, he obtained his Master's degree in Health Philosophy and Ethics at Maastricht University in 1997 . He worked as a psychiatric nurse for several years and for a brief time as an educational developer of ethics courses for nurses at the CLE (Centre for Religion and Ethics). His PhD project concerns the development of an enactivist epistemological perspective through means of Responsive Evaluation, in order to understand teacher's experiences and resistances towards Problem Based Learning. Besides his PhD work he was appointed as a staff member at the Master of Health Professions Education (MHPE) in $200 \mathrm{I}$ where he taught community based education and curriculum analysis and block construction. Further, he combined his PhD work being an ethics teacher at Windesheim University of Professional Education in Zwolle in the year $2005 / 2006$. From November 2006 he joined the Fontys University of Applied Sciences in Eindhoven where he is responsible for the coordination and scientific evaluation of the care innovation units. He is father of three children named Guus, Freek and Imke. 



\section{Een woord van dank - Acknowledgements}

De periode waarin een promotie zich volstrekt is lang. Zeker wanneer je besluit om je niet volledig te richten op het onderzoek, zoals ik dat heb gedaan. Ook is het logisch dat in een dergelijke periode privé en werk niet zijn te scheiden en elkaar beïnvloeden. In de tijd van augustus 2000 tot nu ben ik vader geworden van Guus, Freek \& Imke. Drie schatten van kinderen die een positieve invloed op mijn denken hebben gehad alleen al door hun aanwezigheid. Hen wil ik daarvoor allereerst bedanken.

Daarnaast, zo laat de natuur ons weten, waren deze drie schatten er niet geweest wanneer jij Josie niet ten tonele was verschenen. Josie, heel erg fijn dat je er al die tijd bent geweest voor mij. Zonder jou meedenken had ik dit proefschrift zeker niet afgerond. Luc, vooraleerst kameraad maar bovendien begenadigd ontwerper/DTP'er, dank voor typografische ondersteuning. Ook Hans Horsten en Mereke Gosira wil ik bedanken voor hun ondersteuning bij Nederlandstalige en Engelstalige bewerkingen van de artikelen en samenvatting. Tot slot wil ik Fontys Verpleegkunde in het algemeen en Lucienne Hoogwerf (directeur bij Verpleegkunde) in het bijzonder bedanken voor hun meedenken in en ruimte bieden voor het afronden van dit proefschrift.

Naast een stimulerende en ondersteunende omgeving thuis, is een dergelijke sfeer ook elders te vinden zo heb ik ervaren. Ik spreek dan over de afdeling Onderwijsontwikkeling \& Onderwijsresearch. Hoewel, zo besef ik me terdege, mijn onderzoek "niet geheel in de lijn" van de afdeling te plaatsen is heb ik alle steun mogen ervaren. Hiervoor dank.

Deze dankbaarheid geldt natuurlijk in het bijzonder Dineke, Agnes, Astrid en Susan, mijn directe kamergenoten en sparringpartners in onderzoek. Het waren enerverende en mooie jaren waarin we elkaar hebben zien groeien op professioneel en persoonlijk vlak. Hier heb ik van genoten. Dineke, met name jou praktische hulp en bemoeienis in de laatste afrondende fase heb ik erg gewaardeerd. Daarnaast spreek in nadrukkelijk mijn dank uit aan Cees. Ook in moeilijke tijden ben je me blijven steunen. Wat een dood spoor leek te worden, werd mede dankzij jou bemoeienis en volharding dit - al zeg ik het zelf - mooie boekwerk. 
Tot slot Tineke, Guy, Sanne. Ik noem jullie in één adem, echter ieder met een andere belangrijke rol. Tineke wil ik bedanken voor het vlot trekken van mijn promotie, je inhoudelijke en responsieve coaching, je vertrouwen en enthousiasme. Guy, jou wil ik bedanken voor je directe en scherpe feedback waarmee je me telkens opnieuw dwong de grenzen van mijn eigen kennen op te zoeken. Sanne - collega, "zus", paranimf, naar jou toe wil ik de hoop uitspreken dat we samen nog veel artikelen mogen schrijven.

Theo Niessen 


\section{ICO Dissertation Series}

In the ICO Dissertation Series dissertations are published of graduate students from faculties and institutes on educational research within the following universities: University of Twente, University of Groningen, Maastricht University, University of Amsterdam, Utrecht University, Open University, Leiden University, Wageningen University, Technical University of Eindhoven, and Free University (and formerly University of Nijmegen and University of Tilburg). Over one hundred dissertations have been published in this series. The most recent ones are listed below.

II3. Odenthal, L.E. (2I-03-2003). Op zoek naar balans: Een onderzoek naar een methode ter ondersteuning van curriculumvernieuwing door docenten. Enschede: University of Twente.

II4. Kuijpers, M.A.C.T. (2I-03-2003). Loopbaanontwikkeling: onderzoek naar 'Competenties'. Enschede: University of Twente.

II5. Jepma, IJ. (OI-07-2003). De schoolloopbaan van risico-leerlingen in het primair onderwijs. Amsterdam: University of Amsterdam.

II6. Sotaridona, L.S. (05-09-2003). Statistical Methods for the Detection of Answer Copying on Achievement Tests. Enschede: University of Twente.

II7. Kester, L. (05-09-2003). Timing of Information Presentation and the Acquisition of Complex Skills. Heerlen: Open University.

II8. Waterreus, J.M. (05-09-2003). Lessons in Teacher Pay: Studies on Incentives and the Labor Market for Teachers. Amsterdam: University of Amsterdam.

II9. Toolsema, B. (23-10-2003). Werken met competenties. Enschede: University of Twente.

I20. Taks, M.M.M.A.(20-II-2003). Zelfsturinginleerpraktijken: Eencurriculumonderzoek naar nieuwe rollen van studenten en docenten in de lerarenopleiding. Enschede: University of Twente.

I2I. Driessen, C.M.M. (2I-II-2003). Analyzing Textbook Tasks and the Professional Development of Foreign Language Teachers. Utrecht: Utrecht University.

I22. Hubers, S.T.T. (24-II-2003). Individuele leertheorieën en het leren onderzoeken in de tweede fase. Eindhoven: Technical University of Eindhoven.

I23. Sun, H. (04-I2-2003). National Contexts and Effective School Improvement: An Exploratory Study in Eight European Countries. Groningen: University of Groningen.

I24. Bruinsma, M. (09-12-2003). Effectiveness of Higher Education: Factors that Determine Outcomes of University Education. Groningen: University of Groningen. 
I25. Veneman, H. (OI-07-2004). Het gewicht van De Rugzak: Evaluatie van het beleid voor leerlinggebonden financiering. Groningen: University of Groningen.

I26. Annevelink, E. (27-08-2004). Class Size: Linking Teaching and Learning. Enschede: University of Twente.

I27. Emmerik, M.L. van (22-09-2004). Beyond the Simulator: Instruction for High Performance Tasks. Enschede: University of Twente.

I28. Vries, B. de (15-10-2004). Opportunities for Reflection: E-mail and the Web in the Primary Classroom. Enschede: University of Twente.

I29. Veenhoven, J. (05-II-2004). Begeleiden en beoordelen van leerlingonderzoek: Een interventiestudie naar het leren ontwerpen van onderzoek in de tweede fase van het voortgezet onderwijs. Utrecht: Utrecht University.

I30. Strijbos, J.W. (I2-II-2004). The Effect of Roles on Computer-Supported Collaborative Learning. Heerlen: Open University.

I3I. Hamstra, D.G. (22-II-2004). Gewoon en Anders: Integratie van leerlingen met beperkingen in het regulier onderwijs in Almere. Groningen: University of Groningen.

132. Lubbers, M.J. (09-I2-2004). The Social Fabric of the Classroom: Peer Relations in Secondary Education. Groningen: University of Groningen.

I33. Nijman, D.J.J.M. (IO-I2-2004). Supporting Transfer of Training: Effects of the Supervisor. Enschede: University of Twente.

134. Dewiyanti, S. (25-02-2005). Learning Together: A positive experience. The effect of reflection on group processes in an asynchronous computer-supported collaborative learning environment. Heerlen: Open University.

I35. Stoof, A. (04-03-2005). Tools for the identification and description of competencies. Heerlen: Open University.

I36. Groot, R.W.A. de (I0-03-2005). Onderwijsdecentralisatie en lokaal beleid. Amsterdam: Universiteit van Amsterdam.

I37. Salden, R.J.C.M. (22-04-2005). Dynamic Task Selection in Aviation Training. Heerlen: Open University.

I38. Huong, N.T. (23-05-2005). Vietnamese learners mastering English articles. Groningen: University of Groningen.

139. Gijlers, A.H. (23-09-2005). Confrontation and co-construction: Exploring and supporting collaborative scientific discovery learning with computer simulations. Enschede: University of Twente.

I40. Stevenson, M.M.C. (27-09-2005). Reading and writing in a foreign language: A comparison of conceptual and linguistic processes in Dutch and English. Amsterdam: University of Amsterdam.

I4I. Saab, N. (I4-IO-2005). Chat and explore: The role of support and motivation in collaborative scientific discovery learning. Amsterdam: University of Amsterdam. 
I42. Löhner, S. (II-II-2005). Computer-based modeling tasks: The role of external representation. Amsterdam: University of Amsterdam.

I43. Beers, P.J. (25-II-2005). Negotiating common ground: Tools for multidisciplinary teams. Heerlen: Open University.

I44. Tigelaar, E.H. (07-I2-2005). Desgn and evaluation of a teaching portfolio. Maastricht: University of Maastricht

I45. Van Drie, J.P., (20-I2-2005). Learning about the past with new technologies. Fostering historical reasoning in computer-supported collaborative learning. Utrecht: Utrecht University.

I46. Walrecht, E.S. (O9-OI-2006). Brede innovatie, passende strategie?: De Groninger Vensterschool als casus van onderzoek naar strategie en invoering. Groningen University of Groningen

I47. De Laat, M. (03-02-2006). Networked learning. Utrecht: University of Utrecht.

I48. Prince, C.J.A.H. (2I-04-2006). Problem-based learning as a preparation for professional practice. Maastricht: University of Maastricht.

I49. Van Gog, T. (28-04-2006). Uncovering the problem-solving process to design effective worked examples. Heerlen: Open University.

I50. Sins, P.H.M. (I8-05-2006). Students' reasoning during computer-based scientific modeling. Amsterdam: University of Amsterdam.

I5I. Mathijsen, I.C.H. (24-05-2006). Denken en handelen van docenten. Utrecht: Utrecht University.

I52. Akkerman, S.F. (23-06-2006). Strangers in dialogue: Academic collaboration across organizational boundaries. Utrecht: Utrecht University.

I53. Willemse, T.M. (2I-08-2006). Waardenvol opleiden: Een onderzoek naar de voorbereiding van aanstaande leraren op hun pedagogische opdracht. Amsterdam: Free University of Amsterdam.

I54. Kieft, M. (I9-09-2006). The effects of adapting writing instruction to students' writing strategies. Amsterdam: University of Amsterdam.

I55. Vreman-de Olde, G.C. (27-09-2006). Look Experiment Design: Learning by designing instruction. Enschede: University of Twente.

I56. Van Amelsvoort, M. (I3-10-2006). A space for debate: How diagrams support collaborative argumentation-based learning. Utrecht: Utrecht University.

I57. Oolbekking-Marchand, H. (9-II-2006). Teachers' perspectives on self-regulated learning: An exploratory study in secondary and university education. Leiden: Leiden University.

I58. Gulikers, J. (I0-II-2006). Authenticity is in the eye of the beholder: Beliefs and perceptions of authentic assessment and the influence on student learning. Heerlen: Open University of the Netherlands. 
I59. Henze, I. (2I-II-2006). Science teachers' knowledge development in the context of educational innovation. Leiden: Leiden University.

I60. Van den Bossche, P. (29-II-2006). Minds in teams: The influence of social and cognitive factors on team learning. Maastricht: University of Maastricht.

I6I Mansvelder-Longayroux, D.D. (06-ı2-2006). The learning portfolio as a tool for stimulating reflection by student teachers. Leiden: Leiden University.

I62. Visschers-Pleijers, A.J.S.F. (I9-OI-2007). Tutorial group discussion in problembased learning: Studies on the measurement and nature of learning-oriented student interactions. Maastricht: University of Maastricht. 